\title{
Beiträge zur Kenntniss der Zelle und ihrer Lebenserscheinungen.
}

\author{
Theil II. \\ Von \\ Walther Flemming, \\ Professor der Anatomie in Kiel. \\ Hierzu Tafel VII, VIII, IX $(1,2,3)$. \\ In b a l t. \\ Kerntheilung. (Enthält zugleich die Besprechung der neuesten \\ Literatur über Zelltheilung.)
A. Einleitung.
B. Amphibien (Siredon, Proteus, Triton, Hodenepithel von Salamandra, Krötenlarven).
C. Pflanzen.
D. Säugethiere.
A. Anfangsphasen.
B. Die Segmentirung der Kernfäden, und der Uebergang vom Knäuel zum Stern.
C. Die Umordnung der Sternform zur Aequatorialplatte.
D. Die Längsspaltung der Kernfäden.
E. Die Tochterkernfiguren.
F. Die achromatische Fadenfigur.
Schluss.

Vorbemerkungen über die angewandten Benennungen.

Abschnitt 1. Prüfung hinsichtlich des allgemeinen Vorkommens indirecter

Anhang: Ueber die Kerntheilung bei mehrkernigen Zellen.

Absehnitt 2. Neue Ergebnisse über die Morphologie und Mechanik der Zelltheilung.

Einleitung.

Abschnitt 3. Ueber die Entwicklung der Samenfäden bei Salamandra. Bemerkungen zur Technik.

Literaturverzeichniss. 
Vorbemerkungen über die angewandten Benennnngen.

Bei der Beschreibung eines neuentdeckten Gebietes ist die Wahl der ersten Benennungen nicht gleichgultig, und Uebereinstimmung der verschiedenen Erforscher in der Namengebung sehr wünschenswerth. Ich habe mich deshalb in meiner Terminolngie den früheren und gleichzeitigen Beobachtern möglichst nahe zu halten gesucht, und fir das von mir neu Beschriebene möglichst einfache Ausdrücke gewählt. In einigen Puncten konnte Ersteres nicht geschehen; diese Vorbemerkungen sollen die Gründe dafür darlegen und zugleich bestimmt definiren, was unter den hier gebrauchten Namen zu verstehen ist, um Missdeutungen vorzubeugen.

Den Ausdruck „Ruhe des Kerns“ habe ich, was mir selbstverständlich schien, stets nur im Gegensatz zu den Veränderungen während der Theilung gebraucht, und fahre darin fort. Es soll damit nicht etwa gesagt sein, dass ein nicht in Theilung stehender Kern stets in absoluter Ruhe sein müsste; vielmehr habe ich selbst Bewegungen und Formverinderungen der ganzen Kerne und ihrer Netzwerke, wenn auch geringfügige erwähnt (Th. I, pag, 314, 317), wie solche neuerdings von Prudden ${ }^{1}$ ) und Schleicher (11) näher studirt sind.

Die Namen für die morphologischen Theile des Kerns:

1. Kerngerüst oder Kernuetz, intranucleares G. oder N.; darin als Verdickungen:

2. Netzknoten; und als besonders beschaffene Körper:

3. eigentliche Kernkörperchen oder Nucle olen;

4. Kernmembran oder - Wand;

5. Zwischensubstanz des Kerns, d. i. seine ganze übrige Masse ausser den vorigen Theilen - behalte ich wie früher (Th. I, p. 349) bei; denn sie sind, bei Berücksichtigung der von mir a. a. 0 . und von Anderen gegebenen Beschreibungen dieser Theile, jedenfalls nicht misszuverstehen und involviren keinerlei unbewiesene Voraussetzungen, was bis jetzt mit allen anderen fiur diese Dinge gewählten Namen mehr oder weniger der Fall ist.

Auf Grund eines reinen Missverständnisses hat Klein (12)

1) Beobachtungen am lebenden Knorpel. Virchow's Arch. Bd. 15, H. 2. 
Beiträge zur Kenntniss der Zelle und ihrer Lebenserscheinungen. 153

das Wort „Geriust" angefochten; er meint „dieser Name ${ }^{1}$ ) müsse ein passives Stroma bedeuten, während das Netz der wesentliche und lebende Theil des Kerns sei". Mich wundert nur, dass Klein den Namen "Netz" in dieser Hinsicht für besser hält und allein gebrancht; denn ein Netz ist an sich gerade ebenso todt oder lebendig; wie ein Gerüst. Der letztere Name ist im Sinne der deutschen Sprache genaner und besser, und darum von mir gewählt, weil Gerüst ein Balkenwerk bezeichnet, welches nach drei Dimensione $n$ ausgedehnt ist (wie es im Kern der Fall ist), Netz aber ein bloss flächenhaft ausgedehntes. So ist es ja im Grunde auch sprachlich ungenau, von dem „Reticulum" eines Lymphknotens zu reden. Da aber dieser Gebrauch verbreitet, and Missdeutungen kaum denkbar sind, so habe ich stets auch das Wort „Netz" oder "Netzwerk" abwechselnd und gleichbedeutend mit "Geriist" gebraucht und fahre darin fort.

Hiermit soll also ein für allemal der Gedanke ausgeschlossen sein, als ob ich das Kerngerist für ein ,passives Stroma" hielte; im I. Theil dieser Arbeiten (p. 348 ff., p. 368 u. a. a. 0 .) findet sich genügend ausgesprochen und motivirt, dass und warum ich es vielmehr als einen besonders wesentlichen lebendigen Theil des Kerns ansehe. Freilich haben wir darum noch keinen Grund, es als den allein lebenden zu betrachten, und die Zwischensubstanz schlechtweg für flüssig und unbelebt zn halten; um so weniger, da sie bei der Theilungsmetamorphose des Kerns sichtlich betheiligt ist ${ }^{2}$ ), und da Klein (12) kürzlich gute Grinde dafür beigebracht hat, dass sie nicht flüssig ist.

Von Schleicher (11) ist kürzlich gegen den Ausdruck "reticuläre Structur" oder "Gerïst" der Einwand erhoben worden, dass sie nicht exact seien, weil die so benannten Theile in ihrer Form veränderlich, contractil seien. Das Letztere ist zuzugeben und, wie ich eben erwähnt habe, von mir ja ebenfalls beobachtet; da aber eine gerïstförmige oder "reticuläre" Anordnung der betreffenden Substanz im Kern doch jedenfalls den vorherrschenden Zustand repräsentirt, und wir einmal einen kurzen Ausdruck brauchen, so scheinen mir jene Namen dennoch die besten; ein beweg-

1) Klein übersetzt allerdings: "Framework". Ich würde auf diese Uebertragung nie verfallen sein, sondern mit "intranuclear structure übersetzt haben. Structura heisst ja: Gerüst.

2) Vergl. hiefür und für das Nächstfolgende: Th. I, Abschnitt 2. 
liches Gerüst bleibt doch immer ein Gerüst. - Ich entnehme übrigens einer freundlichen brieflichen Mittheilung Schleicher's, dass er die erwähnten Bedenken im Wesentlichen aufoiebt.

Der summarischen Eintheilung des Gesammtkerns in „Kernsubstanz" und "Kernsaft" " kann ich mich nicht anschliessen; es sprechen gegen diese folgende Gründe: 1) Unter „Kernsubstanz“ müsste man ausser der Kernmembran und dem Geriist auch die Nucleolen einbegreifen, diese sind aber entschieden anders beschaffen, wie jene. 2) Der Name Kernsubstanz sagt uiber die Beschaffenheit des betreffenden Dinges gar nichts aus, nicht einmal morphologisch; der Name Kernsaft wiirde die Voraussetzung bedingen, dass das betreffende Ding flüssig sei; was wir nicht wissen.

Ich habe früher (Th. I p. 361) geäussert, dass man vielleicht die Namen Kernsubstanz und -Saft auf die Theilungsphänomene tubertragen könne, indem man die tingirbare Substanz, welche die Tochterkerne anlegt, Kernsubstanz nennte, das Uebrigbleibende Kernsaft. Bei näherer Prüfung aber erscheint auch dies unthunlich; denn auch in der letzteren Substanz giebt es noch geformte Dinge, die nicht tingirbaren, axial gestellten „Kernfäden" (achromatische Fäden, s. u.), ausserdem noch verästelte Fäden (s. Th. I Taf. 17 Fig. 15); diese Substanz kann also nicht einfach "Saft" genannt werden.

Den Namen Kernsubstanz werde ich also hiernach nur anwenden, um, im Gegensatz zu der umgebenden Zellsubstanz (Protoplasma), Materie zu bezeichnen, welche dem Kern angehört.

Für die Kernvermehrung mit Fadenmetamorphose der Kernmasse habe ich den Namen ,indirecte Kernthei$1 \mathrm{ung}$ " vorgeschlagen, der auf mehreren Seiten schon Verwendung gefunden hat. Eine directe Kerntheilung ist dem gegenüber eine solche ohne Fadenmetamorphose, eine unmittelbare Zerschnurung des Kerns. Indem ich diese Bezeichnungen weiter brauche, muss ich nochmals darauf hinweisen, dass sie provisorische sind. Denn wir wissen bis jetzt nicht, ob es eine directe Kerntheilung in letzterem Sinne wirklich giebt; sie wird nur hypothetisch angenommen, und ich selbst möchte mich dieser Hypothese gegenüber lieber für jetzt neutral halten ${ }^{1}$ ).

1) Ich verweise hierfür auf den unter 13 citirten Aufsatz. 
Beiträge zur Kenntniss der Zelle und ihrer Lebenserscheinungen. 155

Wenn es sich herausstellen sollte, dass in der That keine directen Kernzerschnürungen vorkommen, dass alle anscheinenden derartigen Fälle (z. B. farblose Blutzellen) sich auf Theilung mit Fadenmetamorphose zurückführen lassen, so würde für die letztere das Epitheton „indirect“ natürlich ganz überflüssig werden, sie repräsentirte dann die einzige Form der Kerntheilung.

Inzwischen hat Schleicher (3) für die Bewegungen der nuclearen Fäden bei der Zelltheilung den Ausdruck Karyok ines is eingeführt; allerdings bezog er ihn bisher nur auf diejenigen Stadien, welche der Aequatorialplatte voraufgehen (also meine Knäuel und Sterne), und ebenso ist noch neuerdings Strasburger (8) verfahren. Aus meinem Th. I ergiebt sich aber, dass auch in allen weiteren Stadien, in der Aequatorialplatte sowohl als in den rïckläufigen Phasen der Tochterkerne, Bewegungen der Fäden fortdauern, und zwar Bewegungen, die keineswegs schwächer sind als diejenigen der ersten Mutterphasen; also wird man die Bezeichnung „Kinesis" consequenterweise auch auf alle diese Stadien auszudehnen haben. In diesem Sinne adoptire ich hier den passenden und bequemen Ausdrnck, und nach brieflicher Verständigung hat Schleicher sich mit dieser Ausdehnung desselben einverstanden erklärt. Wir werden also von nun an unter Kary okinesis verstehen: Sämmtliche Bewegungen oder Lageveränderungen, welche die im Kern entstehenden Fäden während der Zelltheilung durchmachen, vom Anfang der Knäuelform des Mutterkerns bis zur Rückkehr der Gerüstform der Tochterkerne.

Hierbei muss ich nur einen Vorbehalt machen. Schleicher (a. a. 0.) nennt dieselben Bewegungen der Fäden, die ihm sonst karyokinetische heissen, zuweilen auch ,amoeboide“. Beides kann ich keinesfalls gleichbedeutend finden, und muss letztere Bezeichnung hier ausdrücklich ausschliessen. Das Wort amoeboid involvirt hier zwar an sich nur einen Vergleich, keine Erklärung oder Deutung; aber wir setzen bei den Bewegungen einer „amoeboiden Zelle" als selbstverständlich voraus, dass die nächsten Ursachen für die Formänderung dabei in der Zelle selbst liegen, und nennen diese deshalb contractil. Bei der Bewegung oder Lageveränderung der Fäden einer Kernfigur aber wissen wir noch durchaus nichts Sicheres darüber, ob ihre nächsten Ursachen in den Fäden, oder ausserhalb derselben liegen, oder ob beides gleichzeitig 
der Fall ist. Und es ist ohnehin nicht zulässig, die typischen Manoeuvres dieser Fäden, die in mehreren Phasen bei ihnen allen fast isochronisch, in einem und demselben Sinne erfolgen ${ }^{1}$ ), mit den ganz unregelmässigen Kriechbewegungen einer Amoebe zu vergleichen. Ich vermeide es sogar, die Fäden contractil zu nennen, damit nicht leichtbefriedigte Gemüther in diesem blossen Wort schon glauben mögen irgend welche Erklärung zu finden.

Statt ,karyokinetische Figur" werde ich der Kürze wegen, wie bisher, Kernfigur sagen. Auch Strasburger hat diesen Namen jetzt acceptirt (8, p. 285), allerdings bisher nur für die Mittelstadien der Reibe, die Spindel- oder Tonnenformen. Ich wende dagegen, wie frïher, den Namen Kernfigur auf alle Formphasen des Fadengebildes an.

Fiir die Theilungsstadien, welche den Sternphasen entsprechen, sollen gelegentlich die Worte Monaster (Muttersternphase) und Dyaster (Tochtersternphase) in Anwendung kommen, welehe von H. Fol fiir die Strahlung im Protoplasma der Eizelle eingeführt, nnd kürzlich bereits von $E$. Klein (12) für die entsprechenden Kernfiguren gebraucht sind. (S. in meinem Th. I, p. 421 Abs. 3.)

Einige der neueren Schriftsteller haben inzwischen Anstoss daran genommen, dass ich in der Formenreihe der Kerntheilung eine bestimmte Anzahl von $\mathrm{Ph}$ as en aufgestellt und benannt habe. Der Haupteinwand, der dabei geltend gemacht wurde: dass Repräsentanten meiner Phasen von Salamandra nicht bei allen andern Objecten zu finden seien, fällt nunmehr fort; denn aus No. 13 des Lit. Verz., aus dem hier folgenden Abschnitt 2, unter Vergleichung der neuesten Publikationen Stra sburge r's, Kle in's und Arnold's geht wohl zur Genüge hervor, dass bei den verschiedensten Zellenarten von Amphibien, Säugethieren, Pflanzen (und wie ich gleich als meine vorläufige Annahme hier notiren möchte: auch bei Eizellen, überhaupt allenthalben bei der (indirecten) Zell theilung) die Kernfiguren während der Theilung successiv Formen durchlaufen, welche sich der Reihe nach durch die Benennungen kurz und passend bezeichnen lassen: Knäuel

1) So wenigstens vom Beginn der Muttersternphase bis zum Ende der Tochtersternphase. 
Beiträge zur Kenntniss der Zelle und ihrer Lebenserscheinungen. 157

(Korb), Stern, Aequatorialplatte, dann für jeden Tochterkern umgekehrt: Stern, Knäuel; wenn dies auch nicht bei allen Zellenarten gleich deutlich hervortritt. Hiernach, und durch die Nothwendigkeit kurzer Ausdrücke, scheint mir mein Verfahren hinreichend berechtigt; auch haben die neueren Autoren schon allgemein von jenen Ausdrücken in ihrer Darstellung Gebrauch gemacht. - Ich will nur nochmals ${ }^{1}$ ) besonders darauf hinweisen, dass ich unter einer Phase keinen bestimmt begrenzten Abschnitt verstehe, was ja dem Sinne dieses Wortes direct zuwider laufen würde; sondern, wie es das Wort sagt, eine Erscheinungsform, welche bei der Scheidung eines Zellkerns regelmässig und in bestimmter Reihenfolge mit den iibrigen durchlaufen wird.

Die Phase, welche der Theilung der Kernfigur voraufgeht (z. B. Fig. 12 Taf. 1 hier) habe ich Aequatorialplat te genannt. Strasburg er bezeichnete das entsprechende Stadium der Pflanzenzellentheilungen frïher als Kernplatte; in seiner neuen Mittheilung braucht er für dasselbe, und zugleich auch noch für die zunächst darauf folgenden Trennungsstadien, auch die Worte "Kerntonne* oder "Kerns pindel“, je nach der Form bei verschiedenen Zellenarten (l. c. p. 284). Für die Stadien mit schon vorgeschrittener Localtrennung (z. B. Fig. 23, 25 Taf. 2 hier) werde ich die letzteren Ausdricke als sehr passende gleichfalls benutzen, für die vorhergehende Phase aber, in der die Elemente in der That im Aequator durcheinandergeschoben und zu einer Plattenform angeordnet liegen, mir den Namen Aequatorialplatte reserviren; denn es ist ja offenbar für die Physiologie des Vorganges von wesentlicher Bedeutung, dass das Stadium, welehes der Trennung vorhergeht, und somit zwischen den progressiven und regressiven Theil der ganzen Karyokinesis mitten inne steht, eine Zusammendrängung der Elemente nach der Aequatorialebene zu darstellt, und es scheint passend, das gleich durch den Namen anzudeuten. Näheres hiertiber wird unten im 2. Abschnitt gesagt werđen.

Es handelt sich für weiteres Studium der Theilungserscheinungen um ein kurzes Wort für Dasjenige, was ich bisher "tingirbare Substanz des Kerns" genannt habe. Da der Ausdruck „Kernsubstanz" offenbar zu vielen Missverständnissen ausgesetzt wäre (s. weiter oben), so will ich dafür einstweilen den Namen

1) Vergl. Th. I, Seite 394 oben. 
Chromatin bilden. Es soll damit nicht präjudicirt sein, dass diese Substanz ein bestimmt constituirter, in allen Kernen sich gleichbleibender chemischer Körper sein müsste; obwohl dies gewiss möglich ist, wissen wir doch noch lange nicht genug über die nuclearen Stoffe, um es anzunehmen ${ }^{1}$ ). Mit Chromatin soll demnach nur bezeichnet sein: diejenige Substanz im Zellkern, welche bei den als Kerntinctionen ${ }^{2}$ ) bekannten Bebandlungen mit Farbstoffen die Farbe aufnimmt. Aus meiner Darstellung der Tinctionsergebnisse bei ruhenden und in Theilung begriffenen Kernen (Theil I, Abschnitt 1) folgt von selbst, dass das Chromatin durch den ganzen ruhenden Kern vertheilt ist, zwar vorwiegend in den Nucleolen, dem Netzwerk und der Membran, aber auch in der Zwischensubstanz; während es bei der Kerntheilung sich lediglich in den Fadenfiguren ansammelt.

Für die nicht färbbare Substanz des Kerns bietet sich damit von selbst der Name Achromatin, und es erklären sich demnach die im Weiteren gebrauchten Worte chromatiseh und achromatisch.

Abschnitt 1 .

Prüfungen bei anderen Objekten (Amphibien, Säugethiere, Pflanzen) hinsichtlich des allgemeinen Vorkommens der indirecten Kerntheilung.

Dieser Abschnitt enthält zugleich die Besprechung der Literatur, welche seit der Abfassung des I. Theils erschienen ist.

A.

Die Fortsetzung meiner Arbeiten über Bau und Lebensphänomene der Zelle hat sich zunächst auf die Frage gerichtet, welche

1) Darum vermeide ich auch einstweilen Beziehungen zu dem Namen Nuclein, so lange wir nicht wissen, ob diese Verbindung überhaupt im Kern bestimmt localisirt und an gewisse morphologische Theile gebunden ist. Vergl. auch Theil I, pag. 356 oben.

2) Bekanntlich giebt es eine Anzahl von Tinctionen, besonders mit verschiedenen Carmintincturen, welche zugleich oder sogar vorzugsweise auf Zellprotoplasma wirken, die Kerne weniger betreffen. Diese Tinctionen sind hier selbstverständlich ausgeschlossen. 
Verbreitung die im ersten Theil beschriebene indirecte Kerntheilung besitzt. Eine vollguiltig sichere Antwort darauf ist zwar natiirlich obne Untersuchung aller betreffenden Objecte nicht möglich; doch habe ich zu dem Schluss gelangen können, dass ein anderer Vermehrungsmodus, als der der Zelltheilung mit indirceter Kernvermehrung, bisher nicht nachgewiesen ist und also vorerst kein Grund vorliegt, an einen anderen zu glauben. Dies gilt wenigstens für die fixen Gewebszellen der Thier- und wohl auch Pflanzenkörper. Für freie, amöboide Zellen bleibt es noch fraglich, ob auch bei ihren Theilungen Vorgänge am Kern mitspielen, die der indirecten Kerntheilung homolog, nur weniger augenfällig sind, - oder ob hier wirklich directe Kernzerschürungen vorkommen.

Die Begründung hierfür habe ich zum Theil bereits in einem andern Ortes (13) erschienenen Aufsatze gegeben.

Es trifft sich eigen, dass gleichzeitig mit meinem eben erwähnten Aufsatz ein anderer von $\mathrm{E}$. Klein veröffentlicht wurde (12), in welchem in dem fraglichen Punkt gerade das Entgegengesetzte ins Auge gefasst wird. - Während nämlich Klein nach eigenen Untersuchungen bei Triton meine sachlichen Angaben über die indirecte Kerntheilung bis in's Detail hinein bestätigt gefunden hat, hält er daneben an der Annabme einer directen noch fest. Allerdings nicht ohne eine Begründung: diese aber kann ich als beweiskräftig nicht anerkennen.

Sie besteht in Folgendem: Klein hat beobachtet, dass das Abwerfen der äusseren Hautepithelschicht beim erwachsenen Triton mit sehr rascher Wiederholung vor sich geht (alle 5-7 Tage), Klein meint deshalb, (s. p. 417 ff.) wenn der Ersatz lediglich durch Zelltheilung mit indirecter Kernvermehrung erfolgte, so müsse man eine sebr grosse Zahl von Theilungsfiguren in den persistenten Epithelschichten finden. Er hat Zählungen der in je einem Schwanzquerschnitt (von zwei Zellen Dicke)vorhandenen Kernfiguren angestellt, und fand in zwei solchen Versuchen einmal 17 Theilungen auf 840 Kerne, das andere Mal 23:240; diese Zahl der Theilungen erscheint ihm zu gering, um den Ersatz für die abgestossen Zellenlagen in wenigen Tagen zu liefern. Lediglich aus diesem Grunde nimmt er an, dass daneben noch eine andere Zellvermehrungsform mit directer Kernspaltung stattfinden müsse.

Ich gestehe, dass ich diesen Schluss in keiner Weise begründet finden kann. Auch wenn ich die von Klein gegebenen Ver- 
hältnisszahlen za Grunde lege, finde ich die Menge der Theilungen vollkommen ausreichend, um den Abwurf einer einfachen Zellenschicht (denn es wird nur eine Lage abgeworfen, wie $\mathrm{K}$ lein selbst p. 410 angiebt) in drei bis vier Tagen reichlich zu ersetzen. Ich stelle hierfür folgende einfache Rechnung zur Erwägung :

An der Stelle von Klein's erster Zählung (17 Theilungen auf 840 Zellen) haben wir ein Gebiet, wo zu gegebener Zeit etwa auf je 50 Zellen eine Theilung kommt. Vorausgesetzt, dass die Frequenz der Theilungen sich auf diesem Gebiet dauernd gleich bleiben soll, wird also jedesmal, wenn eine Zelle mit der Theilung fertig ist, irgend eine andere damit anfangen. Die Daner einer Theilung lässt sich nach meinen Beobachtungen (Theil I) an Salamanderlarven auf durchschnittlich 3 Stunden annehmen; bei Triton wird es wohl ähnlich sein. Es wïrden dann auf den Tag 8 Theilungen kommen, also 6 Tage $^{1}$ ) verlaufen, bis auf dem betreffenden Gebiet aus jenen 50 Zellen 100 (genau 98) geworden sind, d. h. bis sich die Zellenzahl iberhaupt verdoppelt hat.

Auf dem Gebiet von Klein's zweiter Zählung aber, wo die Theilungen weit zahlreicher waren $(23: 240)$ würde fast auf je 10 Zellen schon eine Theilung kommen, und nach gleicher Berechnung die Verdoppelung der Zellen bereits in $1 \frac{1}{4}$ Tag erreicht sein. Nimmt man das Mittel zwischen den beiden Gebieten (etwa $\left.2 \frac{1}{2} \mathrm{Tag}\right)$, so hat man damit selbst noch eine geringere Zeit als diejenige, binnen welcher nach Klein's Beobachtungen die Deckschichte wirklich abgelöst wird, und also ein Ersatz dafür fertig gestellt sein soll (5-7 Tage).

Da nun aber vollends die Zellen an den betreffenden Hautstellen $\mathrm{zwei}$ oder meh $\mathrm{r}$ Lagen dick liegen, und Theilungen nicht bloss in einer, sondern mindestens in zweien dieser Schichten vorkommen, so würden damit noch doppelt so viel Zellen prodacirt werden, als zum Ersatz einer Lage nöthig sind. Es folgt daraus, dass die Zellentheilungen nicht einmal so frequent zu erfolgen brauchen, wie auf den Gebieten, wo Klein gerade gezählt hat, um doch den Ersatz liefern zu können.

Dass das Vorkommen eingeschnürter und gelappter Kernfor-

1) Genau noch weniger, da man eigentlich Zinseszinsrechnung anwenden müsste. 
Beiträge zur Kenntniss der Zelle und ihrer Lebenserscheinungen. 161

men nicht zu Schlïssen auf directe Kernspaltungen berechtigen kann, habe ich a. a. O. (13) und in Theil I d. A. wohl genügend gezeigt: noch Niemand hat an localisirten Gewebszellen eine directe Trennung solcher Kernform unter dem Auge geschehen sehen, wenigstens kenne ich keine Beschreibung, die dies bewährte. Klein hat dies im vorliegenden Falle tiberhaupt nicht versucht, da seine Angaben 1. c. sich nur auf conservirtes Gewebe beziehen; ich habe dagegen sehr vielfach den Versuch gemacht und auf viele Stunden ausgedehnt, ob sich directe Durchschniurungen solcher Kerne am lebenden Object einstellen würden; aber bis jetzt immer mit negativem Erfolg.

Ebensowenig ist es mir verständlich, dass $\mathrm{K} l$ e in eine Stutze für die Annahme directer Kernzerschnuirungen in Bildern finden will, wie sie seine Fig. 33-35 Taf. 18 1. c. darstellen, und damit eine Ansicht Eberth's aufnimmt (2), die ich speciell bestritten habe (Th. I). Es sind dies Knäuelformen ${ }^{1}$ ), die gerade einmal in der Mitte etwas eingeschnürt erscheinen, oder eine solehe Anordnung der Fäden haben, dass sich eine gewisse Doppelsymmetrie ergiebt ${ }^{2}$ ). Solche kann man öfter an fixirten Objecten finden ${ }^{3}$ ); aber nach ihnen den Schluss zu ziehen, dass sich eine solehe Kernfigur im Weiterleben einfach mitten durchgeschniirt hätte, ist nicht im Mindesten gereeht. Ich habe beschrieben, dass in allen von mir lebend beobachteten Fällen von Kerntheilungen niemals solche directe Theilungen der Kernfigur vorkamen, sondern immer regelrecht vorher die Sternform und die Aequatorialplatte auftrat. Dagegen können einzelne conservirte

1) Die Verwechselung, die ich durch mehrfachen Hinweis im Theil I (pag. $374 \mathrm{Anm}$., pag. 405, 406) abzuwenden gesucht hatte, ist bei Klein doch eingetreten (pag 414 a. a. O.): er schreibt Eberth die Bezeichnung von Formen, wie Fig. 4 Taf. 1 hier, als Korbformen (basket) zu. Diese Formen sind vielmehr von mir anfänglich Körbe genannt, während Eberth und Mayzel mit diesem Ausdruck Kernfiguren in beginnender Tochtersternphase meinen, wie etwa Fig. 25 und 26 Taf. 3 hier. Damit daraus keine Missverständnisse entstehen, habe ich die erstgenannten Formen dann Knäuel genannt.

2) Es ist ganz denkbar, dass die Dicentrie schon in den Stadien vor der Aequatorialplatte mehr oder weniger ausgeprägt und erkennbar sein kann. Ich habe manche derartige Figuren in meinen Präparaten.

3) Z. B. meine Fig. 6 und 7, Taf. 1 hier. 
Präparate, nach denen allein $\mathrm{K}$ lein geurtheilt hat, nicht in Betracht kommen ${ }^{1}$ ).

Weit überzeugender aber als der negative Befund, dass man eine directe Kerntheilung noch nicht mit hinreichender Sicherheit gesehen hat, scheint mir die positive Thatsache: dass Zelltheilung mit indirecter Kerntheilung bis jetzt noch an jedem Object gefunden worden ist, welches man ernstlich und mit den nöthigen Cautelen und Methoden darauf untersucht hat, falls es ïberhaupt nicht zu ungünstig war, mit Ausnahme der farblosen Blutzellen.

Ich habe in dieser Richtung eine Reihe neuer Prüfungen an folgenden Objecten angestellt: Axolotl, Krötenlarven, Säugethierembryen, geborenen Sängethieren, Pflanzenzellen (Nothoscorodon und Allium), Ovarialeizellen von Salamandra, Spermakeimzellen von derselben.

Dass sich hier überall indirecte Kerntheilung finden würde, konnte ich zwar von vornherein annehmen. Durch die sehr extensiven Untersuchungen Mayzel's (s. Theil I) wissen wir bereits, dass dieselbe bei Batrachiern and deren Larren, ebenso bei Vogelembryen vorkommt; Semper und Balfour haben Kernfiguren in dem Follikelinhalt wachsender Ovarien von Fischen gesehen, Bütschli an Blutzellen des Hühnerkeims, E. van Beneden an der Keimscheibe des Kaninchens; Mayzel und Eberth haben solche in der Hornhaut von Vögeln und Säugethieren, bei pathologischer Zellenvermehrung, gefunden. Für Pflanzenzellen endlich sind wir durch Strasburger schon lange uber das weit verbreitete Vorkommen von Kernfadenfiguren bei der Theilung unterrichtet ${ }^{2}$ ).

Was ich bei den genannten Objecten zu prifen hatte, war also nicht mehr das Vorkommen dieser Dinge taberhaupt, sondern

1) Ich selbst habe mich im Winter 1877 , wo ich noch keine lebende Theilung sicher beobachtet hatte, nach fixirten Objecten in demselben Irrthum befunden wie jetzt Klein und früher Eberth: ich schloss nach Bildern, wie Klein's Fig. 33, auf directe Theilungen dieser Figuren, und habe damals den Theilungsgang dem entsprechend in einem Vortrag falsch dargestellt (Schriften des naturw. Vereins, Kiel 1878, Februar, p. 31, Fig. 13). Im Sommer 1878 haben mich die lebenden Objecte eines Besseren belehrt. (S. am gleichen Ort, 1. August 1878.)

2) Die betreffende Literatur siehe in $\mathrm{Th} . \mathrm{I}$ und in Nr. 13 des hiesigen Lit.-Verz. 
Beiträge zur Kenntniss der Zelle und ihrer Lebenserscheinungen. 163

die Fragen: 1) finden sie sich auch in physiologisch wachsenden Geweben hier überall in der Reichlichkeit, dass es zulässig ist auch hier die sämmtliche Zellenvermehrung auf diese Processe zurückzufïhren? Und ferner: 2) finden sich auch bei allen diesen Objecten sämmtliche Hauptphasen der indirecten Kerntheilung vertreten, welche ich bei Salamandra aufstellen konnte $\left.{ }^{1}\right)$ ?

Die letztere Frage ist für die Fortführung der Arbeiten über Zell- und Kerntheilung von grosser praktischer Bedeutung. Wenn wir versuchen wollen, auf optischem Wege tiefer in die Mechanik dieser Vorgänge einzudringen - ein Anfang dazu ist im nächsten Abschnitt dieser Arbeit gemacht - so erscheint es mir unumgänglich, dabei besonders die Amphibien und zwar vor Allen die Urodelen zu Grunde zu legen, einfach deshalb, weil diese die grössten Zellen und Kerne haben. Es wird - das kann ich nach vielfältiger Vergleichung behaupten - mit unsern heutigen optischen Mitteln niemals möglich sein, an den bis jetzt auf Theilungsvorgänge untersuchten Arten ron Pflanzenzellen, Sïugethier-, Vögel-, Fisch- und vielen Evertebraten-Zellen so viel Detail von den Theilungserscheinungen zu sehen, wie Salamandra, Triton und Siredon schon bei mittelstarken Linsen sehen lassen. Wenn man aber an letztern Objecten das allgemeine Wesen des Processes weiter studiren will, muss man vorher wissen: sind alle Hauptphasen, die bei ihnen vorkommen ${ }^{2}$ ) auch bei den anderen $\mathrm{Ob}$ jecten vertreten, oder ist vielleicht Manches davon bloss jenen eigenthümlich und deshalb unwesentlich?

Ich konnte freilich auch hier schon vorweg vermuthen, dass letzteres nicht der Fall sein wiirde. Zwar haben viele Untersucher der Säugethier- und Pflanzenzellentheilung die Anfangsund Endformen (Knäuel, Sterne) nicht gesehen oder beobachtet, und lediglich über das Mittelstadium, die Kernspindel oder Kerntonne, berichtet; aber es finden sich auch Angaben von Semper ${ }^{3}$ ) und Balfour über Sternformen bei Fischen; Schneider hat Knäuelformen („Rosetten“) von Würmern (Eizellentheilung) beschrieben, Eberth's Abbildungen zeigen, dass es auch in der

1) S. Theil I, pag. 409.

2) Siehe die Tabelle, Th. I, p. 409, und hier, Abschnitt 2, am Schluss.

3) Siehe Lit.-Verz., Th. I. 
entzïndeten Hornhaut von Säugethieren (Kaninchen) derartige Formen giebt; und da die übrigen Beobachter auf solche Formen überhaupt noch nicht geachtet hatten, so konnten sie in ihren Fällen sehr wohl übersehen sein.

So, wie es hiernach vorauszusetzen war, habe ich denn auch Alles bei den untersuchten Objecten im Wesentlichen gefunden; darum halte ich mich bei ihrer Beschreibung sehr kurz, und gebe diese eigentlich nur, um die Zweifel, die auf vielen Seiten noch gegentiber diesen Dingen zu herrschen scheinen, beseitigen zu helfen, und zugleich zu den Angaben Anderer Stellung zu nebmen.

B.

\section{A $m p h i b i e n$.}

Dass beim Axolotl (und überhaupt bei geschwïnzten Amphibien) die Verhältnisse der Kernfiguren ganz die gleichen sein wïrden wie beim Salamander und seiuer Larve, war vorauszusetzen, und wurde im letzten Frühling und Sommer durch Untersuchung mehrerer älterer, und eines sehr jungen ans dem Ei gezogenen Siredon, am Epithel (Haut, Kiemenbögen, Lunge), im Knorpel (Kiemenbögen), im Bindegewebe (ebenda) und an rothen Blutzellen bestätigt. Vortheile gegenuber Salamandra bietet das Object nicht, die Zellen sind vielmehr etwas kleiner wie dort ${ }^{1}$ ). Das Gleiche gilt für Proteus anguineus, bei dem die übrigen Zellenarten keineswegs so bedeutende Grössen haben, wie es bekanntlich bei seinen rothen Blutzellen der Fall ist. So lange es daher nicht gelingt, Proteus aus dem Ei zu züchten oder experimentell an ihm Zellenvermehrung zu erzielen, möchte ich empfehlen, sich an ihm nicht mit Zelltheilungsstudien za bemühen.

Seit dem Erscheinen des I. Theiles dieser Beiträge sind von zwei anderen Seiten Mittheilungen über die Zelltheilung bei geschwänzten Amphibien (Triton) publicirt worden.

Peremeschko (5) untersuchte bei der Tritonlarve den Vorgang lebend und mit Reagentien. Seine Specialarbeit, die unmittelbar nach der meinigen

1) Nach brieflicher Mittheilung hat Mayzel inzwischen ebenfalls den Axolotl hinsichtlich der Kerntheilung geprüft, mit gleichem Ergebniss. 
Beiträge zur Kenntniss der Zelle und ihrer Lebenserscheinungen.

erschien ${ }^{1}$ ) und diese noch nicht berücksichtigte, lässt einige Punkte erheblich von meinen Befunden abweichen ${ }^{2}$ ), doch in einer so eben publicirten Mittheilung desselben Autor's über die Theilung der rothen Blutkörper bei Krötenlarven (16) erscheint schon Manches von diesen Widersprüchen ausgeglichen. Es bleiben, wenn ich diese letzte Aeusserung Peremeschko's mit zu Grunde lege, noch folgende wesentliche Differenzen zwischen uns:

1) Eine anfängliche bedeutende Vergrösserung des Kerns, welche von P. als wesentliche betrachtet wurde, kann zwar vorkommen, aber fast ebenso oft fehlen.

2) Peremeschko lässt noch immer zunächst Körner im Kern entstehen, und zu Fäden ,auswachsen“, welche die weiteren Kernfiguren bilden. Ich konnte dagegen an den grösseren Kernen bei Salamandra feststellen ${ }^{3}$ ), dass diese anscheinenden Körner nur optische Durchschnitte von Fäden sind, und dass sich das ganze Fadengewinde des folgenden Stadiums in continuo a uf Grund des ruhenden Kernnetzes, wenn auch nicht au s diesem allein, hervorbildet. Dies ist nun auch für Peremeschko's Object (Triton) von Klein bestätigt worden (s. u.).

3) Dass es Stadien geben sollte, wo Körner und Fäden im Kern vermischt vorkämen (Peremeschko p. 452, Fig. 54 u. 55), kann ich hiernach nicht zugeben; die anscheinenden Körner sind hier nichts Anderes als optische Schnitte.

4) Auch in der letztcitirten Mittheilung hält P. daran fest, dass in dem Stadium der Aequatorialplatte (Kerntonne) die Fäden in der Mitte auseinanderreissen sollen. Ich habe im Th. I bereits geschildert, dass dic Sache ganz anders liegt, dass die Fäden der zwei Tochterkernanlagen in diesem Stadium bereits getrennt sind, und verweise für Näheres über die höchst eigenthümliche Mechanik dieser Vorgänge auf den hier folgenden Absehnitt 2.

5) Ferner beschreibt Peremeschko, dass in oder kurz nach diesem Trennungsstadium die Fäden der beiden Tochterkernhälften so liegen sollen, dass sie sich mit ihren Enden untereinander kreazen (l. c. p. 442-443, Fig. 35, 36).

Nach diesem Wortlaut wäre anzunehmen, dass es sich hier um die wirkliche Durcheinanderschiebung der gegenseitigen Fäden handelt, welche z. B. hier in meiner Fig. 10-13 Taf. $I$, in $\mathrm{m}$. Th. $\mathrm{I}$ in Fig. $2 \mathrm{~g}$ und 8 Taf. 16 dargestellt ist; und ich glaube auch, dass Peremeschko's Fig. 63 wirklich einem solchen Zustand entsprechen kann. Die Figuren 35 und 36 aber, auf die er sich ebenfalls bezieht, sind damit keineswegs gleichbedeutend,

1) Peremeschko's vorläufige Mittheilung ging dagegen der meinigen um kurze Zeit voraus.

2) Vergl. dafür: Theil I, pag. 407--408.

3) Es ist kaum nöthig zu bemerken, dass man für diese Feststellung sich an die bestconservirten und schärfst gefärbten, aufgehellten Objecte halten muss, wie mir solche in grosser Zahl vorliegen. 
sie sind offenbar keine eigentlichen Aequatorialplatten mehr, sondern schon getrennte Tochtersterne, und diese nur anscheinende Durchkreuzung der Strahlenenden beruht, wie es mir vorkommt, darauf, dass die Figuren Peremeschko's schräg lagen.

6) In seiner erstgenannten Arbeit hat Peremeschko die Knäuel- und Sternformen des Mutterkerns noch nicht auseinandergehalten und ihre typische Folge (Knäuel-Stern) nicht erkannt. Nach seiner Darstellung der Blutzellentheilung im letztgenannten Aufsatz (p. 674) glaubte ich hoffen zu dürfen, dass wir hierüber jetzt einig seien; doch nach seiner neuesten Arbeit (18, p. 182, s. unten) bin ich nicht sicher, ob dem so ist.

7) Endlich hat Peremeschko die von mir beschriebene rückläufige Metamorphose der Tochterkerne nicht beachtet (obwohl er nach seinen Abbildungen die betreffenden Formen offenbar richtig gesehen hat), und eine Stelle auf p. 674 des letztg. Aufs. (unten) lässt schliessen, dass er die homogenen Klümpchenformen der Tochterkerne (vergl. Fig. 29 Taf. 2 hier) für Natur hält, was sich allerdings mit der regressiven Metamorphose der Töchter schlecht vertragen würde. Ich habe gezeigt, dass diese Formen am leb en den Kern nur scheinbar homogen sind, wegen der Blässe des Objects (s. Th. I, Fig. $3 \mathrm{k}$ Taf. 16, Text p. 388 dort); dass sie ausserdem auch durch Reagentienwirkung künstlich hervorgebracht werden können, davon wird unten (siehe: Pflanzenzellen) noch die Rede sein.

Als Vorstehendes geschrieben war, erschien so eben eine weitere Mittheilung Peremeschko's (18), als Fortsetzung der besprochenen. Aus ihrem Inhalt ist bemerkenswerth der Befund einer Nervenkerntheilung (1. c. p. 172), welche zu beobachten bisher noch nicht geglückt war; ferner, dass Peremeschko das Verhalten der Kerne bei der Theilung weisser Blutzellen als ganź gleich darstellt mit dem bei anderen Zellenarten, und eine Anzahl entsprechender Bilder mittheilt (Fig. 16-25). Wenn sich Letzteres bestätigt, würde es meines Erachtens bei weitem den wichtigsten Theil der Arbeit darstellen; denn nach den bisherigen Befunden haben $B \ddot{t s c h l i}$ und $i c h$ annehmen müssen, dass der Kerntheilungsvorgang bei farblosen Blutzellen gegenüber dem anderer Zellenarten sehr abwiche, so sehr, dass ich ihn vorläufig (vergl. Th. I, am Schlusse) als eine directe Theilung gegenüber der indirecten, karyokinetischen, bezeichnet habe. Doch gestehe ich, gegen diese Trennung von vorn herein eine Aversion empfunden zu haben, und habe deshalb stets betont (1. c. p. 423, und: 13 Lit.) dass möglicher Weise doch die Kernveränderung auch bei der Theilung der amöboiden Zellen im Princip homolog sein könne mit den Verhältnissen bei andern, nur einfacher oder weniger deutlich. Sollte bei Triton diese Deutlichkeit grösser sein, so würde ich mich sehr freuen, durch Peremeschko jetzt die allgemeine Homologie hergestellt zu sehen. Vor der Hand jedoch bin ich 
Beiträge zur Kenntniss der Zelle und ihrer Lebenserscheinungen. 167

durch seine Darstellung (p. 171) noch nicht durchaus überzeugt, dass die fraglichen rundlichen Zellen sicher farblose Blutzellen waren ${ }^{1}$ ).

Dass die Theilungen der Bindesubstanzzellen und Muskelzellen in allem Wesentlichen mit denen der Epithelzellen übereinstimmen, hatte ich bereits beschrieben (Th. I, $394 \mathrm{ff}$.), und dasselbe hatte für die ersteren auch Peremeschko selbst in seiner vorl. Mittheilung erwähnt. Der Autor liefert jetzt dafür noch eine Anzahl Zeichnungen nach dem lebenden Object.

Aus Peremeschko's Besprechung meiner Angaben (am Schluss) geht hervor, dass er die Differenzen, die ich oben notirte, auch jetzt im Wesentlichen aufrecht hält. Gerade das, was ich als mein wesentlichstes Ergebniss ansehe, die Regelmässigkeit in der Folge und Rückfolge der Kernfiguren, hat Peremeschko nicht gefunden. Er sagt wörtlich : "es sei ihm bei Triton nicht gelungen, alle die Phasen der Kerntheilung zu beobachten, die ich bei Salamanderlarven beschrieben habe"; und ich nehme Act von seiner Aeusserung "dass die letzteren wahrscheinlich ein viel günstigeres Objekt für diese Beobachtungen darstellen, als das seinige ist". Dies ist freilich wahr ${ }^{2}$ ); aber Peremeschko hat inzwischen aus Klein's Arbeit (12, s. u.) ersehen können, dass sich gerade auch bei Triton das von mir Beschriebene hinreichend bestätigen lässt, wenn man nur wohlconservirte, scharf gefärbte und klar aufgehellte Präparate benutzt.

In Peremeschko's Besprechung meiner Angaben ist Einiges zu berichtigen. Er bchauptet, ,die gelappten Kerne seien meistens compact, ohne Gerüst", und führt an, „Flemming zeichne sie auch ohne Gerüst", wobei er meine Fig. 10 Taf. XV, Th. I, citirt. Der Autor hat wohl meine Ausführungen über die Reagentienwirkungen auf Kerne nicht berücksichtigt (l. c. p. 329 ff.); er hätte daraus ersehen können, dass die Kerne in dem Object der betr. Fig. 10 nur scheinbar ohne Gerüst sind (vergl. das Citat derselben Figur auf p. 330 l. c., Zeile 10). In Fig. $1 \mathrm{~m}$ Taf. XV, Fig. 1, 2 Taf. XVI habe ich ebenfalls gelappte Kerne, und zwar lebendige gezeichnet, aber mit Gerüsten.

Ferner schreibt mir Peremeschko wiederholt irrig den Ausdruck „Axenplattea zu, offenbar für das Stadium, das ich Aequatorialplatte

1) Ich kann übor Triton zwar nicht urtheilen, da ich bisher vergeblich versucht habe, von ihm Larven zu erhalten. Bei Salamandra aber sind im Larvenschwanz die fixen Zellen oft von so rundlichen Formen, dass die Diagnose zwischen ihnen und Wanderzellen sehr misslich ist. Und innerhalb der Blutgefässe sind die Jugendformen rother Blutzellen, die noch kein oder wenig Hämoglobin haben, von farblosen Blutzellen nicht zu unterscheiden. Erstere aber theilen sich, wie ich beschrieb, indirect.

2) Wenn ich auch die Larve von Triton noch nicht habe studiren können, so kenne ich doch seine Kerntheilungen vom erwachsenen Thier, theils nach Mayzel's, theils nach eigenen Präparaten, und erlaube mir danach obiges Urtheil.

Archiv f. mikrosk. Anatomie. Bd. 18. 
genannt habe. Ich habe ersteren niemals gebraucht; er hat gar keinen Sinn, denn die Theilungsaxe der Zelle ist doch die Linie, die von einem Theilungspol zum andern geht; in dem betreffenden Stadium aber sind die Kernfäden in der Ebene des Aequators zu einer Platte gruppirt. Auch verstehe ich nicht, wie Peremeschko seine Fig. 2 l. c. mit meinen Aequatorialplatten (z. B. Fig. 12, 13 Taf. 1 hier) vergleichen kann. Die erstere ist so undeutlich, dass ich nicht weiss, wo ich sie in der Figurenreihe unterbringen soll; am ersten noch bei den Knäuel- oder Sternformen. Dagegen scheint mir seine Fig. 63 Tafel XIX in der That eine Aequatorialplatte zu sein.

Ich habe in meinem Th. I p. 371 gesagt: "Wenn aber auch in den jetzt folgenden Stadien (grobe Knäuel, Sterne) noch Trennungen der Fäden in freie Körner, und Wiederverschmelzungen der letzteren vorkommen sollten (Schleicher, Peremeschko), so würde mich dies Wunder nehmen". Peremeschko bemerkt jetzt (18 p. 181), dass ich ihm diese Ansicht unrichtiger Weise zugeschober hätte. In der That ist in seiner ersten vorläufigen Mittheilung nicht wörtlich, wie bei Schleicher, von einem Zerfallen von Fäden zu Körnern, sondern nur von einem sehr unregelmässigen Figurenspiel die Rede, und ich bedaure also, mich nicht dem entsprechend genauer ausgedrückt zu haben; der Sache nach war ich aber im Recht, denn Peremeschko zeigt gleich auf der folgenden Seite 182, dass er auch jetzt gerade derselben Meinung ist, der ich damals gegenübertreten wollte, indem er wörtlich sagt: "Man sieht nicht selten auch im sternförmigen Kern, dass an der Stelle der Fäden Körner und kurze Stäbchen auftreten*. Ob man sich das Auftreten dieser angeblichen Körner durch ein Zerfallen der Fäden, oder anders (wie? Flemming) erklären will, war für meine Kritik gleichgültig, denn ich habe ïberhaupt bestritten, dass solche Körner neben Fäden in diesen Stadien bei Salamandra vorkommen, erkläre hier alle scheinbaren Bilder der Art für optische Schnitte, und muss nach K lein's und meinen eigenen Erfahrungen vermuthen, dass es bei Triton und überall ebenso ist.

Endlich erklärt Peremeschko die hellen Höfe um die Kernfiguren, die zuerst Eberth, dann Strasburger und ich gesehen haben, für Artefacte. Er lässt dabei ausser Acht, dass ich diese Höfe an lebenden Epithelzellen bei Salamandra constatirt habe (Th. I pag. 376), was bei den blasseren Elementen der Tritonlarve vielleicht nicht thunlich ist. Dass aber diese Höfe sich allerdings durch Reagentienwirkung vergrössern können, habe ich schon an derselben Stelle erwähnt; und dass sie von Natur verschieden gross ausfallen können, ist schon aus meinen früheren Figuren (1. c. Taf. XVII, XVIII ersichtlich.

Die Arbeit Kleins (12) behandelt das gleiche Object wio die eben erwähnte (Triton, Zelltheilung im Hautepithel des erwachsenen Thiers ${ }^{1}$ )), und

1) Bei Salamandra sind die Theilungen beim Erwachseuen durchaus ebenso beschaffen wie bei der Larve; ich schliesse danach, dass es bei Triton nicht anders sein dürfte. 
giebt für dieses eine vollständige Bestätigung meiner Befunde an Salamandra, bis in die Einzelheiten. Besonders werthvoll ist es mir, dass $\mathrm{Kle}$ in sich auch hier von der regressiven Umwandlung der Tochterkerne überzeugt hat (l. c. p. 415, siehe meinen Th. I, p. 391 u. a.), während alle Anderen, die gleichzeitig oder nach meinen dortigen Angaben über die Sache schrieben (Schleicher, Peremeschko, Strasburger) diese so augenfällige und doch gewiss nicht unwichtige Thatsache unbeachtet lassen oder sogar für viele Objecte negiren (Strasburger, s. u.). Auch darin, dass die ersten Anfangsstadien der Theilung nicht aus Körnern, sondern aus gewundenen Fäden bestehen, finde ich bei Klein Zustimmung. Es bleiben nur wenige Puncte, in denen seine und meine Angaben sich nicht ganz decken, und die mir dabei wesentlich genug scheinen um sie hier zu markiren:

1) Klein lässt das Stadium der A e quatorialplatte oder Kerntonne ${ }^{1}$ ) fast unberücksichtigt, oder identificirt es doch mit der Dyasterfigur, welche der schon erfolgten localen Trennung der Tochterkerne entspricht ${ }^{2}$ ); diese letztere Figur lässt er direct aus dem Mutterstern, dem Monaster, hervorgehen, ohne zu erwähnen, wie er sich die Umordnung dabei denkt.

Nun erscheint mir aber gerade diese Umordnung als eine besonders wichtige Phase der Karyokinesis, weil gerade sie es ist, die den Uebergang aus der Monocentrie in der Zelle zur Dicentrie kennzeichnet. Es ist mir ganz ersichtlich, warum Klein diesen Punkt weniger beachtet hat: er arbeitete nur an conservirten Präparaten, an denen die eigentlichen, flach zusammengedrängten Aequatorialplatten selten gefunden werden, weil sie nur kurz dauern.

Es wärde mir ebenso gegangen sein, wenn ich nicht gleich anfangs viele lebendige Theilungen verfolgt hätte. Bei solchen sieht man niemals, dass ein Mutterstern sich direct in zwei Tochtersterne trennte; sondern es tritt immer ganz unfehlbar ein Stadium dazwischen ein, wo die Fäden sich in den Aequator zusammendrängen, wie in Fig. 10-14 Taf. I hier, erst dann folgt die locale Trennung, die Tonnenform und die Tochtersterne.

2) Die Längsspaltung der Strahlen des Muttersterns (Fig. 9 Taf. I hier, Th. I p. 379) scheint Klein bei Triton nicht gefunden zu haben, wenigstens hat er darüber nichts erwähnt ${ }^{3}$ ). Dass diese Erscheinung bei Triton wirklich ganz fehlen sollte, ist mir bei der sonstigen Uebereinstimmung, und auch nach Peremeschko's unten citirten Befunden, nicht wahrscheinlich. Näheres über die Doppelfäden wird im folgenden Capitel gesagt werden.

1) Siehe z. B. Fig. 10-14 Taf. I hier.

2) Siehe Klein's Fig. 20-22, und Fig. 15, 16 Taf. I hier; Fig. 8, 6, 11 Taf. 18 Th. I.

3) Vergl. dagegen Peremeschko, a. a. 0. p. 182, welcher Doppelstrahlen jedenfalls gesehen hat, wenn er auch über ihre Deutung noch zweifelhaft $z u$ sein scheint. 


\section{Theilungen der Hodenepithelzellen bei Urodelen (Salamandra).}

Die Arbeit an diesem Object habe ich zwar zum grossen Theil mit Hinblick auf die cellularen and nuclearen Vorgänge bei der Spermatogenese aufgenommen (vergl. darïber Abschnitt 3); es stellten sich aber dabei die Hodenepithelien von Salamandra als ein sehr gutes Specimen für Beobachtung der Zell- und Kerntheilung heraus, und zugleich als eines, bei dem die Karyokinese einige eigenthümliche Abweichungen gegeniiber anderen Zellenarten desselben Thieres zeigt. Der Uebersichtlichkeit wegen will ich diese Besonderheiten hier zusammenstellen; Einiges davon findet noch im Abschnitt $2^{1}$ ) und Abschn. 3 specielle Besprechung.

Wenn man einen Salamanderhoden mit zahlreichen Zelltheilungen gefunden hat - was in der geeigneten Jahreszeit (Juli, August) sehr leicht ist - und diese Theilungen ohne Zusatz, oder mit Essigsäure oder Fürbung ${ }^{2}$ ) bei 200-500facher Vergrösserung untersucht, so fillt vor Allem neben den übrigen Theilungsphasen, die den bisher von mir beschriebenen "ganz gleichen, eine Form durch ihre Fremdartigkeit auf: es ist dies das Stadium, das offenbar der Aequatorialplatte entspricht (Taf. 3 Fig. 41, 42, 50). Es präsentirt sich wie eine bauchige Fischreuse. Bei etwas lockeren Figuren dieser Art, besonders wenn man sie schrïg oder gerade vom Pol gesehen vor sich hat (Fig. 41), erkennt man leicht, dass je zwei Fäden an den Polen in einander umbiegen. In der Aequatorialebene aber sucht man oft an diesen Figuren vergeblich nach deutlichen Unterbrechungen der Fäden, wie sie bei anderen Zellenarten ${ }^{3}$ ) so ersichtlich vorkommen ${ }^{4}$ ). Deshalb haben mich diese Formen anfangs sehr frappirt, da sie das Gesetz umzustossen schienen, das ich für die Theilungen anderer Zellenarten bereits früher aufzustellen gehabt hatte: dass die Gruppirung der Fäden in Abschnitte, die je einem Tochterkern zugehören sollen, in der Phase der Aequatorialplatte schon erfolgt ist.

1) Unter: "die Umordnung der Sternform zur Aequatorialplatte".

2) Methoden s. Abschn. 3.

3) S. Th. I, pag. 382, 383 ff., Fig. 13, 14 Taf. 17; hier: Fig. 12 Taf. 1 u. a.

4) Diese Figuren erinnern dadurch sehr an viele Abbildungen B ütschli's (in dessen Werk: Studien über die ersten Entwicklungsvorgänge der Eizelle etc.) von Kernspindeln bei Infusorien. 
Beiträge zur Kenntniss der Zelle und ihrer Lebenserscheinungen. 171

Dieser Widerspruch ist aber nur scheinbar. - Erstens kann man an manchen Fäden in einer solchen Kernfigur deutliche Unterbrechungen im Aequator wahrnehmen, auch wo die Uebrigen hier keine zeigen (s. die Figuren). Ferner sieht man bei Reagentienwirkung (besonders Essigsäure) im Aequator an Fäden, die vorher anscheinend ganz continuirlich von Pol zu Pol der Figur liefen, bald Unterbrechungen, bald blosse Aufblähungen auftreten (Taf. 3 Fig. 59), offenbar ein Zeichen, dass hier eine differente Beschaffenheit des Fadens vorgelegen haben muss. Endlich ganz entscheidend ist die Beobachtung des lebenden Objects, dessen Figurenreihe auf Taf. 3 Fig. 35 gezeigt ist. Da hier in den vorhergehenden Stadien (a, b) ja getrennte Fadenschleifen, von halber Länge wie die Tonnenfigur vorkommen, so muss man urtheiJen, dass der äquatoriale Zusammenhang der Fäden (siehe $35 \mathrm{~d}$, ein Faden) in dieser Figur nichts anderes repräsentirt, als eine temporäre Berührung oder Verschmelzung der einander gegentiberstehenden Fadenenden. Danach ist es verständlich, wenn an diesen Verschmelzungsstellen die Beschaffenheit der Substanz der Art abweichend von der des ïbrigen Fadens ist, dass hier die erwähnten Aufquellungen (Fig. 59) durch das Reagens (Essigsäure) zu Stande kommen.

Ich habe die letzteren bisher nur an Essigsäurepräparaten gefunden; an mit Chromsäurecbehandelten und gefärbten findet sich statt dieser Anschwellungen vielfach an den Zusammenhangsstellen im Aequator eine blassere und etwas verdünnte Stelle. - An den Essigsäurepräparaten finde ich zuweilen eine helle, kreuzförmige oder längsgestellte Spalte in der Mitte einer solchen Anschwellung (Fig. 59 und 59 a, siehe deren Erkl.).

$\mathrm{Ob}$ diese äquatoriale Verschmelzung von Fadenenden vielleicht eine allgemeine Eigenschaft dieser Phase ist, lässt sich noch nicht entscheiden. Dass sie auch bei anderen Zellenarten vorkommt, habe ich frïher besprochen und abgebildet ${ }^{1}$ ), und schon dort nach den vorhergehenden Stadien geschlossen, dass die Fäden, die man hier hie und da im Aequator zusammenhängen sieht, dies nicht schon vorher dauernd gethan haben können, sondern sich erst aneinandergelegt haben mïssen.

1) Th. I, p. 381: 4. Phase, ff.; ebenda p. 387; Fig. 6, 7 Taf. 18, 13 Taf. 17. 
Bei der Trennung der beiden Tonnenhälften bemerkt man hier oft recht deutlich, dass je zwei, vorher verschmolzene Fädenenden einen dünnen Strang zwischen sich ausziehen, der erst später durchreisst. Diese Stränge sind nicht identisch mit den achromatischen Fäden, von denen gleich die Rede sein wird, denn sie zeigen sich oft deutlich tingirt.

Eine andere Eigenheit der Hodenzellentheilungen ist die Deutlichkeit der blassen, achromatischen Fadenfigur ${ }^{1}$ ) innerhalb der chromatischen (s. Taf. 3 Fig. 43-47).

Bei keiner anderen Zellenart von Salamandra habe ich sie bis jetzt so scharf darstellen können; nur annähernd in einigen Fällen bei Knorpelzellen. In Sternformen (wie Fig. 40) finde ich bei den Hodenzellen noch nichts von diesen Fäden, erst nach dem Auseinanderweichen der Aequatorialplatte (Fig. 43) werden sie deutlich. Man sieht in letzteren Stadien oft einzelne chromatische Fadenschleifen aus den ibrigen unordentlich herausgeriickt, manchmal bis an die Pole der achromatischen Spindel gerückt (Fig. 43 bis 44); bei schwächerer Vergrösserung sieht solche Figur aus, als läge in dem Pol der feinfadigen blassen Spindel, oder nahe an ihm, noch ein grobes gefärbtes Korn ${ }^{2}$ ). Es handelt sich dabei um nichts weiter, als um Unregelmässigkeiten in der Mechanik der Kernfigur, wie sie auch in anderen Stadien vorkommen: es liegen ja auch in den Knäuel - und Sternphasen (Taf. 1 Fig. 8, Taf. 3 Fig. 35 b) oft einzelne Schleifen zeitweise weit abgerïckt; so kommt es auch in der Aequatorialplatte und Kerntonne (Taf. 3 Fig. 45, Taf. 1 Fig. 10 u.f.) oft vor, dass der eine Schenkel einer Schleife herausgeklappt gefunden wird. Dass dies blosse Unregelmässigkei-

1) Vergl. Abschnitt 2, am Schluss.

2) An einem kleinzelligeren Object, wie Salamandra ist, würde deshalb auch der sorgfältigste Beobachter solche Bilder nicht anders wie in diesem Sinne deuten. Die Kernfiguren in Fig. 43 und 44 sind eben gross genug, um mit Hartnack 9 à imm. deutlich zu sehen, dass es sich nicht um Körner, sondern um Fadenschleifen handelt, deren einer Schenkel, oder auch beide, natïrlich oft in der Verkürzung gesehen werden, wo sie dem entsprechend liegen.

Diese Dinge sind also etwas ganz Anderes, wie die wirklichen differenzirten Körper besonderer Art, die sich an den Polen bei Eizellen finden (Taf. 2 Fig. 33), und hier, wie es scheint, durch Verschmelzung von Körnern in den achromatischen Fäden entstehen (Taf. 3 Fig. 32). 
ten sind, ergiebt sich einfach aus dem lebendig-beobachteten Verlauf einer Hodenzellentheilung, wie in Taf. 3 Fig. 35 . Man sieht ja hier, dass die regellos herausgerückten Fadenschleifen in $b$ nachher wieder richtig unter die übrigen eingeordnet werden. So wird es denn wohl auch bei Fig. 43 und 44 sein: die einzelnen Schleifen an den Polen haben hier ihren Weg zu diesen schon vorläufig gefunden, mag es nun sein, um gleich dort zn bleiben, oder um vorher noch unter die Uebrigen nach dem Aequator zurückzukehren.

In manchen Fällen habe ich an Kernfiguren von Hodenzellen, wie Taf. 3 Fig. 46 und 47, auch Andeutungen von äquatorialen Differenzirungen in den blassen Fäden gesehen, welche offenbar Strasburger's "Zellplattenelementen" entsprechen. Ob sie hier bei meinem Object abgegrenzte körperliche Elemente sind, oder nur der Ausdruck einer Vacuolisirung (durch die Reagentien) der blassen Fäden an dieser Stelle, oder endlich ob sie nur Unterbrechungen der Fäden im Aequator entsprechen, kann ich bei der Zartheit der Verhältnisse und der Nothwendigkeit von Reagentien hier nicht entscheiden. Am lebendigen Object (Fig. 35) sieht man von den achromatischen Fäden überhaupt nichts.

Endlich ist es auffallend, dass die Längsspaltung der Kernfäden in der Knäuel- oder Sternphase (Taf. 1 Fig. 9), die bei den ektodermatischen Epithelien, den Bindesubstanz-Muskel- und rothen Blutzellen von Salamandra so auffallend und so deutlich ist, sich bei den Hodenzellen nicht ausspricht. In einigen Stern- und Knäuelformen habe ich jedoch auch hier Andeutungen davon gesehen, allerdings nur der Art, dass je ein Faden aus zwei enganeinanderliegenden zusammengesetzt war, nie mit einer so scharfen Spaltung, wie bei jenen anderen Zellenarten (Epithel Taf. 1 Fig. 9 hier, Bindesubstanz Th. I Taf. 17 Fig. 11). Wenn hier also eine solche Spaltung ebenfalls typisch vorkommt, so muss sie kurz dauern und muss im Stadium der Kerntonne auch schon eine Wiederverschmelzung erfolgt sein; denn in diesem ist die Zahl der Fadenschleifen so gering, dass eine Verdoppelung der Elemente des Sterns unmöglich angenommen werden kann. Feinstrahlige Sterne, wie sie im Epithel massenhaft vorkommen (Th. I Taf. 17 Fig. 12) habe ich bei Hodenzellen nie gefunden. - Einiges über die Fädenspaltung wird noch im Abschn. 2 seine Stelle finden. 
Bei Krötenlarven (wahrscheinlich $\mathrm{Buf}$ ) habe ich das Epithel des Mundbodens und der Bindegewebstheile des Kopfes und der Schwanzflosse untersucht, und Knäuel und Sternformen der Mutter- und Tochterkerne, sowie Aequatorialplatten, ganz wie bei Salamandra gefunden. Als Proben aus vielen gebe ich nur zwei Formen auf Taf. 3 Fig. 27 u. 28. Nur Längsspaltung der Sternstrahlen beim Mutterkern war nirgends deutlich erkennbar, was auch für das demnächst zu beschreibende Object gilt: bei der Kleinbeit der Elemente wird es aber kaum möglich sein hier diese Erscheinung zu sehen, auch vorausgesetzt, dass sie existirt.

Es werden aber bei den Batrachiern und ebenso bei den Säugethieren und Pflanzen die Kernfiguren leichter durch die Reagentien entstellt, als bei den geschwänzten Amphibien; besonders häufig betrifft dies die Tochterkernpaare in ihren Stern- und Knäuelphasen (Fig. 28, vergl. Taf. 3 Fig. 29), welche oft zusammenschrumpfen und eine solche Verbackung der Fäilen erleiden, dass sie wie homogene Klumpen erscheinen.

Ueber die Zelltheilung im Knorpel von Batrachicrn ist inzwischen die ausführliche Arboit Schleicher's (3) erschienen; sie wurde gleichzeitig mit meinem Th. I, am Orte anmittelbar vor diesem publicirt.

Auf den ersten Blick scheinen Schleicher's Abbildungen und Beschreibungen gegenüber den meinen grosse Differenzen zu bieten; denn nach Schleicher würden sich freie Körner und Fäden im Kern bilden, und cine Zeit lang Bewegungen ohne alle Regelmässigkeit ausführen (denn wenn auch Schleicher Sternformen des Mutterkerns sehr richtig beobachtet hat, so nahm er sie doch nicht für typische, bei jeder Theilung an bestimmter Stelle wiederkehrende); das Stadium der Aequatorialplatte findet sich bei ihm nicht erwähnt; die Tochterkerne würden nach ihm zunächst zu homogenen Klumpen werden, dann in "Körner und Stäbchen" zerfallen. Kurz, gerade das, was ich gefunden und als besonders wesentlich hervorgehobcn habe, die Regelmässigkeit in der gesammten Formenreihe, nimmt $\mathrm{Schleicher}$ ausdrïcklich in Abrede.

Trotzdem war ich beim ersten Blick auf Schleicher's Figuren überzeugt, dass er vollkommen richtig, nur nicht ausreichend beobachtet hat, und dass in seinen Objecten sämmtliche Phasen der Kerntheilung vertreten sind, die ich beschrieben habe. Ich glaube, wer sorgfältig die beiderseitigen Figurenreihen vergleicht, wird schon danach diese Meinung mit mir theilen. Schleicher's Objecte sind bei ihrer Kleinheit weit ungünstiger wie die meinigen; er hat sie hauptsächlich nur lebend untersucht and nicht durch geeignete scharfe Tinctionen controlirt, hat danach nur soviel beschrieben und offenbar sehr getreu gezeichnet, als sich am lebendigen Präparat mit voller Sicherheit sehen lässt; und dies ist eben lange nicht Alles. Seine Bil- 
Beiträge zur Kenntniss der Zelle und ihrer Lebenserscheinungen. 17

der stellen daher nur Bruchstücke der wirklichen Kernfiguren dar; dennoch kann ich aus vielen derselben ganz gut diagnosticiren, welche Phase sie betreffen.

Ich habe übrigens inzwischen, gleichzeitig mit Schleicher's Publication, schon mitgetheilt ${ }^{1}$ ), dass im Knorpel bei Salamandra ganz dieselbe Formenreihe der Theilung zu finden ist, die ich für alle übrigen Gewebszellen aufgestellt habe. Hiernach durfte ich es wohl überflüssig finden, die Kerntheilung auch im Knorpel der Batrachier nochmals zu prüfen; denn es scheint ganz undenkbar, dass gerade nur im Knorpel bei diesen so grosse Abweichungen vorkommen sollten, wie es Schleicher's Angaben entsprechen würde, während ja, wie so eben erwähnt, im Epithel und Bindegewebe ${ }^{2}$ ) bei denselben Thieren der Process in nichts Wesentlichem von dem bei Salamandra gefundenen abweicht.

Ich erspare es hiernach auch, auf verschiedene Angriffe zu entgegnen, die Schleicher gegen meine vorläufigen Angaben gerichtet hatte; sie sind durch meinen Theil I im Voraus widerlegt und ich hoffe, dass Schleicher, nachdem er die Freundlichkeit gehabt hat, einige meiner Präparate zu prüfen, sie nicht weiter aufrecht halten wird. - Nur das Eine muss ich in dieser Hinsicht bemerken, dass Schleicher's Aeusserung (p. 284): „ich hätte nur das für andere Gewebe gelchrt, was or (Schleicher) schon für den Knorpel beschrieben habe" ${ }^{\prime}$ nicht sachlich richtig ist. Denn erstens sind meine bezüglichen Arbeiten schon ein Jahr vor dem Erscheinen von Schleicher's erster vorläufiger Mittheilung begonnen und ganz unabhängig von dieser gewesen, zweitens aber und besonders habe ich ja keineswegs dasselbe beschrieben wie Schleicher, sondern etwas ganz Anderes, und möchte darum meine Ergebnisse nicht mit denen seiner eben besprochenen Arbeit indentificirt wissen.

Da letzteres inzwischen von einigen Seiten geschehen ist, will ich hier kurz die sehr wesentlichen Unterschiede kennzeichnen, die zwischen Schleicher's und meinen Resultaten bestehen:

Schleicher hat für die Theilung von Knorpelzellen beschrieben, dass in dem vorher homogen beschaffenen Kerninhalt ${ }^{3}$ ) Körner und Fäden von unregelmässiger Form und Zahl auftreten, amoeboide Bewegungen ganz unregelmässiger Art ausführen (Karyokinesis) und dann zu der von Bütschli und Strasburger entdeckten spindel-oder tonnenförmigen Figur zusammentreten; dass diese sich darauf in

1) Th. I p. 395, Taf. 16 Fig. 10.

2) und auch bei rothen Blutzellen, s. u. Peremeschko.

3) Seitdem hat sich jedoch Schleicher auch an seinen Objecten von dem Vorkommen intranuclearer Structuren überzeugt, und befindet sich nach freundlicher briefl. Aeusserung über den Bau des Zellkerns im Ganzen mit $\operatorname{mir}$ in Uebereinstimmung. 
die $z$ wei Tochterkernmassen trennt; dass deren jede dann zu einem homogenen Klümpchen wird; dass dieses auf eine Zeit lang wieder,in Körner und Stäbchen zerfällt", welche wieder Bewegungen ausführen und dann zu einem Kern mit einander verschmelzen.

Ich habe dagegen für die Theilung der meisten Goweb. zellenarten beschrieben, dass sich im Kern im Anschluss an dessen Gerüststructur und Viembran, ein in sich zusammenhängendes Fadengewinde von gleichmässiger Dicke ausbildet, das nach und nach sämmtliche tingirbare Substanz des Kerns in sich fasst, und sich zu einem Knäuel formt, der darin schon regelmässige Ordnung zeigt, dass seine Windungen im Ganzen gleiche Abstände von einander haben. Dann zerfällt dieser gewundene Faden in Segmente, und diese Fadenstü cke machen Lageveränderungen durch, welche regelmässig und typisch folgende Phasen zeigen: Knäuel, Stern (Systolen und Diastolen desselben), Aequatorialplatte; Trennung; dann für die Fäden jeder Hälfte, also jeden Tochterkern, wieder umgekehrt: Stern, Knäuel, Ruhe.

Es ergiebt sich von selbst, dass Dieses etwas Anderes ist, als Schleicher's Befund, und dass die hiermit erkannte Ordnung bessere Aussicht auf Verstehen der Mechanik des Vorgangs giebt, als wenn wir bloss mit ganzirregulären, amoeboiden Bewegungen zu rechnen hätten.

\section{C.}

\section{Pflanzen.}

In den Arbeiten Strasburger's, welche bis 1879 publicirt waren, findet sich für Pflanzenzellentheilungen nur die Mittelform der Kernfiguren (Kernspindel, Kerntonne) beschrieben und ist ausserdem für einige Pflanzen auch von granulirten Anfangsstadien die Rede. Da es mir aber a priori wabrscheinlich war, dass sich Repräsentanten der ganzen, von mir beschriebenen Formenreihe auch hier ergeben würden, so unternahm ich es bei Nothoscorodon fragrans und nahestehenden (Allium odorum u. A.) darnach zu suchen. Dies ist mir inzwischen sehr abgekürzt worden durch zwei im letzten Sommer publicirte Aufsätze Strasburger's $(8,14)$. Nach Kenntnissnahme von Schleicher's und meinen Angaben hat derselbe sich durch eigene Prüfung uber- 
zeugt, dass gewundene Fadenknäuel in den Anfangsstadien auch bei seinen pflanzlichen Objecten vorkommen, und dass sich auch bei den Tochterkernen Formen finden, welche den von mir beschriebenen entsprechen (s. Strasburger's Taf. IV 1. c., Fig. 13 bis $17,31-34,27,55$ ).

Es bleibt hiernach aber noch eine Anzahl, meines Erachtens wesentlicher Punkte, in denen Strasburger noch keine Uebereinstimmung zwischen unseren Objecten gefunden hat; ich aber solche theils wirklich finde, theils nicht ausgeschlossen sehen kann ${ }^{1}$ ).

1) Strasburger hält auch jetzt noch daran fest, dass in den ersten Anfangsstadien distincte Körner in den Kernen auftreten, und erst nachmals zu Fäden auswachsen sollen.

Nach den Exemplaren dieser Stadien dagegen, welche ich selbst bei Allium und Nothoscorodon finde, muss ich sagen, dass mir diese Auffassung nicht begründet scheint. Bei schon etwas weiter vorgeschrittenen Formen, wie in Fig. 20, 18 Taf. 2 hier, kann man ohne Mühe erkennen, dass wirklich nur Fäden, und optische Schnitte von solchen vorliegen; obwohl erst die scharfe Tinction und der Beleuchtungsapparat dies binreichend erkennen lässt. Die Formen Fig. 20 liegen freilich schon nicht mebr weit vor solchen, für die auch Strasburger jetzt das alleinige Vorkommen von Fäden zugiebt (vergl. seine Fig. 14, 15 Taf. 37 a. a. 0.). Aber auch von den vorangehenden Stadien, von denen in Fig. 19 hier eines skizzirt ist, kann man nicht behaupten, dass sie aus Körnern beständen. Wo sie hinreichend locker gebaut sind, unterscheidet man stellenweise deutliche Faden-

1) Es ist mir bei den Allium- und verwandten Arten, die mir Herr College Engler freundlichst verschaffte, leider nicht gelungen recht günstige Stadien der Entwicklung zu treffen, wo die Theilungen im Endosperm so massenhaft gehäuft zu finden sind, wie ich dies an gütig gesandten Präparaten Strasburger's bewundern konnte. Doch habe ich eine hinreichende Anzahl von Theilungsstadien durch längeres Suchen zusammengefunden, um das Obige daraus schliessen zu können.

Die Theilungen lassen sich bei diesen Pflanzen durch Chromsäure und Pikrinsäure nicht so sicher und schön conserviren, wie bei Thiergeweben; es ist dafür zu empfehlen, die Knospen oder sonstigen Stücke vor dem Einlegen anzuschneiden. Ich stimme Strasburger darin zu, dass der Alkohol die Theilungen hier oft sehr gut conservirt; einige Stadien (besonders Tochterknäuel) erleiden jedoch dadurch leichter wie bei Thierzellen Schrumpfung, was auch Strasburger a. a. O. zugiebt. Meistens habe ich Alkoholbärtung und Kernfärbung mit Alauncarmin gebraucht. Der Alkohol ist auch bei Thierzellentheilungen brauchbar, aber viel unsicherer als Chrom und Pikrin. 
windungen; doch gehören dazu bei der Kleinheit der Objecte, und bei der hier sehr dichten Lagerung der fraglichen "Windungen oder Körner", scbon starke Systeme, und ich gebe gern zu, dass die Sicherstellung, ob allein Eins oder das Andere vorliegt, an diesen Kernen unmöglich ist. Hier aber scheint mir der Analogieschluss in sein volles Recht treten zu können. Ein Epithelkern von Salamandra, wie ihn meine Fig. 2 c Taf. 17 im I. Theil dieser Beiträge zeigt, befindet sich im entsprechenden Zuständ wie der kleine runde Pflanzenkern in Fig. 19 Taf. 2 hier; jener ist aber viel grösser, dabei von flacher Form, deshalb gelingt es bei ihm leicht festzustellen, dass er nur Windungen und nicht Körner entbält ${ }^{1)}$.

Bei dem Pflanzenkern von Fig. 19 hier dagegen ist dies nicht möglich, auch wenn hier ebenfalls bloss Windungen da sind; da dieselben bei ihrer Feinheit und der Kleinheit des Kerns entsprechend viel dichter liegen, und da ausserdem, weil der Kern mehr rund ist, relativ viel mehr Windungen übereinander liegen und sich gegenseitig verdunkeln, als es bei dem platten Epithelkern der Fall ist.

Daher erlaube ich mir, aus dem günstigen Object auf das ungünstigere zu schliessen; und verstehe es nicht recht, dass Strasburger und Andere sich dazu in diesem und anderen Fällen nicht entschliessen wollen. Denn durch mein Verfahren wird auch für diese Stadien die Homologie bei Thieren und Pflanzen hinreichend hergestellt, durch die Annahme aber von körnigen Anfangsstadien bei Pflanzen u. A. - welche doch, wie hier erörtert ward, durch die Thatsachen nicht postulirt ist - wird gleich für die ersten Theilungsphasen cine erhebliche Verschiedenheit bei den genannten Objecten aufgestellt.

2) Das Vorkommen von Sternformen des Mutterkerns hat Strasburger an Pflanzenzellen bisher nicht speciell bestätigt; nur für Psilotum triquetrum (Sporenmutterzellen) bemerkt er, dass zuweilen eine radiäre Anordnung vorkomme, doch nicht so ausgesprochen wie bei meinen Objecten. Ich muss zugeben, dass ich die Muttersteme bei Allium und Nothoscorodon noch nicht in solcher Deutlichkeit und Eleganz der Form vorgefunden habe, wie bei Thierzellen; sie scheinen dort immer mehr zusammengedrängt zu sein und zu Biegungen der Strahlen zu neigen. Doch glaube ich den betreffenden Formen, die ich bis jetzt bei Pflanzen gefunden habe (Beispiel Fig. 21 und 22 Tafel 2) immerhin einen deutlich radiären Bau zuschreiben zu müssen, um so mehr, da an den Tochterkernen auch hier, bei den Planzen, recht augenfällige Radiärformen sich finden (Fig. 24).

3) Die Stadien bei Pflanzen, die Strasburger früher mit dem Namen Kernplatte belegt hatte (z. B. seine Fig. 20-22 Taf. IV, Lit.-Verz. 8),

1) Vergl. den Text $\mathrm{Th} . \mathrm{I}$, p. 368 oben: die einzelnen scheinbaren Körner in der Fig. $2 \mathrm{c}$ Tafel 17 sind nur optische Schnitte, wie auch in anderen der Figuren. 
entsprechen offenbar denjenigen, welche ich bei Thierzellen Aequatorialplatte genannt habe.

In diesen sind nun an meinen thierischen Objecten aufs Deutlichste zwei Systeme von etwa gleichlangen und gleichdicken Fäden vorhanden, je einem künftigen Tochterkern entsprechend; jeder Faden ist $z$ u einer Schleife geknickt, die den Umbiegungswinkel nach dem betreffenden Pol kehrt ${ }^{1}$ ), und die aequatorialen Enden der beiden Fädengruppen liegen zwischeneinandergeschoben oder einander etwa gegenüber. (Siehe Fig. 10-14 Taf. 1 hier.) Eine Continuitätstrennung der Fäden beider Tochterkerngruppen findet von diesem Stadium aus nicht mehr Statt, sie hat schon vorher Statt gefunden: nur kann allerdings eine temporäre Verschmelžng, und dann Trennung von Fadenenden jetzt Statt finden.

Nach Strasburger's Darstellung dagegen würden die Elemente der Kernplatte bei den Pflanzen nebeneinandergelagerte Körner sein, von etwa elliptischer Form, die sich erst jetzt halbiren (s. Strasburger's Fig. $20-22,47-48,35,56$ u. a.).

Für solche Fälle, in denen Strasburger zugiebt, dass vor diesem Stadium Fäden, nicht Körner vorhanden sind (Nothoscorodon u. A.), ist es mir nicht verständlich geworden, wie er sich die Lagerung dieser Elemente zur Aequatorialplatte, resp. Kerntonne denkt.

Ich habe in Fig. 23 Taf. 2 hier eine Aequatorialplatte von Allium odorum (aus dem Umfang des Fruchtknotens) wiedergegeben, mit Hartnack $9 \grave{a ̀ ~}$ imm. gesehen und vergrössert dargestellt ${ }^{2}$ ). Soviel ist an dieser Figur, und anderen ähnlichen, ganz sicher, dass Fäden da sind, und nicht unregelmässig geformte und verwaschen aussehende Körner, wie sie Strasburger in den entsprechenden, vorher citirten Figuren darstellt. Im Specielleren aber habe ich freilich die Verhältnisse in dieser Figur nur so dargestellt, wie sie mir zu sein scheinen, nnd wie sie jedenfalls sein können. Sie liegen schon zu sehr an der Grenze des Erkennbaren, als dass man dies behaupten könnte. Das Element links oben in der Figur scheint eine abgerückte gebogene Fadenschleife zu sein; an den Polarseiten glaube ich Umbiegungen von Fäden zu sehen. - Aber wenn dies für diesen Fall und viele ähnliche nicht zu beweisen ist, so darf man ebensowenig behaupten, dass Alles dies nicht da sei, und dass etwa gar die Fäden an den Polen alle frei aufhörten. Denn der aequatoriale Durchmesser der färbbaren Figur in Fig. 23 Taf. 2

1) Abgesehen von Unregelmässigkeiten in der Lagerung (vergl. Abschnitt 2, und Fig. 14 Taf. 1, Fig. $35 \mathrm{~d}$ Taf. 3 hier.

2) Stärkere Immersionen (z. B. Seibert und Krafft Nr. 11) nützen hierfür auch nicht mehr. Was sie an der Vergrösserung verstärken, nehmen sie an Licht weg. Ich bin für solche Objecte allmählig dahin gekommen, dass ich nichts mehr beschreibe, als was ich nicht auch mit Imm. 9 von Hartnack sehen kann. 
ist $=18 \mu$, der polare $=15-16 \mu$; der aequatoriale Durchmesser der Aequatorialplatte in Fig. 14 Taf. 1 dagegen, von Salamandra, beträgt $28 \mu$, der polare $22 \mu$. Hier kann man gerade noch ganz deutlich sehen, dass man Fadenschleifen vor sich hat, die an der Polseite umbiegen; dort bei der Pflanze, bei den kleineren Verhältnissen, ist das nicht zu verlangen.

Hiernach kann ich nicht glauben, dass wirklich eine so tief greifende Heterologie zwischen diesen Stadien bei Pflanzen und Thieren besteht, wie sie aus Strasburger's Angaben folgen würde; sondern muss es für das Wahrscheinlichste halten, dass die Aequatorialplatten der Pflanzen im Wesentlichen in derselben Art gruppirt sind wie bei Thierzellen, wenn man dies auch bei ersteren nur an besonders günstigen Objecten wird entscheiden können.

Ich übersehe hierbei nicht, dass bei dem letztuntersuchten Strasburger'schen Object (Tradescantia-Haare) die Grössenverhältnisse günstiger sind; nach seinen Massangaben p. 3 l. c. würden die Kerndimensionen hier denen von Salamandra ziemlich nahe kommen. Aber so viel ieh entnehme, hat Strasburger bei diesem Object bis jetzt noch keine geeigneten Tinctionen angestellt; vielleicht sind sie hier auch nicht ausführbar. $\mathrm{Ohne}$ gute Tinction and Aufhellung mit aetherischem Oel aber würde ich auch bei Salamandra den Bau von Aequatorialplatten, wie in Fig. 10-14 Taf. I hier, nicht sicher erkennen können, sie würden meistens nur als Anhäufungen von undeutlichen Körnern oder Stäbchen erscheinen. Die Reagentien, welche auch Strasburger angewandt hat, (Chromsäure, Alkohol, Osmiumsäure) würden mir hierbei obne Tinction sehr wenig belfen; und da Strasburger auch sonst die letztere noch nicht in derselben Weise, wie ich, ausgenutzt zu haben scheint, so muss ich mir zunächst erlauben, mich mehr auf meine eigenen Erfahrungen zn verlassen.

4) Strasburger scheint für sicher zu halten, dass bei Pflanzen nach dem Stadium der Kerntonne die beiden Tochterkernmassen je zu einem homogenen Klümpchen verschmelzen, und erst nachträglich diese Klumpen sich wieder zu Fadencomplexen differenziren.

Hieran muss ich zweifeln. Ich würde diesen Zweifel nicht äussern ohne eigene Prüfung lebender pflanzlicher Theilungen, wenn ich mir von solcher eine Entscheidung versprechen könnte; das ist aber nicht der Fall. Denn soviel ist gewiss, dass, wie ich früher erwähnt habe, in dem Stadium meiner Fig. 28 Taf. 2 hier die Windungen der Tochterkernfäden meistens sehr dicht zusammenrücken; am lebenden Object sehen die Tochterkerne dann selbst bei der grosskernigen Salamandra scheinbar homogen ans (vergl. in $\mathrm{m}$. Theil I Taf. 16 Fig. $3 \mathrm{i} \mathrm{k}$ ), und man braucht erst Essigsäure oder andere Dinge, um zu zeigen, dass sie es doch nicht sind (Ebenda, $\mathbf{k}^{1}$ ). Bei einem kleineren Pflanzenkern wäre darüber auch so keine Sicherheit zu hekommen.

Ich habe aber ein anderes Argument. Aus eigenen conservirten und tingirten Präparaten von Salamandra kann ich in Menge Tochterkerne de- 
monstriren, welche sich durchaus als homogene, höckerige Klumpen darstellen (z. B. Fig. 29 Taf. 2). Das sind fast durchweg solche Präparate, an denen auch die übrigen Kernfiguren, sowie die ruhenden Kerne mehr oder minder Schrumpfung und (die ersteren) Zusammenballung erlitten haben. Je besser dagegen im Allgemeinen die Conservation, je regelmässiger geformt die Muttersterne und -Knäuel sind, desto weniger findet man von solchen homogenen Tochterkernen. Ich kann dies behaupten, nachdem ich nunmehr ein recht grosses Material geprüft, und einige Tausende von conservirten Kerntheilungen, von verschiedener Güte der Erhaltung, vor Augen gehabt habe.

Ich halte also dafür, dass man an diesem Stadium im Leben überhaupt nicht feststellen. kann, ob es homogen oder fadig differenzirt ist; dass aber in der That das Letztere stattfindet, und dass überall, wo solche Tochterkernpaare an Reagentienpräparaten homogeu erscheinen, eine künstliche Verklumpung der Fadenwindungen vorliegt. Besonders leicht verklumpend wirkt in dieser Hinsicht der Alkohol. -

Auch bei den Tochtersternen (in Formen wie Fig. 26 Taf. 2 u. 24 Taf. 2) kommen solche künstliche Conglutinationen oft vor, und zwar natürlich besonders an der Stelle, wo die Fäden der Halbsterne am engsten genähert liegen, nämlich an der Polarseite, resp. im Centrum des Sterns. Es hat dies verschiedene der Schriftsteller zu der Meinung geführt, dass die Fäden der Tochterfiguren in dieser Form ,zunächst an der Polseite mit einander verschmölzen". Auch diese Bilder muss ich vielmehr als Artefacte auffassen.

Dabei bestimmt mich noch ganz besonders Folgendes:

In Präparaten von Amphibien u. A., welche überhaupt an Schrumpfungen reich sind, findet sich, dass ausser dieser Tochterkernphase auch unter den Mutterkernfiguren gerade die am häufigsten zu einer homogenen Masse zusammengeklumpt sind, in welchen ebenfalls die Fadenelemente besonders dicht gedrängt liegen: nämlich die systolischen Sterne und die Aequatorialplatten. Bei diesen kann aber nicht der geringste $Z_{\text {weifel sein, }}$ dass dies Artefacte sind und dass die Fïden in natura getrennt waren. Der Schluss daraus ergiebt sich fast von selbst: In der Mutterfigur folgen auf einander die Formen: Knäuel-Stern-Aequatorialplatte, indem dabei sicher und nachweisbar keine Verschmelzung, keine Wiederneubildung von Fäden erfolgt, sondern die Fäden durch die beiden Figuren hindurch morphologisch erhalten bleiben und nur umgeordnet werden. Bei den Tochterfiguren andererseits folgen auf einander die Formen: Aequatorialplatte-Stern - Knäuel. Es liegt schon a priori am Nächsten, dass es dabei in Bezug auf das morphologische Erhalten-Bleiben der Fäden nicht anders sein wird, als vorher beim Mutterkern; dies wird, wie mir scheint, noch stärker dadurch bezeugt, dass die bestconservirten Präparate es zeigen, und nicht dadurch in Frage gestellt, dass man es an den lebenden und an weniger gut conservirten Objecten nicht immer sehen kann. 
Ich möchte nicht dahin verstanden werden, als ob ich hiermit die Vollkommenheit der Präparate Strasburger's irgend herabsetzen wollte, deren Schönheit mir die gesandte Probe hinreichend gezeigt hat. Aber gerade für diese Stadien der Tochterkerne sind diese pflanzlichen Objecte besonders ungünstig, man wird daran vielleicht niemals etwas anderes erzielen können, als die erwähnten artificiellen Verschmelzungen. Denn die Kerne und Kernfiguren sind hier erstens relativ klein, und zweitens ist die Menge der Windungen resp. Fadenstücke grösser, daher die Lagerung dichter, als bei vielen Zellen von Amphibien; je enger aber ihre Lagerung, desto leichter sind sie natürlich der Conglutination durch die Reagentien ausgesetzt, und desto mehr macht solcher Knäuel am lebenden Kern den Eindruck des Verschmolzenseins.

Vielleicht mögen, wie ich gern zugeben will, die Verhältnisse in diesem Stadium bei Pflanzen vielfach überhaupt so liegen, dass eine Unterscheidung: ob Windungen, ob homogene Beschaffenheit - wirklich unmöglich bleibt. Es kann ja sein, dass in den Stadien der Tochterkerne, welche Strasburger z. B. von Tradescantia (l. c. p. 7 unten) nach dem Leben beschreibt, und ebenso in vielen anderen Objecten, die Fäden dieser Kerne wirklich ganz bis zur Berührung aneinandertreten. Aber es ist doch noch ein Unterschied zwischen Berührung und Verschmelzung. Nehmen wir die erstere an, so bleibt der Fadenbau auch in diesem Stadium gewabrt, und es lässt sich damit eine hinreichende Homologie der Formenreihe für Thicr- und Pflanzenzellen durchführen; nimmt man eine Verschmelzung an, so ist diese Homologie zerstört. So lange die Wahl zwischen diesen zwei Annahmen bleibt - und das scheint mir noch durchaus der Fall zu sein - ziehe ich entschieden die erstere vor ${ }^{1}$ ).

5) Die Längsspaltung der Fäden (Th. 1 Taf. 17 Fig. 10, 11, 16 Fig. 5, hier Taf. 1 Fig. 9) hat Strasburger bei Pflanzen nicht gesehen und scheint nicht anzunehmen, dass sie hier vorkommt. Nach Objecten, wie sie meine Fig. 21 Taf. 2 hier zeigt, muss ich Letzteres doch glauben, obwohl sie offenbar auch hier viel undeutlicher ist wie bei Thierzellen, und obwohl ich auch für Letztere zugebe (s. o. b. Hodenzellen), dass die Erscheinung vielleicht in manchen Fällen fehlen kann. - In Fig. 21 sind nur diejenigen Fäden doppelt dargestellt, bei denen dies Verhalten ganz deutlich und unzweifelhaft mit Hartn. Imm. 9 und Zeiss Imm. 2 vorliegt, auch schon mit schwächeren Systemen erkennbar ist. Es ist möglich, dass in derselben Kernfigur auch alle übrigen Fäden gespalten sind und nur die Hälften enger aneinanderliegen, wie bei den doppelt dargestellten; bei manchen sieht es so

1) Strasburger giebt übrigens in seiner letzten Mittheilung zu, dass der Alkohol gerade in den hier in Rede stehenden Phasen Veränderungen gedachter Art machen könne. Auch Chrom- und Pikrinsäure verhalten sich hierin, so viel ich finde, bei Pflanzen nicht unschuldiger. 
Beiträge zur Kenntniss der Zelle und ihrer Lebenserscheinungen. 183

aus, ich habe es aber in der Zeichnung nicht dargestellt, wo es nicht ganz sicher war.

Ich bemerke dazu noch, dass die betreffenden Objecte von Allium Alkoholpräparate sind, und dass ich an solchen auch bei Thierzellen die Fädenspaltung nie so deutlich finde, wie an Chrom- und Pikrinpräparaten.

6) Eine der hauptsächlichsten Differenzen endlich ist folgende: gerade diejenige Erscheinung bei der Kerntheilung, die mir für die Physiologie und Mechanik des ganzen Processes besonders bemerkenswerth erschienen ist, die rückläufige Wiederholung der Figurenreihe des Mutterkerns durch die der Tochterkerne, erkennt Strasburger zwar für meine Objecte an, leugnet sie aber für die seinigen.

Dies ist mir nicht ganz verständlich, weil Strasburger's eigene Beschreibung im Wesentlichen sämmtliche Formen enthält, welche durch die rückläufige Metamorphose der Tochterkerne postulirt werden: (Siehe seine Taf. IV 1. c. Fig. 23, 24, 57, 58: Tochtersterne; 26, 27, 28, Tochter$\mathrm{kn}$ äuel, allerdings stark parallelfadig. In der Beschreibung der Zelltheilung bei Tradescantia, p. 5, heisst es : „Die Stäbchen legen sich nunmehr etwas fächerförmig auseinander". Es ist sehr möglich, dass dieses Auseinanderklappen bei Pflanzenzellen nicht so hochgradig wird, wie bei vielen Thicrzellen; immerhin involvirt es eine Sternform, besonders deutlich wenn vom Pol gesehen. Was darauf folgt (Str. ebenda p. 7): die "quere Streifung" dann die "fleckige Zeichnung" der lebend gesehenen Kerne würde ich eben für aequivalent halten mit den gegitterten und Knäuelphasen der Tochterkerne, wie sie in meinen Figg. 17 Taf. 17, 2, 3 Taf. 18, 18 Taf. 17, Theil I dieser Beiträge, gezeichnet sind; nur dass die Copie der Mutterphasen durch die Tochterphasen bei den Thierzellen viel deutlicher ausfällt).

Wenn ich also in allen bis hier besprochenen Puncten noch keinen Grund finde, erhebliche Verschiedenheiten des Theilungsvorgangs bei Pflanzen und Thieren anzunehmen, so sind dagegen in einigen andern wirkliche Differenzen bei beiden Objecten jetzt sicherzustellen.

Erstens in dem Verhalten der Nucleolen. Diese erhalten sich bei Pflanzen während der Karyokinesis im Mutterkern weit länger in ihrer Form, als bei Thieren, und umgekehrt treten sie dort in den Tochterkernen weit früher wieder auf, wie hier. Dies ist durch die neue Mittheilung Strasburger's (8) erwiesen, und ich kann es durchans bestätigen (s. Fig. 18 Taf. 2 hier). Nach einigen Figuren Eberth's (2) wäre ein ähnliches Verhalten auch bei manchen Wirbelthieren anzunehmen. Ich habe mit Rücksicht darauf nochmals viele der betreffenden Stadien (lockere Knänelform) von Salamandra und Siredon, wie auch von Säugethieren bei bestem Licht mit starken Systemen geprüft, kann jedoch versichern, dass hier in der That nichts von Nucleolen zu erkennen ist (vergl. Fig. 3, 4, 5 Taf. 17, Th. I).

Für die Beurtheilung der physiologischen Rolle, die die verschiedenen Bestandtheile des Kerns bei der Theilung spielen, ist diese Thatsache jedenfalls als wichtig zu notiren (s. Abschnitt 2).

Archiv f. mikrosk. Anatomie. Bd. 18. 
Eine andere Differenz liegt darin, dass bei Pflanzen die blassen, nicht tingirbaren Fäden, die noch innerhalb der tingirbaren Kernfigur in axialer Lagerung vorkommen (z. B. Fig. 22-26 hier), weit deutlicher hervortreten. Dasselbe ist jedoch auch bei manchen Thierzellenarten der Fall ${ }^{1}$ ). Dieser Unterschied ist aber kein fundamentaler. Ich habe nunmehr auch bei Salamandra diese Fäden gefunden; sie sind freilich bei Epithel-, Blut- und Bindegewebszellen (s. Fig. 12 Taf, 1 hier) nur selten, und auch dann fast. niemals besonders scharf zu sehen, deutlicher bei den Hodenepithelien und zuweilen bei Knorpelzellen (womit eine Beobachtung Schleicher's bestätigt wird (Fig. 3, 4, 10 Taf. 13); in allen diesen Fällen ist übrigens Untersuchung in nicht zu stark brechenden Medien nöthig, um sie hier zu erkennen. Hiernach muss ich denken, woran ich früher noch zweifelte ( $\mathrm{Th}$. I), dass diese Fäden, in mehr oder minder deutlicher Ausprägung, ganz wohl ein allg eme in es Vorkommen bei der indirecten Zelltheilung sein können und müssen sie gewiss, neben der eigentlichen tingirbaren Kernfigur, für das weitere Studium des Vorgangs grosse Beachtung verdienen. (Weiteres hierüber und zur Begründung s. im Abschnitt 2.)

Hiermit gerathe ich nun in einige Collision mit der Definition und Eintheilung der Kerntheilungstypen, welche Strasburger so eben in seiner citirten Schrift (8 p. 284) aufgestellt hat. Er bezeichnet diejenigen Formen der Aequatorialplatte, welche er selbst in dem Integument der Ovula beNothoscorodon, und ich überall bei Salamandra fand (z. B. Fig. 12 Taf. 1 bier) als Kerntonnen, die Formen mit jenen blassen Fasern als Kernspindeln; seine Ansicht geht dahin, dass bei den Spindeln eine Sonderung der Kernsubstanz in die eigentlichen Kernplattenelemente ${ }^{2}$ ) und jene blassen Fasern stattfände, bei den Tonnen aber eine solche Sonderung überhaupt nicht einträte. - Nun aber finde ich, wie gesagt, dass diese Sonderung auch in den letzteren bei Salamandra nicht ausbleibt; es wird sich also fragen, ob jene Unterscheidung aufrecht erhalten werden soll, da sie hiernach vielleicht nur auf ein Mehr oder Minder der Deutlichkeit herauskommen dürfte ${ }^{3}$ ). Als bequeme Bezeichnungen der Totalform kann man die Ausdrücke Tonne und Spindel natürlich trotzdem benutzen.

Stras burger hat in jïngster Zeit ausgesprochen: „die Beobachtungen der Kerntheilung in ausgeprägten Thieren und Pflanzen gäben bis jetzt, oft bis in die feinsten Details, tibereinstimmende

1) So: beim Endothel der Froschhornhaut (Mayzel); ferner bei Eizellen und Furchungszellen.

2) Das ist das Nämliche, was ich Kernfigur nenne, das Tingirbare.

3) Vergl. am Schluss des Abschnitts 2, unter: „Die achromatische Fadenfigur". 
Resultate $^{\text {; }}$ und: „diese Uebereinstimmung sei trotz bestehender Abweichungen noch gross genug, um in beiden Fällen auf gleiche, die Theilung beherrschende Kräfte schliessen zu lassen."

Ich habe eine solche Uebereinstimmung von vornherein für wahrscheinlich gehalten, und hoffe, dass sie sich noch bis in viel feineres Detail wird durchführen lassen, als dies jetzt anzugehen scheint. Soll dies aber geschehen, so werden vor Allem erst die obigen Punkte aufgeklärt werden müssen, die ich deshalb hier unter 1) bis 6) genau zusammengestellt habe: denn wenn Strasburger's bisherige Ansichten über sie aufrecht gehalten würden, dann scheint mir durch sie keineswegs eine Uebereinstimmung, sondern eine so erhebliche $\mathrm{Differenz}$ bedingt $\mathrm{zu}$ werden, dass es vielmehr sehr schwer sein würde, für beide Fälle auf gleiche wirkende Kräfte zu schliessen. Ich führe als ein besonders deutliches Beispiel dafür nur das oben unter 3) besprochene Stadium der Aequatorialplatte an: wenn wir wirklich im einen Fall (Pflanzen) hier Körner hïtten, die sich erst $\mathrm{nm}$ diese Zeit theilen; im anderen (Thiere) aber Fadensegmente, die sich schon lange vorber, im Knäuel- oder Kranzstadium getrennt haben und in der Aequatorialplatte nur einander gegenüberrücken - so würde ich zunächst keine Möglichkeit sehen für beide Erscheinungen gleiche wirkende Kräfte zu construiren.

D.

\section{Sä ugethiere.}

Für pathologische Fälle sind durch Eberth (2) vom Kaninchen schon einige Kernfiguren beschrieben worden, in denen sich deutlich Knäuel- und Sternformen erkennen lassen. Es fragte sich fuir mich, ob sich dieselben auch im physiologischen Wachsthum ergeben wiirden.

Ich habe sie in grosser Menge gefunden: 1) bei Kaninchenembryen im Epithel und der Bindesubstanz des Amnion, im Körperepithel und Bindegewebe, im wachsenden Muskel und im Knorpel. Das Amnion ist ein besonders bequemes und an Theilungen reiches Object. Behandlung: Chromsäure 0,1 pCt., Safranin oder Hämatoxylin; oder Pikrinsäure, Hämatoxylin oder PartschGrenacher'sches Alauncarmin. 
Ferner 2) bei saugenden Kätzchen im Mesenterium und Omentum (Bindegewebszellen und Zellen der jungen Fettanlagen). Behandlung ebenso, oder noch bequemer: Essigsäure 0,5 pCt. auf die am Objectglas ausgebreitete Membran, vorsichtiges Abwaschen mit Wasser, Hämatoxylin.

Fig. 30 a-d geben nur einige Beispiele. Die Kernfiguren unterscheiden sich, so weit man bei ihrer geringeren Grösse urtheilen kann, in nichts Wesentlichem von denen bei Salamandra. Deutliche feinfadige Kernspindeln (im Sinne Strasburger's, s. 0. bei "Pflanzenzellen") konnte ich hier bisher nicht sehen, halte dies aber bei der Kleinheit der Verhälnisse für keinen Beleg gegen ihr Vorkommen. Die Tochter-Kernknäuel (s. Fig. 28, 29 von der Krötenlarve), die systolischen Sterne und Aequatorialplatten werden öfter durch die Reagentien verschrumpft und zu homogenen klumpigen Massen geballt, als bei den Amphibien, was bei den kleinen Elementen natürlich ist, denn je kleiner die Kernfigur, desto weniger locker liegen die Fäden, desto leichter werden sie also conglutinirt werden.

Der Versuch, am frischen Omentum die Theilung auf geheiztem Objectglas $z u$ verfolgen, war resultatlos, denn die lebenden Kernfiguren bleiben hier wegen ihrer Blässe undeutlich.

Untersuchungen, die ich tuber die Kernvermehrung bei der Theilung thierischer Eizellen begonnen habe, sind noch nicht zum Abschluss gelangt. Vorläufig möchte ich aber die Vermuthung aussprechen, dass auch hier, so abweichend die Verbältnisse auf den ersten Blick aussehen, in den Hauptsachen Homologie sich ergeben wird. Die färbbaren Elemente („Kernplattenelemente") sind bekanntlich in Ei- und Furchungszellen relativ klein und schwer zu beobachten; ich sehe bis jetzt jedoch keinen stichhaltigen Einwand dagegen, dass auch hier die Theilung mit Knäuel- und Sternformen beginnen kann; für die Eier von Mesostomum hat Schneider ja die ersteren bereits nachgewiesen.

Die Skizzen Taf. 2 Fig. 31-34 habe ich mir erlaubt nach Präparaten von Toxopneustes lividus zu zeichnen, die mir von Herman Fol vor zwei Jahren zum Geschenk gemacht wurden ${ }^{1}$ );

1) Osmium-Carmin. Ein anderes mitgesandtes Präparat Fol's, Pi- 
sie sind ganz einfach gehalten, da sie nur zeigen sollen, in welcher Art ich ihre Formen auf die Verhältnisse bei anderen Zellen beziehen möchte. Fig. 34 würde die Aequatorialplatte sein (vergl. Taf. 1 Fig. 10-14 von Salamandra, Taf. 2.Fig. 22 (eigentlich noch Stern) und Fig. 23 von Pflanzen); Fig. 31: Trennung und beginnende Tochtersternform $=$ Fig. 25, weiter Fig. 26, Taf. 2. Fig. 32, 33: Knäuelform der Tochterkerne $=$ Taf. 2 Fig. 28, Taf. 3 Fig. 35g.) - Bei der Kleinheit der Kernfiguren der Eizellen, der Feinheit ihrer Fäden und der Verdunkelung durch die grosse körnerreiche Masse des Eiprotoplasmas, ist es freilich nicht möglich den Bau dieser Figuren so klar zu sehen wie bei den anderen Objecten, und ich kann nicht beweisen, dass er wirklich derselbe ist; halte dies aber für das Nächstliegende. Eigenthümlich sind bei den Eizellentheilungen Wirbelloser die Elemente, die in den blassen Kernfäden, an oder nahe den Polen, in den Stadien der Tochterknäuel deutlich werden (Fig. $32 \mathrm{x}$ ) und bald zu einem glänzenden Körper zusammenzuriicken scheinen (Fig. $33 \mathrm{x}$ ). Es ist dies, was H. Fol (6) ,corpuscule central d'un aster" nennt.

H. Fol selbst hat in dem eben citirten Werk zahlreiche schöne und sorgfältige Abbildungen der betreffenden Stadien gegeben (Taf. 6 ua a. a. 0.), die, wie mir scheint, mit der hier gekennzeichneten Auffassung nicht in Widerspruch stehen, wenn auch Einzelnes darin auf den ersten Blick so erscheint. So besonders, dass die Tochterkernfiguren, welche ich als Knäuel ansehen möchte (Fig. 32, 33 hier), in den Abbildungen Fol's und Anderer aus getrennten Körperchen zu bestehen scheinen. Ich gebe zu, dass man bei manchen solchen Figuren mehr den letzteren Eindruck erhält; andere sehen mir aber wieder ganz wie zusammenhängende und etwas geschrumpfte Knäuel aus, und da einige Veränderung durch die Reagentien mir hier in allen Fällen im Spiel zu sein scheint, so halte ich die Annabme, dass meine Auffassung durchführbar ist, für gestattet.

Das wesentliche Ergebniss der vergleichenden Untersuchung, über die ich so eben berichtete, lautet also kurz:

krinsäure, zeigt die achromatischen Fäden sehr schön erhalten, die chromatische Kernfigur dagegen ist hier weniger deutlich. 
1) Die Hauptglieder der von mir bei Salamandra aufgestellten Reihe der Kerntheilungsfiguren:

\begin{tabular}{|c|c|}
\hline $\begin{array}{l}\text { M utterkern } \\
\text { (progressiv): }\end{array}$ & $\begin{array}{l}\text { Tochterkern } \\
\text { (regressiv). }\end{array}$ \\
\hline Ruhe (Gerüst) & Ruhe (Gerüst) \\
\hline Knäuel & Knäuel \\
\hline$\downarrow$ Stern & $\uparrow$ Sterne \\
\hline
\end{tabular}

baben sich bei fast allen den antersuchten Objecten in gleicher Reihe wiederfinden lassen und zeigen nur bei manchen formelle Abweichungen, welche nicht als wesentlich zu betrachten sind; bei denjenigen der Objecte, wo die Uebereinstimmung in einzelnen Punkten nicht klar ausgesprochen ist, liegen die Beobachtungsverhältnisse so ungünstig, dass es mindestens ebenso gut freistehen muss jene Uebereinstimmung anzunehmen, als sie $\mathrm{zu}$ bezweifeln.

Es ist also gestattet, das bei Salamandra gefundene Gesetz, wonach die Mutterformen in umgekehrter Reihe durch die Tochterformen copirt werden, auch auf die iibrigen untersuchten Objecte auszudehnen; und es ist hiernach ferner denkbar (obschon, wie ich ausdrücklich zugebe, noch nicht erwiesen), dass die Mechanik des Theilungsvorganges, wie sie im folgenden Abschnitt für die Urodelen näher dargelegt wird, für alle Zellenarten uberbaupt bei Thieren und Pflanzen Geltung hat. Diese Annahme beansprucht für sich dasselbe Recht, mit welchem wir auch in anderen Dingen Analogieschliasse von Bekanntem auf Unbekanntes machen.

2) Irgend welche Belege dafür, dass ausser dem Typus der indirecten Kerntheilung oder Karyokinesis noch andere, fundamental davon verschiedene Kernvermehrungsarten vorkämen, haben sich bei dieser Untersuchung nicht ergeben ${ }^{1}$ ).

1) Vergl. Nr. 13, Lit.-Verz. 
An hang.

Ueber die Kernvervielfältigung bei mehrkernigen Zellen.

Auf die mehrkernigen Zellen ist in jüngster Zeit ein besonderes Interesse gelenkt, indem ein in Dingen der Cellularphysiologie ausgezeichneter Forscher, Ed. van Beneden, sie als Repräsentantinnen einer directen, ohne Fadenmetamorphose verlaufenden Kerntheilung in Anspruch genommen hat (1). Ich habe an einem anderen Orte (13) ausgeführt, weshalb ich meinem Freund van Beneden hierin nicht beitreten kann, und dass nichts im Wege steht, auch in den mehrkernigen Zellen die Kernproduction auf indirecte Theil ung zurückzuführen.

Kurz darauf hat M. Treub (17) für verschiedene mehrkernige Zellenarten von Phanerogamen (Humulus, Vinca, Urtica) nachgewiesen, dass bei der Kernvermehrung in ihnen die typischen Kernfiguren zu finden sind; und das Gleiche ergiebt sich aus den neuerdings veröffentlichten Untersuchungen von Schmitz (15) für die vielkernigen Zellen der Siphonocladiaceen (Thallophyten).

Einen indirecten Beweis dafür, dass es bei Thierzellen ebenso ist, hatte ich schon am eben citirten Ort erbracht (13, p. 14); den directen kann ich jetzt nachtragen.

Objecte, die sich zum Studium der Production vielkerniger Zellen ganz vorzüglich eignen, sind die Hodenepithelien von Salamandra ${ }^{1}$ ) zur Zeit, wo die Samenbildung beginnt (Juli, August). Wie im Abschnitt 3 näher beschrieben wird, führen die massenhaften indirecten Kernvermehrungen, die hier auftreten, nar zum Theil zur Zellvermehrung; anderntheils bleibt diese ans und es resultiren vielkernige Zellen (Taf. 3 Fig. 49-52), die zum Theil zu einer Grösse und einem Kernreichthum anwachsen können, der ihnen vollsten Anspruch auf den Namen Riesenzellen giebt ${ }^{2}$ ). Die Abbildungen zeigen obne Weiteres, dass die Reproduction der Kerne hier nach dem Typus der indirecten Theilung verläuft; und wenn es auch nicht zu widerlegen ist, dass etwa

1) Und wohl auch von anderen Thieren.

2) Ueber die Beziehungen dieser Bildungen zu von la Valette St. George's Spermatocysten siehe Abschnitt 3. 
daneben noch directe Kernzerschnürungen vorkommen könnten, so sieht man doch durchaus keinen Grund für eine solche Annahme.

Zwei Erscheinungen sind nun bei diesen Objecten besonders auffallend, und bemerkenswerth für die Physiologie der Kerntheilung.

Erstens, dass die Kerne in je einer multinuclearen Zelle vorwiegend alle zugleich in Theilung gefunden werden. Dieselbe Erfahrung hat auch Treub bei seinen Pflanzenobjecten gemacht; er sagt (a. a. 0. p.2 Sep. Abd.): „Les noyaux d'une même cellule se divisent de préférence tous à la fois."

Zweitens, dass sogar fast immer die Kerne in je einer multinuclearen Zelle sich sämmtlich in der gleichen Theilungsphase befinden (für Beides s. d. Abbildungen).

Man sieht dies Beides so häufig, dass ich es anfangs für ein unabänderliches Gesetz gehalten habe; doch mit Unrecht. Denn bei längerem Suchen fand ich eine ziemliche Anzahl von Fällen, wie der in Fig. 52 dargestellte (s. d. Erkl.), wo die Mutterzellen, Kernfiguren von ver s chiedenen $\mathrm{Ph}$ asen enthielten; und wo also anzunehmen ist, dass die einen Kerne entweder später als die anderen in Theilung getreten, oder langsamer damit vorwärts gekommen sind.

Es kommt auch vor, dass ein Kern in einer multinuclearen Zelle ganz ungetheilt verharrt, während andere sich theilen. Allerdings habe ich bis jetzt bei allem Suchen nur wenige derartige Fälle gefunden, in denen ruhende Kerne neben Theilungsfiguren lagen. Erstere waren dann in der Minderzahl (Fig. 49a).

Die eben erwälnten Fälle sind aber gegenüber der gleichzeitigen Theilung aller Kerne relativ so selten, dass die letztere jedenfalls als die Regel betrachtet werden muss. Danach lässt sich der selbstrerständliche und nicht unwichtige Schluss ziehen, dass die nächsten Ursachen, welche einen Kern zur Theilungsmetamorphose veranlassen, nicht oder nicht allein in ihm selbst wirken, sondern zugleich durch die ganze Substanz der Zelle hindurch thätig sind, in welcher er liegt. Wenn dies für vielkernige Zellen gilt, so wird es sich auch auf einkernige beziehen lassen; und damit werden wir darauf gefuhrt, auch in dem Protoplasma der in Theilung tretenden Zelle nach etwa erkennbaren Erscheinungen, die darauf Bezug haben, genauer zu suchen als dies bis jetzt geschehen ist. 
Ausserdem kommt hier in Betracht, was im Abschnitt 3 näher besprochen wird: dass sogar in ganzen Abschnitten 'der Hodenkanäle, und zwar in Abschnitten von recht bedeutender Ausdehnung, die Theilnngen zum grössten Theil, oft sogar sämmtlich in gleichem Stadium gefunden werden. Dies zeigt offenbar, dass die zur Theilung disponirenden Einflüsse von Aussen her auf die betreffenden Zellen wirken miissen; man wird wohl selbstverständlich hier an die Beschaffenheit der Transsudate denken, welche aus den Blutgefässen her, oder indirect durch die Lymphwege, an die Zellen herangelangen.

Fälle, die den gleichen Gedanken anregen, hatte ich schon früher an Kiemenblättern von Salamandra gefunden. Ich habe mehrere solche vor mir gehabt, an welchen fast sämmtliche Bindesubstanzellen des Kiemenblattes zweikernig waren.

Ich erinnere hierfür an die bekannten Befunde, nach denen in der Leber des Kaninchens oft auf grosse Strecken hin die Leberzellen sich grossentheils zweikernig oder mehrkernig ergeben. Ich selbst habe an einer Schweinsleber ausgedehnte Stellen gefunden, wo etwa 50 Procent der Leberzellen zwei oder mehr, zum Theil bis fünf Kerne besassen.

Schon ehe ich die indirecte Theilung bei den vielkernigen Hodenzellen auffand, war mir im Frühling d. J. ein einzelner Fall der Art auch bei einer Epithelzelle des Mundbodens von der Salamanderlarve vorgekommen. Die Zelle (Taf. 1 Fig. 16) enthält sechs Kernfiguren, und zwar sind es drei Paar Tochtersterne. Es scheint dies aber im Epithel bei Salamandra eine Seltenheit zu sein, denn es blieb bis jetzt der einzige Fall, den ich hier bei aller Aufmerksamkeit fand. - Ein gutes Object für das Studium solcher Riesenzellentheilungen muss das Amnion von Säugethierembryen (Kaninchen) sein; denn seine Bindesubstanz ist stellenweise sehr reich an schönen, vielkernigen Zellen. Bis jetzt habe ich aber noch keine solche mit Kerntheilungen fixirt gefunden und vermuthe darum, dass es sich hier ebenso, wie vielfach anderswo, um schubwe is es Auftreten von Theilungen handelt, und dass ich bisher nicht so glïcklich war, einen solchen Schub mit der Fixirung zu treffen.

Das beschriebene kann, wie mir scheint, auch zur Aufklärung einer Angabe von Eberth (2) dienen: dieser stellt in seiner 
Taf. 19 Fig. 19 eine Zelle mit vier Kernfiguren dar (Phase wahrscheinlich: Tochterknäuel), die er als eine gleichzeitige Viertheilung einer Zelle auffasst. Wie Strasburger und ich selbst (Th. I p. 404) dem gegeniuber hervorzuheben hatten, haben wir niemals gesehen, dass eine Zelle sich zur Zeit in mehr als $\mathbf{z}$ wei Zellen getheilt hätte; trotzdem glaube ich, dass Eberth's Beobachtung vollständig richtig ist, dass sie aber die Theilung einer zweikernig gew esenen Zelle repräsentirt, deren Kerne, ganz wie bei meinen Objecten, gleichzeitig in Action getreten, und in der Phase der Tochtersterne fixirt worden waren.

Schon nach dem hier Mitgetheilten und den erwähnten Befunden Treub's besteht also kein Recht zu dem Glauben, dass die vielkernigen Zellen durch einen anderen Modus der Kernvermehrung entstiinden, oder ihre Kerne auf eine andere Weise vermelurten, als durch indirecte Kerntheilung, mit den auch sonst allgemein verbreiteten Phasen der Karyokinesis.

\section{Absehnitt 2 .}

Nene Ergebnisse ïber Morphologie und Mechanik der Zelltheilung.

Unser verehrter Altmeister in der entwicklungsgeschichtlichen Forschung, v. B is ch off, sagt in einem kürzlich erschienenen Aufsatz :

„So glaube ich noch jetzt, bei aller Conjugation der Kerne, und bei allen karyolytischen, spindelförmigen und sonnenstrahligen Figuren, dass das Wesen der Befruchtung nicht beobachtet, sondern nur mit dem Gedanken erfasst werden kann ${ }^{1}$ )."

Mit ebenso vielem Recht, wie über das Wesen der Befruchtung, könnte man diesen Satz über das Wesen der Zelltheilung aussprechen. Für beide Fälle ist er unbestreitbar, so weit es sich um das wirklich-letzte Wesen der Prozesse handelt. Alle die

1) Leopoldina XV, Aug. 1879, p. 128. 
Beiträge zur Kenntniss der Zelle und ihrer Lebenserscheinungen. 193

Arbeit, welche gegenwärtig in die Vorgänge bei der Befruchtung, bei der Zelltheilung, überhaupt bei allen Lebensäusserungen der Zelle einzudringen sucht, kann sich zunächst nur auf das morphologischund chemisch-Wahrnehmbare richten. Wer aber jenen Ausspruch zum Motto nehmen wollte, um dieser Arbeit die Wichtigkeit abzusprechen, würde Unrecht haben. Wir werden allerdings das innerste Wesen dieser Vorgänge wohl niemals sehen können. Wir können auch nicht sehen, welches im lebenden Körper die Stellungen der Herzklappen bei Systole und Diastole sind; trotzdem dürfen wir behaupten sie gut zu kennen, weil wir sie hinreichend mit dem Gedanken erfasst haben; dieser Gedanke aber ist lediglich abgeleitet aus genauer anatomischer, physiologischer und physikalischer Beobachtung. Wenn wir jetzt Beobachtungen uiber die Lebenserscheinungen der Zelle sammeln und vergleichen, so geschieht auch dies in der Hoffnung, dass sie zu erklärenden Gedanken und physikalischem Verständniss jener Erscheinungen helfen werden und miissen, und dass sie dazu unumgänglich nöthig sind. Ohne diese Idee würde ich keinen Grund sehen, mein Mikroskop weiter zu benutzen.

Mit dieser Einleitung wollte ich es motiviren, dass ich in der folgenden Beschreibung mich ziemlich stark in's Detail vertiefe, and die grossen Lücken meiner Beobachtungen nur darin finde, dass sie noch lange nicht detaillirt genug sein konnten.

Um über die Mechanik dieser Vorgänge auch nur Vermuthungen zu machen, muss man zunächst genan wissen, welches ihre sichtbaren Formers cheinungen sind und was daran regulär, was variabel ist.

Welche Kräfte sind in der Zelle während ihrer Theilung thätig? - Der erste Schritt zur Lösung dieser Frage muss gẹthan werden durch Beantwortung der anderen, rein morphologischen: Erfolgen die Lageveränderungen der sichtbaren geformten Elemente in Zelle und Kern nach einem bestimmbaren Schema, und wenn, nach welchem?

Nach den ersten Arbeiten von Bütschli, Strasburger and o. Hertwig schien sich ein solches Schema ziemlich einfach zu geben; man kannte nur die Kernplatten und Kernspindeln, man 
glaubte sonach zu haben: eine längsfaserige Differenzirung des Kerninhalts, darin eine Anhäufung von Körnern im Aequator, eine Theilung dieser Körner, und ein Abrücken ihrer Hälften gegen die Pole.

Nach den neueren Arbeiten ïber Thierzellentheilungen ist dies Schema nicht mehr zu halten, zum Mindesten nicht als Allgemeingültiges. Es ist ohne Erlänternng klar, dass die Knäuel- und Sternformen gar nicht darin unterzubringen sind. Ebensowenig passt in dasselbe der Bau der Aequatorialplatten ${ }^{1}$ ) bei Thierzellen. - Bei solcher Sachlage muss man eben fast von vorn anfangen, und vor Allem wo möglich die Morphologie des Vorgangs genauer feststellen, als dies bisher geschehen ist.

Hierfür blieb mir zunächst fast allein der Weg, an fixirten und conservirten Präparaten zu arbeiten. Denn die Hoffnung, bei Salamandra und äbnlich giunstigen Objecten an der lebenden Zelle noch weiter zu kommen, erwies sich zunächst als trügerisch; nur bei den Hodenzellen (s. u.) habe ich hierin geringe Erfolge gehabt, im Uebrigen an der Salamanderlarve mich in diesem Sommer ïberzeugt, dass sich in vivo nicht mehr sehen lässt, als was ich schon beschrieben habe.

Die conservirten Präparate haben mich dafür etwas entschädigt. Ich habe nach und nach eine grosse Sammlung von solchen angelegt, und indem ich stets die bestconservirten Kerntheilungen ausmusterte und verglich, und viele Hunderte von solehen fur jedes Stadium vor Augen bekam, manche neue Einblicke erhalten.

Eine solche Massenuntersuchung ist schon desshalb werthvoll, weil je nach der Einwirkung der Reagentien die Kernfiguren bald mehr locker, bald mehr zusammengedrängt ausfallen; in ersterem Fall lässt sich ihr Bau natürlich besser durchblicken. Ferner hat mir an scharfgefärbten Präparaten das Arbeiten mit dem Beleuchtungsapparat sehr geholfen; indem man durch ihn die Reflexe mildert und fast nur das Gefärbte im Object sieht, kann man die Fäden oft genauer verfolgen.

1) Vorläufige Beschreibungen und Vermuthungen hinsichtlich dieser Phase hatte ich schon im I. Theil, p. 383 gegeben. Für das Nähere siehe weiter unten in diesem Abschnitt. 
A.

\section{Anfangsphasen.}

Fïr diese war die neue Ausbeute am geringsten. Ueber die Art, in der sich die tingirbare Kernfigur aus dem ruhenden Kern hervorbildet, kann ich meinen früheren Angaben (Th. I p. $364 \mathrm{ff}$.) nichts Wesentliches hinzusetzen. Bei der Durchmusterung einer sehr grossen Menge von ersten Anfangsstadien, wie die im Th. I Taf. 17 Fig. 1, 2, hier Taf. 1 Fig. 1, 2 gezeichneten, und einer noch viel grösseren Zahl noch nicht in Theilung getretener Kerne, ergab sich nur immer iiberzeugender der Eindruck: dass die feinfadige dichte Knäuelform (Fig. 1 b) mit der die Karyokinesis anhebt, sich bildet auf morphologischer Grundlage des Netzwerks im ruhenden Kern, aber au der gesammten tingirbaren Substanz des Kerns. Nach der hier angenommenen Bezeichnung driicke ich dies so aus: das Chromatin des ganzen Kerns wird allmählig in das Netzwerk aufgenommen, dieses wächst dadurch und nimmt eine gleichmässige 1) Anordnung an, dergestalt, dass seine Fäden mehr und mehr einen ebenmässig gewundenen Verlauf bekommen, und dass diese Windungen im Ganzen gleiche Distanzen gegeneinander erhalten; abgesehen davon, dass die Windungen ausserdem noch meistens in der Peripherie der Kernfigur sich enger lagern, als im Centrum. - Darauf Verkürzung, und zugleich Verdickung dieses zusammenhängenden Fadengewindes. Eine Discontinuität desselben schon in diesen Stadien halte ich selbst bei Salamandra nicht für nachweisbar, viel weniger bei anderen $\mathrm{Ob}$ jecten mit kleineren Kernen; trotzdem für nicht unmöglich.

Nicht der geringste Anhalt ergab sich dafür, dass anfangs Körner vorhanden sein, und „zu Fäden auswachsen" sollten, wio dies Andere behaupten (Peremeschko, Strasburger 1. c.). Ich empfehle diesen Behauptungen gegenüber recht gut gefärbte, und mit Balsam aufgehellte Objecte, natïrlich von grosskernigen Geweben.

Besonders habe ich ferner das Verhalten der Nucleolen während der Entstehung der Kernfigur in's Ange gefasst. Fur Salamandra liess es sich dabei ganz sicher stellen, dass sie schon

1) Statt der ungleichmässigen, die es normal im ruhenden Kern hat. 
in sehr frlihen Stadien des Mutterknäuels (Th. I Taf. 17 Fig. 2 e) verschwunden sein kïnnen, und dass sie, umgekehrt entsprechend. erst in den spätesten Tochterstadien wieder auftreten. In beiden Fällen zeigen sich die betreffenden Körperchen tubrigens als Verdickungen der Netzbälkehen; ob sie schon den eigentlichen Nucleolen entsprechen, oder nur Verdickungen der Bälkchen, in welehen noch die Nucleolen als besondere Körper liegen, oder sich bilden werden, ist hier nicht zu entscheiden.

Bei den Theilungen der Pflanzenzellen dagegen ist es ganz evident - und ich kann darin Strasburger's neueste Angaben (1. c.) nur bestïtigen - dass die Nucleolen in der Mutterkernfigur sich viel länger erhalten, so wie sie auch hier in den Tochterfiguren relativ viel frubzeitiger wieder auftreten ${ }^{1}$ ) (S. Strasbuger's Figuren, Lit. 8).

Ich glaube zu sehen, dass die Nucleolen in diesen Fiallen nie ganz frei liegen, sondern stets mit Bälkchen zusammenhängen und möchte deshalb mit Strasburger (l. c. p. 279), vermuthen, dass ihre Bildung durch Anschwellung einzelner Bälkchen eingeleitet wird. Sie sind bei vielen Pflanzenzellen relativ bei Weitem grösser, als bei Thierzellen.

Ich finde, dass hier sowohl die schwindenden Nucleolen in den Mutterstadien, als die wiedererscheinenden in den Tochterstadien, regelmässig excentrisch liegen. Auch für die ruhenden Kerne scheint mir übrigens eine solche Lage die Regel zu sein.

Aus diesen wenigen Kenntnissen über das Verhalten der Nucleolen bei der Zelltheilung lassen sich immerhin schon einige bemerkenswerthe Schliusse ziehen:

Erstens der: dass die Nucleolen nicht die zunächst wichtigen und anstossgebenden Factoren bei der Kerntheilung, beziehungsweise Zelltheilung sein können. - Nach dem Verhalten bei Thierzellen, wo die Nucleolen sich im Beginn des Theilungsvorganges schon vertheilt haben, könnte man zu der Annahme versucht sein, dass ihre Auflösung und Aufnahme in das Netzwerk erst die Anregung zu dessen weiterer Umgestaltung giebt. Ich habe mich vor solcher Hypo-

1) Dieser Umstand ist wohl auch ein deutlicher Hinweis darauf, dass von einer regressiven Metamorphose der Tochterkerne auch hier bei Pflanzenzellen geredet werden kann. Weiteres darüber s. u. 
Beiträge zur Kenntniss der Zelle und ihrer Lebenserscheinungen. 197

these wohl gehütet. Das Verhalten bei Pflanzenzellen zeigt anfs Klarste, wie unrichtig sie wäre; denn hier persistiren die Kernkörperchen noch mitten im Knäuelstadium.

Zweitens: Dass die Nucleolen überhaupt keinerlei morphologischen Antheil an der Kernvermehrung nehmen was sich nach dem Mitgetheilten von selbst versteht.

Drittens, und dies ist allerdings noch kein Schluss, sondern nur eine aufgeworfene Vermuthung: dass die Dinge, die wir Nucleolen nennen, vielleicht gar keine morphologisch wichtige Theile des Kerns sein mögen, sondern nur Ablagerungen von Substanzen, welche für den Stoffwechsel im Kern verbraucht und wieder neugebildet werden; sie würden damit gewiss physiologisch wichtige Theile des Kerns bleiben, - was ohnehin durch ihr fast allgemeines Vorkommen bewährt wird, - aber doch keine eigentlich organischen d. h. morphologisch-wesentlichen Kernbestandtheile.

Nach dem, was wir uber ihre Entstehung bisher wissen (s. o.) scheint ihr Auftreten in den Netzbälkchen zu erfolgen oder doch von diesen auszugehen; es ist also der eben gebrauchte Ausdruck Ablagerung nicht so zu verstehen, als ob sie frei in der $\mathrm{Z}$ wischensubstanz anschössen.

Es ist hiefür besonders bemerkenswerth, dass nach Strasburger (14 p. 4) Körner in den Tradescantiak ernen vorkommen, welche er nach ihrer Jodreaction als Stärke anspricht.

Ich stelle jedoch das eben Gesagte nicht als Hypothese auf, und will nur Aufmerksamkeit auf den Gegenstand lenken, was bei unserer bisherigen totalen Unkenntniss über das Wesen der Nucleolen wohl angebracht ist.

Es dürfte hier am Orte sein, eine Frage zu berühren die ich im ersten Theil dieser Beiträge schon einmal kurz gestreift habe ${ }^{1}$ ). Viele sehr gute Beobachter ${ }^{2}$ ) haben Endigungen von Nervenfasern im Kernkörperchen beschrieben. Ich glaube, dass Zweifel an der objectiven Richtigkeit dieser Beobachtungen nicht berechtigt sind; wohl aber kann es die Frage sein, ob die gesehenen Stränge in den betreffenden Fällen wirklich Nervenfasern gewesen sind, und

1) A. a. O, p. 351 .

2) S. am eben citirten Ort, sowie in dem Aufsatz J. Arnold's: „Ueber feinere Structur der Zellen etc.", Virchow's Archiv Bd. 77, 1879. 
nicht etwa $\mathrm{Netzbälkchen} \mathrm{des} \mathrm{Kerns,} \mathrm{die} \mathrm{gerade} \mathrm{einen} \mathrm{etwas}$ gestreckten Verlauf hatten und in der Continuität von Nervenfasern lagen, welche an die Zelle heran oder an ihr vorbeizogen. - Das Verhalten der Nucleolen bei der Zelltheilung scheint mir wenigstens die Annahme sehr schwierig zu machen, dass dieselben intranucleare Nervenendorgane sein sollten; denn man hätte in diesem Fall anzunehmen, dass ein solches Endorgan bei der Zelltheilung im Mutterkern sich morphologisch auflösen, im Tochterkern sich ebenso neu bilden mitsste, und dabei im letzteren Falle stets richtig sein Nervenende wieder treffen mïsste. Ehe man sich zu einer solchen Annahme entschliesst, müssten, wie es mir scheint, noch zwingendere Gründe für eine intranucleare Nervenendigung vorliegen, als ich sie bis jetzt in den oben erwähnten Beobachtungen finden kann.

Ich will hierzu vorläufig bemerken, dass ich in meinen Kiemenblattpräparaten von Salamandra sehr schön Nervenfasern bis zwischen die Epithelzellen verfolgen, auch nicht ausschliessen kann, dass sie vielleicht Zweige an die Epithelzellen schicken, obwohl sich dies nicht sicher sehen laisst; dass ich aber bei sorgfältigem Suchen noch kein einziges Bild geschen habe, nach welchem man auf das Eintreten einer nervösen Endfaser in einen Kern schliessen könnte.

B.

\section{Die Segmentirung der Kernfäden und der Uebergang vom Knäuel zum Stern.}

Für diese Stadien und das folgende habe ich jetzt wesentliche neue Einblicke gewonnen, nach denen sich meine früheren Anschauungen und Vermuthungen tiber die Lageveränderungen der Fäden ergänzen und verbessern lassen.

Es ist im I. Theil (p. 368, 375) gesagt worden, dass in Knäuelformen vom Habitus der Fig. 16, 2, 3 Taf. I hier Unterb rech un gen des Fadengewindes bei den geschwänzten Amphibien noch nicht mit Sicherheit zu erkennen sind, geschweige denn bei Organismen mit kleineren Kernen. Es bleibt bei der anfänglichen Feinheit der Fäden, und der Dichtigkeit der Windungen trotzdem möglich, dass solche Unterbrechungen, oder dazu disponirte Stellen 
schon jetzt, ja schon von Anfang an existiren, es ist aber an meinen sämmtlichen, oben im Abschnitt 1 besprochenen Objecten nichts zu sehen, was einen solchen Schluss sicherstellen, oder gar ein „Auswachsen von Körnern zu Fäden" annehmen lassen könnte.

Die ersten sichern Unterbrechungen in dem Fadenknäuel sehe ich in Stadien wie Fig. 4 T. 1. Aber dann kann man wiederum spätere, schon mehr lockere Knäuel finden, schon auf dem Uebergang zu Kranzformen, oder selbst Kränze, in denen noch keine, oder nur einzelne Discontinuitäten zu sehen sind. Man darf daraus vermuthungsweise schliessen, dass die Zertheilung des continuirlichen Fadenknäuels in einzelne Fadenstücke an keinen ganz bestimmten Zeitpunkt der Karyokinesegebunden ist.

Und sie kann sogar noch später erfolgen. - Frïher nahm ich vermuthungsweise an ${ }^{1}$ ), dass in der Kranzphase (Fig. 6 Taf. 17 Th. I) schon alle Fadenabschnitte von gleicher Länge gebildet seien, dass jeder davon sich zunächst in die ungefähre Form einer 8 lege, so dass er eine Schlinge nach central, die andere peripheriewärts kehre - und dass dieses die Kranzform sei; dass ferner dann die peripheren Umbiegungen des Kranzes sich trennten, and so der Stern mit seinen freien Enden resultirc; und dass endlich — was freilich nur rein vermuthet wurde auch die centralen Umbiegungen sich trennen könnten, und demnach die Aequatorialplatte (Fig. 14 Taf. 17 Th. I, Fig. 17 ff. T. 1 hier) aus zwei gleichen Gruppen isolirter Hälften von Fadenabschnitten bestehen würde; abgesehen von der Lüngsspaltung der Fäden, die ausserdem inzwischen jeden Abschnitt noch einmal in 2 Längshälften getheilt hat.

Nach meinen jetzigen Erfahrungen gestaltet sich die Sache anders, und zwar etwas einfacher. Wenn man davon ausgeht, dass die Segmentirung des Fadenwerkes bald früher bald spïter erfolgt, steht der Annahme nichts entgegen dass sie sich zum Theil auch bis in die Kranz- und Sternphase hinein verzögern kann. Dann sind ihre letzten Nachzügler in Bildern zu finden, wie sie z. B. meine Fig. 11 Taf. $17 \mathrm{Th}$. I zeigt, wo gerade noch eine letzte Schlinge- in der Abtrennung begriffen ist. Diese muss nicht (wie dort bei 5,52) an der äussersten Umbiegung in der Peripherie, sondern kann auch weiter central erfolgen.

1) Th. I, p. 377, weiter p. 383. 
Mit andern Worten: die richtenden Kräfte, die das Fadengebilde in die Kranzform und weiter in die regelmässigere Sternform bringen, beginnen im einen Fall auf den Knäuel schon zu wirken, ehe er in gleiche Segmente zerfallen war, im andern Fall auch erst dann, wenn dies schon geschehen ist. (Offenbar sind ja Kranzformen, wie Fig. 6 Taf. 17 Th. I, schon die Ansätze zum Stern, indem viele Fäden hier schon im Ganzen radiäre, wenn auch noch stark gebogene Verlaufsrichtungen bekommen haben.)

Ich würde sehr gern die Erklärung auf einem andern Wege suchen, der mit den Ansichten Strasburger's, Peremeschko's und Schleicher's 11. cc. mehr zusammenführte: wenn, wie nach Diesen, zunächst im Kerne Körner entstehen und zu Fäden ảuswachsen, so könnten hiernach die Unterbrechungen, die sich in den Knäueln und Kränzen wie Fig. 4, 5 Taf. 1 hier, Fig. 6 Taf. 17 Th. I finden, einfach auf freie Enden von Fäden zurückzuführen sein, die noch in der Verlängerung begriffen sind: die Discontinuität wäre damit das Primäre, nicht, wie ich und ebenso Klein es ansehen, das Secundäre.

Aber eine solche Annahme wird mir eben deswegen unmöglich, weil, nach ihr, selbstverständlich um so mehr Unterbrechungen zu finden sein müssten, je weiter zurückliegende Stadien man untersucht; während, wie aus meiner Beschreibung hervorgeht, gerade das Umgekehrte der Fall ist. Ferner auch schon deswegen, weil ich bei meinen Objecten überhaupt niemals Körner finde.

Noch bemerkenswerther für die Mechanik des Vorganges scheint mir der weitere Punkt, den ich jetzt, für Salamandra wenigstens, sicherstellen kann: die centralen Umbiegungen der Fäden in der Kranz- und Sternform trennen sich ïberhaupt nicht ${ }^{1}$.

1) Ich will im Folgenden mit "Schleife" ein Fadensegment von der Form eines $\mathrm{v}$ oder $\mathrm{u}$ bezeichnen, an dem also ein Winkel, und zwei gleich dicke und gleich- oder nahezu gleichlange Schenkel mit freien Enden zu unterscheiden sind. Der Winkel kann bald spitzer bald stumpfer sein, und ist in den meisten Fällen ausgerundet, nicht scharf; die Schenkel sind bald gerade, bald geschwungen, zuweilen um einander gedreht.

Ich weiss wohl, dass Schleife kein ganz scharfer Ausdruck für einen solchen $v$-förmig oder u-förmig geknickten Faden ist; doch ist er ja in einigen Fällen in ganz entsprechendem Sinne schon eingebürgert (Schleife eines Weges; Henle'sche Schleifen in der Niere), ich weiss keinen besseren und komme ohne ein kurzes Wort nicht aus. 
Beiträge zur Kenntniss der Zelle und ihrer Lebenserschcinungen. 201

Diese Sicherheit habe ich erst durch sorgfültige Vergleichung einer grossen Menge von Kernfiguren der betreffenden Stadien gewonnen.

Es giebt nämlich Varianten, in Bezug auf die Länge der entstehenden Fädensegmente sowohl ${ }^{1}$ ) als auf die Dichtigkeit ihrer Lagerung. Wo letztere gross ist, bleibt es unmöglich zu entscheiden, ob im Centrum eines Sterns freie Enden liegen oder nicht. Aber die Figuren fallen in vielen Fällen so locker aus, dass man jeden einzelnen Faden darin abgrenzen kann, und es trifft das besonders immer zusammen mit grosser Kü rze der Segmente. Unter solchen Exemplaren findet man nun viele, welche, wie Fig. 8, 9 Taf. I, Fig. $35 \mathrm{a}$ b und 40 Taf. 3, das Zustandekommen und den Bau der Sternfigur sehr anschaulich demonstriren können. Als die zusammensetzenden Elemente zeigen sich F adenschleifen, genau oder nahezu in der Mitte ihrer Länge geknickt oder auch sanfter gebogen; diese Schleifen können, bevor es zur eigentlichen Radiärform kommt, oft sehr wirr durcheinander oder auseinandergeruickt liegen ${ }^{2}$ ), wie in Fig. 5, 6, 7, 8 Taf. I, 35 a b Taf. 3 hier. Oftmals liegen einzelne Fäden ganz aus der übrigen Gruppe dislocirt (Fig. 8, 9, 35). Die Ordnung aber, welcher auch diese sich $z u$ fügen haben, liegt darin, dass mit dem Antritt der Monasterphase nunmebr die Umbiegungswinkel der Schleifen nach dem Centrum hingezogen, die freien Enden der Schenkel rom Centrum abgekehrt werden.

Es können dazu oft lange vergebliche Ansätze gemacht werden, und dadurch recht wirre Figurenbilder entstehen, deren Verstehen mir lange Miihe gemacht hat. Dahin gehören besonders Anordnungen wie in Fig. 6 und 7 Taf. I, wo die Schleifen, in zwei ziemlich gleichen Portionen, nach den Polen zu fast von ein-

1) Vielleicht auch ziemlich grosse Varianten in der $Z a h l$ von Segmenten, und damit der Strahlen der Sterne (die letztere selbstverständlich die doppelte der Segmente).

2) Und es begreift sich wohl, dass Andere (Schleicher, Peremeschko), offenbar nach solchen Objecten urtheilend, den Bewegungen der Fäden in diesen Stadien alle Regelmässigkeit abgesprochen haben. - Ich selbst habe diese anscheinend ordnungslosen Formen zwar wohl berücksichtigt (Th. I p. 377 oben), aber absichtlich zunächst nicht sie, sondern die regulären zum Ausgangspunkt der Beschreibung genommen und früher fast nur von Letzteren Beispiele gezeichnet. 
ander abricken, so dass man denken könnte, sie wollten sich jetzt schon zu den Tochterkernen sondern, obne sich vorher zur Aequatorialplatte gruppirt zu haben. Auf diesen Glauben ist auch Klein verfallen (12). Aber ich kenne solche Bilder hinreichend von den lebenden Theilungen her, und weiss, dass man bei deren Verfolgung niemals eine derartige directe Trennung geschehen sieht, sondern dass die Fäden sich stets vorher wieder im Aequator zus ammenfinden. - In solchen Figuren liegen viele der Schleitenwinkel schon deatlich nach dem Centrum oder der Aequatorialebene hingewandt (s. Fig. 6, 7 Taf. I), andere noch nicht; und es ist möglich, dass auch die schon centrirten Schleifen diese Lage noch zeitweilig wieder aufgeben können; dass, um mich so auszudrïcken, die Centralattraction in ihrer Stärke längere Zeit schwankt, und zeitweise ganz erlahmt, so dass es dann wieder sehr unregelmässige Fiadenlagen giebt. Endlich aber uberwiegt die centrirende Kraft; auch die letzten ungehorsamen Fadenschleifen werden einrangirt und die Sternform ist fertig, nach dem einfachen Schema: Winkel der Schleifen nach dem Centrum, Euden der Schenkel nach der Peripherie (Fig. 8, 9, 40 hier und Fig. 10, 11 Taf. 17 Th. I).

Es muss hier nun eingeschaltet werden, dass die Sternformen nicht bei allen Zellenarten so regelmässig ausfallen, wie in denen des Epithels, Bindegewebes, Blutes (d. h. rothe Zellen) und (wie ich wenigstens für Salamandra auch behaupten kann) des Knorpels. Bei den Hodenzellen von Salamandra, deren Theilungsfiguren sich zugleich besonders durch $K$ ürze der Fadensegmente auszeichnen, rücken die Umbiegungsschleifen der Fäden nur selten so dicht an das Centrum, dass die betreffende Figur recht deutlich den Eindruck eines Sternes macht (Fig. 40).

Hier, bei Hodenzellen, konnte ich die betreffenden Stadien lebend unter dem Auge verfolgen, wobei man Bilder wie in Fig. 10 a-c auftreten und sich langsam verändern sieht $\%$. Nach

1) Verfahren: Freischwimmende Zellen in frisch aus dem angeschnittenen Hoden entnommener Flüssigkeit, ohne jeden Zusatz eingedeckt. Die Theilungen halten sich dabei häufig längere Zeit lebend und im Fortgang, sterben aber doch viel öfter ab als am Larvenschwanz. Die Fäden sind an jenen ganz freiliegenden Zellen natürlich klarer erkennbar, als am letzteren Object. 
dem Eindruck solcher Objecte würde man zunächst an wirklich ganz unregelmässige karyokinetische Bewegungen denken, wie sie Schleicher als typisch angesehen hat; doch wenn man dieselben fixirt (mit Essigsäure, Pikrinsäure) und färbt, so lässt sich durch die Schraube feststellen, dass auch in anscheinend ganz regellosen Figuren doch eine Ordnung besteht, nämlich eben die, dass die Winkel dem Centrum mehr genähert liegen als die freien Enden der Schleifenschenkel (vergl. Fig. 40 and deren Erkl ärung).

Es ist tibrigens möglich, dass anch bei Hautepithelzellen die Annäherung der Schleifen an das Centrum in manchen Fällen nicht weiter geht wie z. B. in Fig. 9 Taf. $\left(\right.$ hier ${ }^{1}$ ); die Regel aber sind bei Epithel-, Bindegewebs- und rothen Blutzellen gut ausgesprochene Sterne, in denen die Schleifen sich im Centrum ganz oder nahezu berühren.

Für die eben citirtcn Abbildungen bitte ich Folgendes zu berücksichtigen: Es ist nicht wohl möglich, eine solche Gruppe von umgebogenen Fïden, die nach dem angegebenen Typus: „Biegungswinkel central, Enden peripher" gelagert sind, wirklich anschaulich durch Zeichnung wiederzugeben, man müsste denn ein sehr grosses Format und körperliche Schattirung dazu nehmen. Wenn also auch an meinen Objecten, wie z. B. Fig. 9, 10, die Einstellung zeigt, dass die Schleifen durchweg dem Centrum näher liegen als die freien Enden, so konnte dies in der Zeichnung nur dadurch ganz schematisch angedeutet werden, dass die Schleifen meistens dunkler dargestellt sind als die Enden. - Es kommt nun aber noch hinzu, dass nicht alle Füden gleichweit vom Centrum entfernt liegen; ferner, dass man natürlich vicle Fäden mehr oder weniger von oben, im queren oder schrägen optischen Durchschnitt sieht; endlich, dass die Fadenschenkel nicht stets rein radiäre Richtungen einhalten, sondern vielfach gebogen und gewunden liegen. Alles dies wirkt zusammen dahin, dass die Sternform auch nach Tinction an vielen Exemplaren kaum herauszukennen ist (insbesondere bei den Hodenzellen mit ihren kurzen Fadensegmenten); und gar am blassen lebenden Object, wo man die einzelnen Fäden nur schwer mit der Einstellung verfolgen kann, wird sie vielfach ganz undeutlich, es sind da systolische Sterne mit gebogenen Strahlen oft gar nicht unterscheidbar von Aequatorialplatten, und die

1) Solche stark zerstreute Figuren, wie sie mir von Epithelzellen in Menge vorliegen, theils mit einfachen, theils Doppelfäden, entsprechen jedoch wohl gewiss Diastolen; die betreffende Systole kann immerhin ein kurzstrahliger Stern sein, wie Taf. 2 Fig. 30 c. Bei den Hodenzellen aber braucht es, nach meinen directen Beobachtungen am lebenden Object, zin einer so engen Centrirung wirklich nicht zu kommen. 
einzige Möglichkeit der Diagnose des Stadiums liegt in fortgehender Beobachtung.

Im Abschnitt 1 bei ${ }_{\text {Pflanzenzellen }}$ " wurde schon gesagt, dass auch bei diesen ganz reine Sternformen nicht zu finden waren; vermuthlich wohl aus ähnlic hen Gründen.

Die Segmente, d. i. Schleifen, scheinen in je einer Kernfigur immer nahezu gleiche Länge zu haben ${ }^{1}$ ) (dagegen sind sie in der einen Kernfigur länger wie in der anderen); und ferner sind die zwei Schenkel einer Schleife zu der Zeit, wo die eigentliche Sternform besteht, untereinander ziemlich gleich lang. 'Auch dies ist durch die Zeichnung nicht gut wiederzugeben: diejenigen Fäden, resp. Schleifenschenkel, die in vielen meiner Figuren hier, sowie in Fig. 8, 10, 11, 12 Taf. 17 Th. I, in der Verkürzung, als o in optischen Schnitten gesehen wurden, mussten natürlich so dargestellt werden, dass sie kürzer als die übrigen erscheinen; was also nicht reell zu nehmen ist. - Peremeschko $(5,16)$ hält dafür, dass bei Triton während dieser Phasen abwechselnde Verlängerungen und Verkiirzungen, Verfeinerungen und Verdickungen der Fïden vorkommen. An meinen lebenden Objecten von Salamandra kann ich hiervon nichts feststellen; alle anscheinenden Verkuirzungen von Fïden können hier auf blosse Lageveränderungen bezogen werden, der Art, dass die Fäden schräg oder vertikal gegen die Objecttischebene $z u$ liegen kommen und also nur verkürzt gesehen werden. - Doch will ich hiermit Peremeschko's Annahme nicht entgegen treten, da ich die lebende Tritonlarve nicht untersuchen konnte.

'Wenn ich frither' annahm, dass in der systolischen Sternform wenigstens die polaren Strahlen sich verkürzen mïssten (Th. I p. 381), so kann ich diese Annahme jetzt nicht mehr fiir nothwendig halten. Die Erklärung dafür findet sich unter dem folgenden Titel.

1) Doch kann ich die Möglichkeit nicht ausschliessen, dass bei sehr Alachgeformten Zellen (z. B. Endothelien, vergl. Fig. 10 Taf. 17 Th. I) die Strahlen des Sterns, die sich gegen die Flachseiten richten, wirklich etwas kürzer sind; jedoch ist dies nicht so hochgradig wie es in der Figur erscheint, wo man auf diese Strahlen fast der Länge nach sieht und wo sie deshalb sehr verkürzt gezeichnet werden mussten. 
C.

\section{Die Umordnung der Sternform zur Aequatorialplatte.}

Dies Stadium ist für die Erkenntniss der Physiologie der Zelltheilung deshalb besonders wichtig, weil es den Uebergang des monocentrischen Kräftespiels in der Zelle in ein dicentrisches enthält.

Die Form der Kernfigur, die ich Aequatorialplatte genannt habe (Taf. 1 Fig. 10-14) entspricht offenbar Stras b u rger's „Kernplatte", zum Theil auch noch seiner "Kerntonne oder Spindel." Der genannte Forscher und Andere nehmen für ihre Objecte als selbstverständlich an, dass dabei eine bündelförmige Gruppe von Kernfäden vorliegt, in der Mitte der Zelle etwa parallel zur Axe geordnet, welche sich sämmtlich in ihrer Mitte, also im Aequator der Zelle, erst jetzt halbiren, und auseinanderrücken.

Dass diese Annahme für meine Objecte nicht zutrifft, ist bereits in meinem Th. I, p. 381 ff. begriindet, indem dort gezeigt wurde, dass man bei allen dort untersuchten Zellenarten in diesen Stadien stets Unterbrechungen der Fäden im Aequator findet, niemals aber Aequatorialplatten, in denen alle Fäden in der Axenrichtung durch die ganze Kernfigur hindurchreichten. Wie aber diese Figur morphologisch zu Stande kommt, hatte ich damals noch nicht ermitteli und deshalb nur einige Vermuthungen darüber geäussert (l. c. p. 383), die ausdrïcklich als solche bezeichnet wurden.

Diese Luicke kann ich jetzt ausfiullen, und zwar in unerwartet einfacher Weise.

Wie oben angefiuhrt, trennen die centralen Fadenschleifen sich nicht während des Bestehens der Sternform. Sie thun es ebensowenig während der Dauer der Aequatorialplatte. Sie werden vielmehr aus der Sternform mit herübergenommen, und nur amgeordnet in einer Weise, die sich am Einfachsten aus folgendem Schema ergiebt:

Nehmen wir der Uebersichtlichkeit wegen an, man hätte einen Stern von nur acht Strahlen, d. b. also von vier Fadenschleifen, deren jede den Winkel nách dem Centrum, die Schenkelenden nach der Peripherie wendet ( 1 im Holzschnitt) : 
Holzschnitt I.

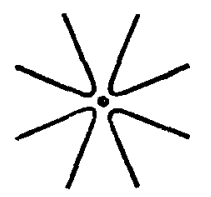

1.

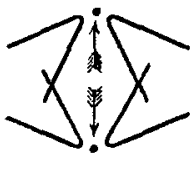

2.

Man denke sich nun einen als Kraftcentrum wirkenden Punkt, der die Eigenschaft haben soll, die Winkeltheile der Fäden anzuzieben, die freien Schenkelenden abzustossen; dies Centrum wird bei der Anordnung Fig. 1 die Sternform zu erhalten streben. Man denke sich ferner dieses Centrum in zwei getheilt, und diese nach den Polen auseinanderrückend. Ein jedes wird die Umbiegungswinkel, die ihm zunächst liegen, mit sich ziehen in die Lage, welche durch Fig. 2 im obigen Holzschnitt gezeigt wird: darnit ist der Stern auseinandergeklappt in zwei Hälften, in welchen die Fadenschleifen jetzt nach dem Typus liegen: Winkel nach dem Pol, Schenkelenden nach dem Aequator.

So sind zwei, noch flache oder glockenförmige Tochtersterne entstanden, in deren jedem zugleich, mit Bezug auf das Territorium der künftigen zugehörigen Halbzelle, wieder dieselbe Anordnung herrscht wie vorher im Mutterstern: Winkel central, Schenkelenden peripher.

Dass es so und nicht anders zugeht, ergiebt sich fast sehon aus einem unbefangenen Blick auf die vorhergehenden und folgenden Formen: Taf. 3 Fig. $35 \mathrm{a}-\mathrm{e}$ nach einer lebend verfolgten Theilung. In ab ist offenbar die gleiche Anzahl Fadenschleifen in der Matterfigur vorhanden, wie in e in beiden Tochterfiguren zusammen; und so wird man dies uiberall in den gleichen Stadien finden; wenn auch nicht alle Fäden ganz deutlich einzeln zu verfolgen und zu zählen sind, kann man es doch sehr wohl abschätzen. Es brauchen also nur die in Fig. 35 a b vorhandenen Schleifen in der oben (Holzschnitt) bezeichneten Weise umgeordnet zu werden, damit Fig. $35 \mathrm{~d}$ und weiter 35 e daraus entsteht.

Das Stadium nun, in welchem dies geschieht, Fig. $35 \mathrm{c}$, wird sich freilich an der lebenden Zelle bei allen bisher benutzten Objecten schwerlich genan darauf prïfen lassen: da die blassen lebenden Füden in ihm besonders dicht gelagert sind, sieht man 
Beiträge zur Kenntniss der Zelle und ihrer Lebenserscheinungen. 207

immer nur undeutliche Bilder dieser Phase, wie Th. I, Taf. 16 Fig. $1 \mathrm{~g}, 4 \mathrm{~d}$, Fig. $35 \mathrm{c}$ hier. Aber an gut conservirten und scharf tingirten Aequatorialplatten erhält man hinreichenden Aufschluss. Unter Hunderten von solchen, die ich nach und nach untersuchte ${ }^{1}$ ), fanden sich viele, in denen die Fäden hinreichend locker lagen ${ }^{2}$ ), um grossentheils im ganzen Verlauf verfolgt zu werden. Aus diesen Vielen sind einige Beispiele in Taf. 1 Fig. 10-14 gezeichnet.

Niemals habe ich zunächst, wie gesagt, eine solche Aequatorialplatte gefunden, in welcher sämmtliche Fäden nachweisbar im Aequator zusammengehangen hätten(wie es der AnsichtAnderer entsprechen würde). Man findet dies (für Epithel-Bindegewebs-Blutzellen) immer nur bei einzelnen Fäden. Eine Abweichung bilden wieder die Hodenzellen, bei denen allerdings ein solcher Zusammenhang im Aequator sebr vielfach zu beobachten ist (Fig. $35 \mathrm{~d}, 42,59$ ). Aber gerade hier liess sich durch fortlaufende Beobachtung des lebendigen Objects (Fig. 35) finden, dass dieser Zusammenhang, weit naturgemässer als ein secundärer, denn als ein primärer aufuufassen ist. Denn die dort verfolgte Reihe ergiebt ja, dass vor dem Stadium, in welchem solche Znsammenhänge im Aequator vorkommen (Fig. $35 \mathrm{~d}$ ), ein anderes liegt (Fig. $35 \mathrm{ab}$ ), in welchem im Ganzen eine gleiche Anzahl gleich grosser Fadenschleifen vorhanden ist, wie später in beiden Tochterportionen zusammengenommen. Um demnach aus der ersteren Figur die letzteren abzuleiten, erscheint es als das Nächstliegende und Naturgemässeste anzunehmen : die Schleifen in Fig. 35 b lagern sich so, dass ihre Winkel nach den Polen, die freien Enden nach der Aequatorialebene zu liegen kommen, und die freien Enden gerathen dabei theilweise in Berührung und vielleicht temporäre Verschmelzung.

Dieser Annahme entspricht nun vollständig dasjenige, was man an recht locker and durchsichtig gebauten, gut gefärbten Aequatorialplatten sehen kann. Ich will dies durch ein Holzschnitt-

1) Die Präparate liegen sämmtlich aufbewahrt vor.

2) Denn hier, wie in allen Stadien, giebt es individuelle Verschiedenheiten; bei der einen Zelle enggedrängte, bei der anderen verstreutere Lage der Fäden der Kernfigur. 
schema, wie oben, unter Verweis auf die genaueren Abbildungen der Objecte selbst verdeutlichen:

Holzschnitt II.

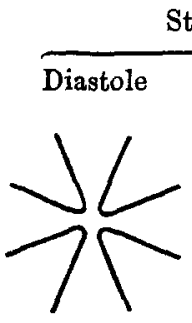

1.

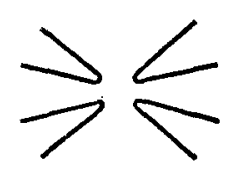

2.

Aequatorialplatte-Kerntonne

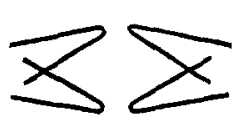

3.

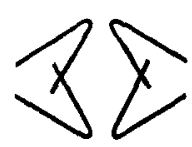

4.

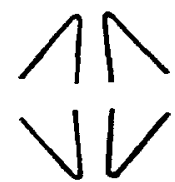

5.

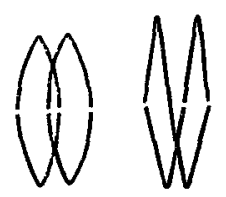

6. 7.

Gehen wir aus von dem diastolischen Stern, 1. (vgl. z. B. Fig. 9 hier). In der Systole, 2. neigen sich seine Strahlen, d. h. die Schenkel der Fadenschleifen, gegen die Aequatorialebene (vgl. Fig. 8 hier, Fig. 5 T. 18 Th. I). In der dann folgenden eigentlichen Aequatorialplatte (3) schlägt diese Neigung über die Parallelebene des Aequators hiniiber, die Winkel werden polarwärts, die Schenkelenden äquatorialwärts gezogen, die Schleifen sind jetzt umgeklappt; aber sie liegen bis jetzt noch schwach geneigt gegen die Acquatorialebene, daher die stark abgeplattete Form dieser Kernfigur (3. im Holzschnitt, vergl. Taf. 1 Fig. 10, 11, 13). Mehr un d mehr werden dann die Winkel polarwärts abgerïckt, die Schenkel stellen sich immer steiler gegen den Aequator (4. im Holzschnitt, vergl. Taf. 1 Fig. 12, 14, Taf. 2 Fig. 23), bis endlich die tonnenartigen Formen erreicht sind. In den letzteren Stadien (oder auch schon vorher) kann es nun zur Bertihrung und Verschmelzung von Schenkelenden kommen (im Holzschn. 6, 7 angedentet), die sich bei der folgenden Entfernung der Tochterkernfignren wieder trennen.

Wenn man sich statt der wenigen Fadenschleifen, die im Holzschnittschema angegeben sind, die vielen denkt, welche die 
Beiträge zur Kenntniss der Zelle und ihrer Lebenserscheinungen. 209

Abbildnngen zeigen; wenn man ferner berïcksichtigt, dass man es mit körperlichen Figuren zu thun hat und dass die meisten Fäden nicht so gesehen werden, wie sie das Schema auf die Papierebene projicirt, sondern in verschiedener Verkürzung, resp. als optische Durchschnitte ; und wenn man endlich hinzunimmt, dass die Schleifenschenkel vielfach nicht gerade gestreckt, sondern in Curven liegen, und dass nicht alle mathematisch-genan einrangirt sind, sondern dass manche Unregelmässigkeiten vorkommen: so wird man wohl ohne Schwierigkeit die Figuren der Tafeln in dem gegebenen Schema unterbringen können, und wird es verstehen, dass am lebenden Object, wo man fast nichts als blasse optische Schnitte sieht, das Bild einer solchen Aequatorialplatte nicht anders ausfallen kann, als es in den Figuren der Taf. XVI Th. I angedeutet ist.

Auch werden hiernach leicht die anscheinend sonderbaren Bilder verständlich, welche in der Phase der Aequatorialplatte sich oft an minder dentlichen Objecten, besonders an lebendigen bieten, wie ich sie im Th. I. auf Taf. 16 Fig. $2 \mathrm{k}$ und 6 , Taf. 17 Fig. 13 dargestellt habe: man findet hier, besonders im Aequator, geschlängelte Fäden, die oft (Taf. 16 l. c. Fig. 6) Verbindungsbriicken zwischen den polar angeordneten Fäden zu sein scheinen, aber es nicht $\operatorname{sind}{ }^{1}$ ). Man denke sich im Holzschnitt II Fig. 3 u. 4 statt der 4 Fadenschleifen deren etwa $20-60$, körperlich in einer Tonnenform angeordnet, aber nur zum Theil mit graden, zum andern Theil mit stark geschlängelten Sehenkeln, die durcheinandergeschoben liegen: so werden bei wechselnder Einstellung Bilder entstehen müssen wie in jener, Fig.13, Th.I Taf.17, Fig. 6 Taf. 16.

Die auf Taf. 2 Fig. 15 a gezeichnete Aequatorialplatte giebt ein Beispiel solcher geschlängelter und etwas irregulärer Lage eines Theiles der Fäden, in einem Zustand, wo die Figur schon kurz vor der Scheidung in ihre Tochterhälften steht.

Die einzige sonstige Möglichkeit, an die ich denken könnte, um die Figuren in anderer Weise aus einander abzuleiten, und zwar in solcher Art, dass ein wirklicher primärer Zusammenhang der Fäden aus dem Sternstadium her und eine nachträgliche Trennung im Aequator dabei zulässig bleiben könnte, würde folgende sein:

1) Vielleicht gehören hierher auch Bilder, wie sie vor mir bereits Eberth beschrieben hat (a. a. 0. Fig. 9 a b Taf. 19, s. Text p. 529); er bezieht sie auf Verbindungsbrücken der Fäden. 
Man könnte annehmen, dass die Fadenschleifen der Sternfigur sich gerade streckten, und die so gestreckten Fäden sich zu einem Bündel parallel der Axe um diese anordneten, und dass dann eine Halbirung jedes Fadens in der Aequatorialebene erfolgte. Der Process würde dann etwa nach diesem Schema darzustellen sein:

Holzschnitt III.

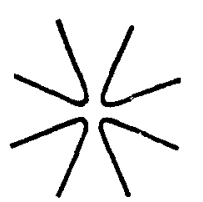

1.

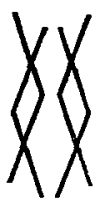

2.

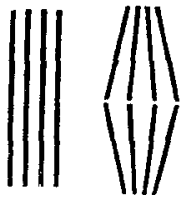

3. 4 .

Dies ist aber mit dem wirklichen Habitus der Figuren nicht vereinbar, aus folgenden Gründen:

1) bei einem solchen Verlauf müsste man an den Polarsciten der Aequatorialplatten und Kerntonnen stets freie Fadenenden finden (vergl. obiges Schema, 2, 3, 4). Dies ist nicht der Fall; wo nur irgend die Figur locker genug ist, um dort überhaupt etwas deutlich zu sehen, sieht man Umbiegungen (Fig. 12, 13, 14 an den Polsciten).

2) Unterbrechungen der Fäden in der Aequatorialebene müssten erst in den späten Stadien der Kerntonnen (Holzschnitt III, 4) zu finden sein; man sieht sie aber in allen Aequatorialplatten.

3) und besonders: die Figur müsste in polarer Richtung viel länger gestreckt sein, als sie ist; sie müsste immer mindestens eine Länge haben, gleich dem Durchmesser eines diastolischen Sterns (folgt einfach aus der Betrachtung des Schema's, Holzschn. III).

Dies trifft aber keineswegs ein, die Aequatorialplatten haben vielmehr bedeutend geringere polare Länge, als der Stern Durchmesser hat; dies Verhältniss ist durchweg dasjenige, welches dem früheren Schema (Holzschnitt II) entspricht (s. dort 1, 3, 4).

Aus all' diesen Gründen muss ich die eben erwähnte Annahme unmöglich finden und die meinige ihr gegenüber festhalten. Fir die letztere spricht übrigens weiter noch sehr deutlich das Verhalten der Tochterkernfiguren in ihrer ersten Phase, der Sternform: denndie Tochtersternebestehen aus gerade ebenso langen Schleifen wie der Mutterstern, nicht aus einzelnen geradlinigen Fäden (s. weiter unten); es ist von selbst klar, dass dies sich nach dem Schema Holzschnitt II auf's Einfachste ergiebt, bei anderen Voraussetzungen aber sehr complicirte Erklärungen erfordern würde. 
Unter den Voraussetzungen, die oben bei der Erläuterung des Holzschnitts II gemacht wurden, würde sich auch ein Verständniss für eine bis jetzt räthselhafte Erscheinung eröffnen, nämlich für die abwechselnden Systolen und Diastolen der Sternformen (Th. I p. 380).

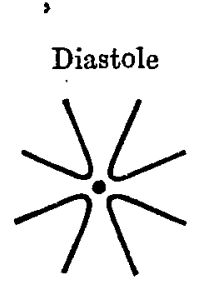

1.

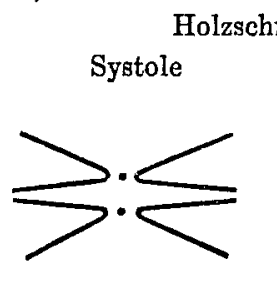

2.

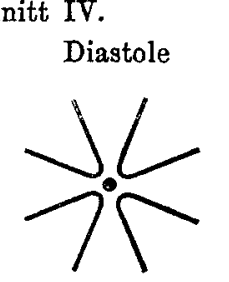

3.
Aequatorialplatte

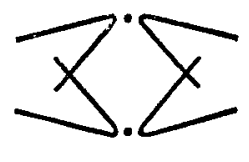

4.

In den Figuren sollen die in der Mitte angebrachten Punkte eine ganz schematische Bezeichnung für die hypothetisehen Kraftcentren sein. In der diastolischen Sternform (1.) ist ein solches Centrum da; man kann nun annehmen, dass ein Ansatz zur Zerlegung dieses Centrums in zwei beroits mit jeder Systole gemacht wird (2), dass aber diese Versuche mehrmals misslingen, und die Fadenfigur zunächst wieder in die Monocentrie zurïckfällt (3), bis endlich die trennende Kraft das Uebergewicht erhält (4). Bei jedem verfehlten Versuche dieser Art werden die Schleifenwinkel durch die auseinanderrückenden Centren etwas nach polarwärts von einander abgezogen, dadurch die Schleifens chenkel nach äquatorialwärts gegeneinander geneigt (2), und das entspricht vollkommen der systolischen Form der Sterne.

Dass eine solche Neigung der Strahlen gegen den Aequator bei dieser Form zu Grunde liegen müsse, habe ich schon früher angegeben, glaubte aber zugleich noch annehmen zu müssen, dass eine Verkürzung der polaren Strahlen mitspiele (Th. I p. 381). Es ist auch schwierig zu entscheiden, ob eine solche nicht wirklich vorkommt, doch würde nach dem obigen Schema ihre Annahme nicht nöthig sein, um den Habitus der systolischen Sterne zu erklären.

D.

Die Längsspaltung der Kernfäden.

Diese Erscheinung habe ich bei der Darstellung an diesem Ort bis jetzt unberücksichtigt gelassen. - Sie ist $\operatorname{mir}$ in ihrer 
Bedeutung ebenso vollkommen räthselhaft geblieben, wie früher (Th. I, p. 380, 383). Nach sehr viel ausgedehnterer Untersuchung kann ich, wie schon damals, behaupten, dass sie bei den Theilungen der Epithelien, Bindesubstanzzellen, Muskelzellen, rothen Blutscheiben und Knorpelzellen von Salamandra ein constantes Pbänomen der Kerntheilung, und hier an jedem gut conservirten und gefärbten Object ${ }^{1}$ ) schon mit 300 facher Vergrösserung dentlich erkennbar ist. An Kunstproducte wird Niemand denken, wenn er nur einige, geschweige denn viele wohlerhaltene Exemplare gesehen hat. Wollte man ja annehmen, dass die vollständige Spaltung in zwei Längsfäden erst durch Wirkung von Reagentien ${ }^{2}$ ) zu Stande käme, so müsste man doch zugeben, dass eine Disposition dazu, also ein Aufbau der Fäden aus zwei differenzirten Längshälften, dafür schon vorgelegen haben muss; sonst wäre die Erscheinung kaum zu verstehen. Ausserdem spricht der Umstand, dass bei den genannten Zellenarten die Fädenstücke der Aequatorialplatten, der Kerntonnen und der Anfangsphasen der Tochterkerne von halber Dicke und von doppelter Zahl gefunden werden, wie am dickstrahligen Mutterstern wohl hinreichend für die Natürlichkeit der Doppelfäden.

Allerdings bin ich aber bei der Untersuchung der Hodenzellentheilungen (s. o. Abschnitt 1) zunächst zweifelhaft geworden, ob die Fädenspaltung allgemeine Verbreitung hat. Denn hier konnte ich, wie am eben cit. Orte mitgetheilt ist, nur in einzelnen Fällen Andeutungen von Längsspaltung an Reagentienpräparaten sehen, an den lebenden freischwimmenden Hodenzellen nichts davon mit Sicherheit feststellen (s. Fig. 35). Auch sind hier die Fäden der Kerntonnen und die Tochtersterne ebenso dick wie die der Muttersterne und -Knäuel (vergl. Fig. 35).

Es bleiben demnach zwei Möglichkeiten: entweder, die Fädenspaltung kommt uiberhaupt nicht bei allen Zellenarten vor; oder sie ist bei Objecten, wie den Hodenzellen, ein wenig augen-

1) Wo dagegen etwas Quellung eingetreten ist, da werden die Doppelfäden häufig wieder mit einander verbacken. Dies tritt sehr gewöhnlich an Essigsäurepräparaten auf, anch wenn im Uebrigen die Formen der Kernfiguren gut fixirt sind.

2) In einigen günstigen Fällen habe ich jedoch die Doppelfäden ja auch lebend wahrnehmen können, s. Th. I, p. 380, Fig. 5 Taf. 16. 
Beiträge zur Kenntniss der Zelle und ihrer Lebenserscheinungen. 213

fälliger und sehr rasch vorübergehender Process, dergestalt, dass die Fädenhälften sich kaum von einander entfernen und im Stadium der Kerntonne meist schon wieder mit einander verschmolzen sind.

Dass man von der Fädenspaltung an den anderen Objecten, die im Abschnitt 1 dies. Abb. besprochen sind (Triton, Batrachier, Pflanzen, Säugethieren), bis jetzt nichts sehen konnte, beweist übrigens an sich nicht, dass sie bei diesen fehlen müsste, weil diese Objecte fast alle viel $\mathrm{zu}$ klein und ungtinstig für Entscheidungen darüber sind (für Pflanzen siehe jedoch Taf. 2 Fig. 21).

Sonst habe ich noch Folgendes über die Fädenspaltung feststellen können:

1. Sie kann schon im lockeren Knäuelstadium oder in der Kranzform, oder endlich, was doch das Häufigste bleibt, in der Sternform auftreten. Ich habe dies schon früher a. a. O. vorläufig ausgesagt, kann es aber jetzt durch eine viel grössere Zahl von Objecten belegen.

2. Die Fïdenspaltung tritt entweder durchaus gleichzeitig bei allen Schleifen oder Fadensegmenten der betreffenden Kernfigur auf; oder, wenn sie sich auch an den einen Fiaden etwas friher als an anderen vollzieht, so ist ihr Auftreten auf einen sehr kurzen Zeitraum confinirt. Dies geht deutlich daraus hervor, dass man fast immer, wo uberhaupt Fiddenspaltung in einer Kernfigur vorliegt, dieselbe durch die ganze Figur hindurch antrifft: sebr selten dagegen Bilder, wo einzelne Fadenstïcke schon gespalten, andere noch ungegespalten sind 1). - Dies beweist, dass das Moment, welches die Tendenz zur Längsspaltung der Kernfäden setzt, gleichzeitig durch -die ganze Kernfigur hindurch wirksam sein muss.

E.

\section{Die Tochterkernfiguren.}

Während sie sich aus der Aequatorialplatte sondern und auseinanderzurïcken beginnen, zeigen sie die etwas variablen Formen,

1) Ein Bild letzterer Art ist in der Fig. 7 Taf. 17, Theil I, dargestellt. Die Stelle in Fig. 5 Taf. 17 daselbst hingegen, wo ein ganz kleiner Fadenabschnitt breit gespalten dargestellt ist, beruht auf einem Zeichenfehler. 
die mit Körben (Eberth), Halbtonnen (Strasburger) oder halbaufgeblïth en Compositenblumen (Mayzel) verglichen worden sind Doch wird ibr Bau durch diese Vergleiche nicht vollständig erläutert. Nach allen drei Vergleichsobjecten würde man an Stäbchen denken, die sowohl nach dem Pol wie nach dem Aequator freie Enden haben. Das ist jedoch (sicher wenigstens bei den Urodelen) nicht der Fall, sondern wie sich schon aus den oben beschriebenen Bauverhältnissen der Aequatorialplatten ergiebt, haben wir nach der Trennung ebenso wie vor derselben: Fadenschleifen, deren Schenkel an den Polen in einander übergehen. Dies wird die schematische Figur 15 Taf. I leicht erläutern, vergl. Holzschnitt II, 5. Zuweilen finden sich tibrigens solche Figuren, die diesem Schema an Regelmässigkeit kaum etwas nachgeben: jede Tochterfigur hat etwa Palmenform, indem die eine Hälfte der Schleifenschenkel central als Stamm, die andere peripher als Blïtterglocke gruppirt ist; doch allerdings die erstere nie so ganz dicht gelagert, wie es das Schema Fig. 15 giebt. Besonders häufig finde ich regelmässige Formen solcher Art bei rothen Blutzellen.

Ob diese Form constant durchschritten wird, kann ich nicht sagen; jedenfalls ändert sie sich bald in der Art, dass die central liegenden Schenkel ebenfalls mehr in die Peripherie, zwischen die übrigen rücken (Fig. 11 Taf. $18 \mathrm{Th}$. I). Die polaren Umbiegungen bleiben auch jetzt erhalten ${ }^{1}$ ) (Fig. 35 e Taf. 3, Fig. $15 \mathrm{c}$, 15 d Taf. 2).

Dass diese Tochterkernfiguren einen radiären $\mathrm{Bau}$ haben, - wenn auch den von abgeflachten und hohlgeformten Sternen - versteht sich besonders bei der Ansicht vom Pol von selbst, und ich glaube daher ganz im Recht zu sein, wenn ich schon in dieser Phase die Repetition des Muttersterns sehe. Bei vielen Exemplaren wird die Aehnlichkeit mit letzterem noch vollkommener, indem ein Theil der Strahlen des Tochterkerns am Rande nach der Polseite hin umklappt (Fig. 16 Taf. 17 Th. I); doch gebe ich zu, dass letzteres nicht in allen Fallen eintritt, und dass auch, wo es vorkommt, die Tochtersterne doch immer etwas abgeflacht bleiben.

1) Wenigstens finde ich dies überall, wo die Figur hinreichend locker gebaut ist um dergleichen deutlich zu sehen; wo die Fäden eng liegen, sind solche Dinge nicht zu entscheiden. 
In solchen Fällen, wo die Kernfiguren iberhaupt recht locker angeordnet sind, zeigt sich die radiäre Anordnung bei den Tochtersternen besonders deutlich; ebenso lässt sich an solchen auf das Sicherste sehen, dass die Schleifen an der Polseite erhalten bleiben (Fig. 15 c, $15 \mathrm{~d}$ Taf. 2, s. Erkl.).

Ich habe die Vermuthung hingestellt (Th. I p. 393), dass die Fädenschleifen bei Salamandra noch in der Kerntonne, oder auch erst in den Tochtersternen, je 2 zu 2 der Länge nach mit einander wieder veršchmölzen. Es wäre in der That schwierig, diese Annahme zu umgehen, mit Hinblick auf die Längsspaltung, die vorher im Mutterstern stattfand. Nach dieser zeigen sich die Fäden, ganz wie zu erwarten, halb so dünn und doppelt so z ahlreich wie vorher (s. Fig. 10, 11-14 hier), aber in den späteren Formen der Tochtersterne sind sie wiederum halb so zahlreich und doppelt so dick, wie in den feinstrabligen Figuren. Die Annahme einer Längsverschmelzung von zwei zu zwei Fäden bietet dafür gewiss die nächstliegende Erklärung. -

Ich finde nun, dass sich durch diese Annahme auch ein anderer Befund aufklären lïsst, den ich früher beschrieb und der damals räthselhaft erscheinen musste. Man findet hin und wieder - nicht häufig - Doppelsterne in einer Zelle (Fig. 9 Taf. 17 Theil I), welche man zunächst als Tochtersterne ansehen könnte gleich denen in Fig. 24 oder $30 \mathrm{~d}$ hier, - wenn sie nicht doppelstrahlig wären, gerade so wie die in Spaltung begriffenen Muttersterne Fig. 9 hier. Aus letzterem Grunde habe ich ihre Deutung früher fraglich gelassen, und selbst für möglich gehalten, dass sie Abnormitäten des Theilungsvorganges vorstellen könnten. - Wenn man sich aber erinnert, dass die Längsspaltung der Strahlen am Mutterstern bald früher bald später eintreten kann (s. oben), so liegt es nahe zu erwarten, dass es sich mit dem regressiv-entsprechenden Vorgang, der (hypothetischen) Wiederverschmelzung je zweier Fadenschleifen, ähnlich verhalten mag. Für gewöhnlich würde dieselbe schon in der Kerntonne oder selbst schon in der Aequatorialplatte erfolgen, wo sich bei der dichten Lagerung der Elemente daron nichts Deutliches erkennen lässt; hie und da könnte sich aber die Wiederverschmelzung bis in die spätere, eigentliche Sternform der Tochterkerne verzögern, und damit fänden dann Bilder, wie die doppelstrahligen Doppelsterne in Fig. 9 Taf. 16 Theil I, von selbst ihre Erklärung. - 
Nach andern Untersuchern soll in den Stadien der Fig. 15 Taf. 1, 24, 26 Taf. 2 eine Verschmelzung der Fỉden an der Polseite eintreten, und von bier aus gegen den Aequator weitergreifen. Für die urodelen Amphibien kann ich dies nicht zugeben, und bei den anderen Objecten, die ich untersuchte (Abschn. 1) wenigstens keinen Beweis dafür finden. -- Es ist wahr, dass in vielen Fällen die Fiaden, und besonders die Fadenschleifen an den Polen, recht eng gedrängt liegen, so dass sie am lebenden Object den Eindruck einer confluirten Masse gebeu; ebenso, dass man oft an gefärbten Reagentienpräparaten solche Polverschmelzungen sieht; ich besitze solche in Menge, aber es sind dies immer solche, an denen auch andere Kernfiguren Quellungen oder Schrumpfungen zeigen: je sehöner und vollkommener conservirt das Object, desto weniger findet man von solchen verbackenen Tochterkernen. Ich muss dieselben also für Kunstproducte halten, und kann mich dabei auch für Triton auf $\mathrm{K}$ lein berufen, der von einem Homogenwerden der Tochterkerne nichts aussagt, und der nach seinen Abbildungen zu urtheilen über sehr schön conservirte Objecte verfügt hat.

Ueber die folgenden Formen der Tochterkerne habe ich meinen früheren Mittheilungen wenig hinzazusetzen: ich finde durch ausgedehntere Untersuchung nur bestätigt, dass auf die Sternform eine Kranzform folgt, also auch noch von radiärem Typus (Fig. 17 Taf. $17 \mathrm{Th}$. I), aber mit gewundenen und gescblungenen Fïden, an denen sich immer weniger Unterbrechungen finden; und die, von der Polseite betrachtet, häufig eine freie Mitte erkennen lässt. Es scheint mir diese Umformung nicht besser erklärbar, als durch die Annahme, dass jetzt die peripheren Enden der Schleifenschenkel in den Tochterkernen mit einander verschmelzen; die centralen Umbiegungen brauchen, wie sich aus dem Obigen ergiebt, überhaupt niemals getrennt gewesen zu sein. -

Es scheint, dass ganz reine Kranzformen, mit freiem Mittelfeld, nicht immer vorzukommen brauchen; deshalb habe ich auch die Kranuform als besondere Phase gestrichen und in die folgende einbezogen (gilt ebenso für die Mutterformen, s. o.).

Es verengert sich darauf die Figur zu einem Knäuel, und dessen Windungen lagern sich so dicht, dass sie am lebenden Präparat als homogener Klumpen imponiren und durch Reagentien oft zu einem solchen entstellt werden (Fig. 29; Näheres darïber 
s. in Abschnitt I bei „Pflanzenzellen“. - Ich behaupte nicht, dass nicht bei Zellen anderer Organismen (Strasburger u. A.) wirklich Zusammenlagerungen der Fäden in diesem Stadium vorkommen, welche bis zur Berührung gehen; sehe aber keinen Grund dies eine Verschmelzung zu nennen, um so weniger, da in dem alsbald folgenden Stadium der Fadenbau der Tochterkerne wieder auf's Deutlichste hervortritt.

Denn es folgen jetzt die Tochterfiguren mit querer Gitterung (Fig. 2, 3 Taf. 18 Th. I) und gehen endlich in die unregelmässigeren Geriste über, die zum Ruhezustand zurickleiten. In Formen der Töchter, wie sie Fig. 1 b Taf. 1 vom Mutterkern zeigt, bemerkt man bei Urodelen zuerst unregelmässige Verdickungen in den Bälkchen: den Netzknoten, vielleicht schon den Bildungsstellen von Nucleolen entsprechend. Wie Strasburger (8) gezeigt hat, treten die letzteren dagegen bei Pflanzenzellen schon weit frìher auf.

F.

Die achromatische Fadenfigur.

Durch die Arbeiten von Bütschli, Strasburger, 0. Hertwig und Mayzel ll. ce. waren schon seit lüngerer Zeit von verschiedenen Objecten ${ }^{1}$ ) jene Formen der Kerntheilungsfigur bekannt, in dẹen ein Bündel feiner Fasern, meist in Gestalt einer Spindel, von Pol zu Pol angeordnet liegt, und an der Mitte dieses Bündels sich gröbere Elemente angehäuft finden (z. B. Fig. 34); welche letzteren dann sich trennen und, als Grundlagen des Tochterkerns, polarwärts auseinanderrücken. Diesen Formen verdankt der Name „Kernspindel" seine Entstehung.

Die genannten Autoren hatten anfangs angenommen, dass die letzterwähnten gröberen Elemente (die sie meist als „Körner" bezeichneten und die identisch mit Strasburger's "Kernplattenelementen" sind) Anschwellungen jener feineren Fasern (der „Kernfasern") seien.

In Mayzel's Ergebnissen an der Frochhornhaut und anderen Objecten (1876-77, siehe die Figuren bei Strasburger. Jenai-

1) So: Eizellen von verschiedenen Wirbellosen, Infusorien, Pflanzen (Bütschli, Strasburger, Hertwig); Endothel der Froschhornhaut (Mayzel). 
sche Zeitschr. Dec. 1877, nach Präparaten Mayzel's) ist jedoch bereits die richtige Erkenntniss enthalten, dass die „Kernplattenelemente" nicht bloss Körner sind, und dass sie, was noch wichtiger, nicht Anschwellungen der feinen „Kernfasern" darzustellen brauchen, sondern ohne Continuität mit diesen sein können. Dass Letzteres der Fall sein kann, hat auch Strasburger am cit. Ort bereits zugegeben.

Ich habe mich nun inzwischen tiberzeugt:

1) dass die erwähnten Kernplattenelemente an jenen Objecten jedenfalls die Homologa sind zu den Bestandtheilen der tingirbaren Kernfigur, also zu den Kernfäden, bei Salamandra u. a. Amphibien (Th. I, 420 u. a).

2) Dass dieselben sich von jenen anderen, feinen "Kernfasern" durch jene eben erwähnte Eigenschaft durchweg unterscheiden: die ersteren sind stark tin'girbar, die letzteren nicht - ein Unterschied, dem von anderen Seiten keine Aufmerksamkeit geschenkt $z u$ sein scheint ${ }^{1}$ ).

3) Dass die tingirbaren Kernfäden an allen denjenigen Objecten, die ich schon damals prüfen konnte, nicht Anschwellungen der blassen Kernfasern, sondern neben ihnen gelegen sind (s. Th. I. Taf. 18, Fig. 17).

Diese Punkte habe ich nun an allen weiteren Objecten, die ich prïfte, bestätigt gefunden.

Zunächst konnte ich auch bei denselben Zellenarten von Salamandra, deren Theilungen im Th. I beschrieben sind und wo ich die blassen Fäden friiher vermisste und deshalb ihr Vorkommen noch für zweifelhaft hielt ${ }^{2}$ ), jetzt das letztere nachweisen. Dies

1) Arnold (s. am Schluss) hat soeben die gleiche Wahrnehmung mitgetheilt.

2) Theil I p. 419, 420. Dass hierfür Grund vorlag, und dass diese Zweifel nicht etwa bloss auf oberflächliche Untersuchung hin erhoben wurden, dafür kann ich mich jetzt auch auf einen so ausgezeichneten und sachkundigen Beobachter wie Strasburger berufen. Dieser selbst hat, nach Kenntniss meiner Beschreibung und Präparate von Salamandra und nach eigener genauer Prüfung seiner pflanzlichen Objecte, gerade ebenso geurtheilt, wie ich es damals vermuthungsweise that: indem er annahm, dass in den betreffenden Fällen (Salamandra, Nothoscorodon u. A.) die feinen Kernspindelfasern in der That fehlten (Strasburger, 8, p. $283 \mathrm{ff}$.). Wenn ich ihm jetzt also hierin entgegentrete, so habe ich damit anch mich selbst zu berichtigen. 
gelingt hier allerdings nicht leicht, und nur an einer Minderzahl von Zelltheilungen.

Da die feinen Fäden bei scharfer und reiner Kerntinction keine Spur von Farbe aufnehmen, und bei starker Aufhellung ganz unsichtbar werden, so bemerkt man grade an den besten Präparaten von gefärbten Kernfiguren von ihnen nichts. Um sie aufzusuchen, habe ich also jetzt diese Methoden vermieden, und einfach mit Essigsäure gearbeitet, oder Chrom- und Pikrinpräparate bloss in Wasser oder verdünntem Glycerin untersucht. Hierbei fand ich an Theilungen von Epithelzellen, Bindegewebs- und Knorpelzellen, in den Stern- und Aequatorialplattenphasen, zuweilen deutlich erkennbare, wenn auch immerhin sehr zarte derartige Kernfasern an den Polen (Taf. 1 Fig. 12).

Noch viel klarer erkennbar sind sie bei Hodenzellentheilungen von Salamandra (Taf. 3 Fig. $43 \mathrm{ff}$.); die Objecte sind mit Chromsäure fixirt und in Glycerin aufbewahrt; bei klarer Dammarlackaufhellung sicht man dagegen attch in den Hodenzellen diese Fäden nicht. Sehr deutlich sind sie öfter in Objecten, bei denen die Lackaufhellung unvollkommen gerathen, Wasser oder Alkohol zurückgeblieben ist.

Es ist wahr, dass bei den anderen, vorher erwähnten Zellenarten diese blassen Fäden an den Polen, und ebenso die zwischen den Trennungshälften der Kernfigur im Aequator ausgespannten Fäden (Fig. 46, 47, 31 ff.) viel zarter, und meist weniger regelmässig geradlinig gestreckt sind wie bei den Hodenzellen und anderen Objecten; dass vielfach nur Spuren, und in den meisten Fällen gar nichts von ihnen erkennbar ist; doch glaube ich auch hier, dass die wenigen positiven Fälle schwerer wiegen müssen als die vielen negativen, wenn sich durch erstere der Schluss auf eine allgemeine Gleichartigkeit dieser Vorgänge gewinnen lässt.

An Pflanzenzellen sind diese achromatischen Fäden oft ausserordentlich deutlich, wie schon Strasburger's zahlreiche Abbildungen zeigen. Strasburger ist das verschiedene Verhalten der beiden Fädenarten gegen Tinction noch nicht bekannt gewesen; es lässt sich gerade hier, bei Pflanzenzellen sehr schön demonstriren, da die Kerntinctionen hier schärfer auszufallen pflegen wie bei den meisten Thiergeweben (s. Fig. 25 und 26 von Allium odorum, aus der Peripherie eines Fruchtknotens. Die Farbenintensität ist (wie auch in meinen früheren Bildern) möglichst ge- 
nau so gegeben, wie sie an den Präparaten vorliegt). Uebrigens kann auch hier bei den einen Kerntheilungsfiguren die achromatische Fadenspindel aufs deutlichste $z u$ sehen sein, während andere, unmittelbar daneben in derselben Gewebsformation liegend, sie nur verwaschen oder gar nicht zeigen.

Mit den eben beschriebenen blassen Fäden nun scheint mir eine Erscheinung geradezu identisch zu sein, welche vielfach erwähnt, aber so viel ich finde, noch in keine Beziehung zu jenen gesetzt ist. Es sind dies die blassen Fäden, die nach der Beschreibung Strasburger's und Anderer beim Auseinanderweichen der Tochterfiguren zwischen diesen ausgespannt liegen bleiben, und welche Strasburger neuerdings als Zellfäden bezeichnet hat, da sich in ihnen bei Pflanzen die "Zellplatte" anlegt.

Beim Ansehen der zahlreichen Abbildungen in Strasburger's Buch: "Ueber Zellbildung und Zelltheilung " ist es mir fast befremdend, dass der Gedanke an die Identität dieser Fäden mit den späteren "Zellfäden" nicht schon zum Ausdruck gekommen ist. Strasburger hat aber offenbar nicht die Ansicht, die ich hier vertrete, da er in seiner neuen Arbeit $(8$, p. 277) bei der Beschreibung des Trennungsstadiums von Nothoscorodon sagt: „Fig. 22 zeigt den nächsten Zustand: die Kernplattenhälften sind weiter auseinandergerückt, es beginnt das Einziehen der feinfaserigen Spindelhälften in dieselben. Zwischen den beiden auseinander weichenden Kernplattenhälften werden die Fäden sichtbar, die ich nicht weiter Kernfäden nennen will, vielmehr von jetzt an $Z$ ellfäden. Diese Namenänderung ist nothwendig, weil die Bezeichnung Kernfäden einerseits zu einer Verwechselung mit den Fäden innerhalb der Kernfigur führt, andererseits aber die Zellfäden auch nicht von der Kernsubstanz stammen, vielmehr von dem zwischen die Kernhälften eindringenden Zellplasma gebildet werden, so weit aber zunächst Kernsubstanz in diesen Fäden vorhanden ist, diese alsbald in die beiden Schwesterkerne einbezogen wird." Strasburger nimmt also an, dass die früheren Kernspindelfäden morphologisch zu existiren aufhören, in die Tochterkerne aufgenommen werden, und dass die von ihm Zellfäden genannten Dinge neu zwischen den Kernhälften auftreten. - Die Objecte, auf die sich diese seine Beschreibung bezieht, sind Alkoholpräparate von Nothoscorodon, wie auch ich sie (nebst Allium) benutzt habe, nur dass ich auch noch Färbung anwandte. Ich kann an diesen Objecten nichts finden, was zu Strasburger's obiger Ansicht nöthigte; Kernfiguren, wie z. B. in Fig. 23, 25, 26 hier machen ganz den Eindruck, dass die blassen Fäden an den Polen Fortsetzungen der blassen Fäden im Aequator sind, und dass eine und dieselbe feinfadige 
Beiträge zur Kenntniss der Zelle und ihrer Lebenserscheinungen.

achromatische Spindel vom Stadium Fig. 22 bis zum Stadium Fig. 26 bestehen bleibt. - Dagegen will ich dem nicht widersprechen, dass bei der Rückverwandlung der Tochterkerne diese achromatischen Fäden in jene wieder mit einbezogen werden können, wie Strasburger dies annimmt.

Ich finde, dass diese Fäden überall, wo ich sie überhaupt deutlich darstellen kann, eben denselben Untersehied gegen die Kernfäden zeigen, wie jene blassen Fasern der Kernspindel: sie sind nicht tingirbar (Fig. 25, 26). Und es scheint mir, wie gesagt, die einfachste Annahme, dass diese Fäden gar nichts Anderes sind als jene: dass sie nicht etwa von den Kernhälften ausgesponnen, oder anderweitig gebildet werden, sondern von vorn herein im Innern der Aequatorialplatte und Kerntonne angelegt sind, schon ehe diese sich trennt; und dass also die beiden tingirbaren Trennungshälften sich nur an ihnen entlang verschieben, indem sie nach den Polen riicken and dadurch die blassen Fäden im Aequatorialtheil frei werden lassen. - Jedenfalls steht dieser Annahme, so viel ich sehe, für jetzt nichts im Wege.

Allerdings ist mir eine Erscheinung wohl bekannt, die man gegen die eben vorgetragene Ansicht, und fïr ein Ausgesponnenwerden der Fäden, geltend machen könnte: die chromatischen Fädlen in den auseinanderrückenden Tochterfiguren sind an ihren äquatorialen Enden zuweilen verdünnt, und solehe verdiunnte Enden werden zuweilen mit gegenüberliegenden zusammenhängend gefunden (Fig. 42,43). Doch es ist ja oben (in diesem Abschnitt C) schon gezeigt, dass öfter in dieser Phase Berührung mit Verschmelzung von Fädenenden vorkommt, und es lässt sich ganz wohl denken, dass an diesen Stellen dann, beim Auseinanderrücken, jene Verbindungsfäden wirklich ausgezogen werden; darum können aber jene hier in Rede stehenden, achromatischen Fäden ganz unabhängig hiervon noch daneben existiren und brauchen beide Dinge nichts miteinander zu thun zu haben.

Der Annahme, dass diese achromatischen Fäden nur von den auseinanderrïckenden Tochterkernfiguren selbst ansgesponnen, also ans ihnen heraus entwickelt würden, würde auch schon folgende einfache Thatsache widersprechen, die jedes gute Tinctionspräparat solcher Formen zeigt: die tingirbaren Tochterkernfiguren sind an Masse stets gleichzuschäten der vorherigen Mutterkernfigur. Sollte eine so beträchtliche Substanzmenge, wie sie namentlich bei den Pflanzenzellen die achromatischen Fä- 
den ausmachen, aus ihnen heraus entwickelt werden, so wïrde sich schwer begreifen lassen, dass sie dabei gleiches Volum bewah ren.

A usserdem ist die Annahme, dass diese Fäden (Zellfäden Strasburger) mit den blassen Fäden der Kernspindel identisch sind, in keinem Widerspruch mit bisher beobachteten Thatsachen: sie bedingt vor Allem keinerlei $Z_{w}$ eifel an der Richtigkeit von Strasburger's Angaben über die Theilung bei Tradescantia (14). Allerdings bemerkt derselbe fïr dieses Object nichts uiber das Vorhandensein von feinen Fasern in den vorhergehenden Phasen, und rechnet diese Theilung deshalb unter die Gruppe der "Kerntonnen"; doch halte ich es für vollkommen möglich, dass hier, so wie bei vielen anderen Objecten (gerade auch Salamandra) die feinen Fäden im Stadium der Aequatorialplatte nur deshalb nicht erkennbar sind, weil sie durch die hier sehr dicken und massigen tingirbaren Fäden verdeckt werden. Bei einer Aequatorialplatte von Nothoscorodon oder Allium, wie in Fig. 23 hier, freue ich mich schon, gerade deutlich sehen zu können, dass die tingirbare Figur aus Fäden, nicht aus Körnern besteht; ob nun dazwischen in dieser Figur noch feine untingirbare Fasern stecken, wie deren einzelne in der Mitte, an der Scheidungsstelle, und viele an den Enden ja sichtbar werden), das ist nicht erkennbar, aber völlig möglich. - An manchen derartigen Figuren sind auch an den Polen die blassen Fäden nicht erkennbar.

Die neueste Aeusserung Strasburger's über die betreffenden "Zellfäden" bei Tradescantia: „Es kann keinem Zweifel unterliegen, dass diese Substanz schon vorher zwischen den Kernstäbchen (d. i. den tingirbaren Kernfäden) vertreten war, denn man sieht die Stäbchen sich deutlich aus derselben zuriickziehen" würde sich mit meiner Auffassung sehr gut vereinbaren lassen, wenn sie auch offenbar nicht dasselbe mit ihr besagt.

Diese meine Auffassung also ist kurz wiederholt folgende: In der Theilungsmetamorphose des Zellkerns sondern sich in demselben zwei morphologisch unterscheidbare Figuren. Die eine nimmt sämmtliches Chromatin des Kerns auf und stellt die tingirbare Fadenfigur dar. Die andere besteht aus Achromatin; es ist dabei aber festzuhalten, dass nicht die sämmtliche achromatische Substanz des Kerns in sie einzugehen braucht, da zwischen den blassen Fasern der Kernspindeln in vielen Fällen 
noch erheblicher Raum ubrig bleibt. In welchem Zeitpunkt der Karyokinese die letztere Figur sich morphologiseb zuerst ausprägt, wissen wir nicht; nach den jetzigen Kenntnissen wird sie erst um die Zeit, wo die tingirbare Figur die Form des Sterns oder der Aequatorialplatte hat, in Gestalt einer polar-gestreckten Fadenspindel deutlich. Es bleibt jedoch möglich, dass die Fäden dieser Spindel auch schon vorher, während der Knäuelform der tingirbaren Figur, irgendwie morphologisch angelegt sind.

Man kann also die beiden differenten Fadenfiguren, die so entstehen, als chromatische und achromatische Figur unterscheiden; die erstere ist identisch mit dem, was hier sonst für gewöhnlich Kernfigur genannt wird; die zweite. identisch mit Strasburger's Zellfäden, und zugleich mit der feinfaserigen „Kernspindel" der Antoren. Ich werde jene Bezeichnungen im Weiteren gebrauchen.

Der äusseren Form nach besteht noch der Unterschied, dass bei den einen Zellenarten die achromatische Figur sehr lang gestreckt ist, deshalb in den Stadien des Sterns und der Aequatorialplatte an den Polen über die chromatische deutlich hervorragt (Th. I. Taf. 18 Fig. 17, Fig. 25, 34 hier); bei den anderen aber eine kurzgestutzte Form hat, und deshalb in der chromatischen Figur oft verborgen bleibt.

Jene würden Strasburger's „Kernspindeln", diese seinen „Kerntonnen" entsprechen. - Fig. 12 hier zeigt eine Aequatorialplatte letzterer Form (Epithel von Salamandra), in welcher an den Polen die achromatischen Fäden, allerdings sehr blass, etwas hervorragen.

Die achromatisehen Figuren verdienen jedenfalls ein nicht minder aufmerksames Studium, als die chromatischen; denn in so fern es überhaupt zulässig ist, Richtungs- oder Attractionscentren anzunehmen und zu localisiren, welche die Umlagerungen der chromatischen Kernfäden beherrschen, muss man die Lage solcher Centren in den Raumbereich der achromatischen Figur fallen lassen.

Ihr Studium ist aber bei Wirbelthierzellen wegen ibrer grossen Blässe sehr schwierig. Ich habe bis jetzt in wenigen Fällen, bei Knorpel-, Bindesubstanz- und Epithelzellen, in den achromatischen Fäden äquatoriale Differenzirungen wahrnehmen können, welche den Strasburger'schen Zellplatten zu entsprechen scheinen (Taf. 2 Fig. 15b), welche letzteren bei Pflanzen ja äus- 
serst deutlich sind. Ob diese Dinge bei den Thierzellen constant zu nennen sind und hier dieselbe Bedeutung haben, die ihnen Strasburger für die Pflanzenzelltheilung gab, kann ich noch nicht beantworten. Nach Strasburger und Treub haben die Zellfaden in solchen Fällen, wo die Theilung des Zellkörpers nicht durch Abschnürung, sondern durch Spaltung geschieht, diese Spaltung einzuleiten oder doch dabei mitzuwirken. (Näheres s. in: 14 u. A.) Bei Thierzellen finden sich jedoch diese Fäden, oder Zellplattenelemente, auch in Fällen, wo die Theilung sicher mit Abschnürung erfolgt (z. B. Schleimzellen des Epithels, Salamanderlarve, Th. I. Taf. 16 Fig. 4 ; s. auch Strasburger 14, p.12); grade ein solcher deutlicher Fall ist z. B. auf Taf. 2 Fig. $15 \mathrm{~b}$ hier abgebildet, man sieht dort mitten in dem Einschnärungshals eine lichte Marke, in der sehr feine Elemente in der Aequatorialebene in gleichen Abständen vertheilt zu sein scheinen. Deutliche Fäden waren in diesem Falle nicht sichtbar, doch eine Längsstreckung der Reticulirung im Zellplasma in der Nähe der Theilungsmarke zu erkennen. - Natïrlich würe es a priori das Annehmbarste, dass diese Dinge hier überall dieselbe Bedeutung für die Zelltheilung haben, wie bei Pflanzenzellen, dass also anch in den Fällen, wo die Zelltheilung durch Abschnürung erfolgt, diese Differenzirungen der blassen Fäden dazu in Beziehung stehen.

Die achromatische Fadenfigur ist gerade an denjenigen $\mathrm{Ob}$ jecten besonders augenfällig ausgesprochen, an welchen $B$ iitschli, H. Fol, Strasburger, O. Hertwig zuerst gearbeitet haben: so besonders Eizellen, viele Pflanzenzellen. Daher erklärt es sich, dass diese Formen der "Kernspindel", mit verhältnissmässig massigen blassen, polar geordneten Fasern und verhältnissmässig kleinen chromatisclien Fäden (vergl. Fig. 31-34) den genannten Untersuchern anfangs als typisch für die Kerntheilung iberhaupt erschienen sind '). Sie sind dies ebensowenig, als andererseits ein specifischer Unterschied zwischen ihnen und den sonstigen Formen zu existiren braucht; nach dem, was hier entwickelt ist, handelt es sich doch wabrscheinlich nur um formale Verschiedenheiten, und wird damit die Gesammtauffassung sehr vereinfacht. Bei den ebengenannten Objecten, Eizellen u. A., sind die Kerne eben wohl relativ ärmer an Chromatin, als sie es z. B.

1) Auf die Färbungsresultate haben übrigens die genannten Autoren noch keine Aufmerksamkeit gerichtet. 
bei sämmtlichen Zellen von Salamandra sind; so wird nattirlich dieses Verhältniss auch in der Theilung stark hervortreten, indem die chromatischen Fäden - Strasburger's „Kernplattenelemente“ an Masse oft weit zurtickstehen gegen die achromatischen. Es wird freilich wohl so bald nicht gelingen, z. B. bei Eizellen zu entscheiden, ob diese kleinen chromatischen Fäden (Fig. 31-33, 34) hier wirklich dieselben Lagerungen und Formen durchmachen, wie bei den Gewebszellen. Bisher sind dieselben von Strasburger und Anderen vielfach nur als Körner erwähnt worden, die sich trennen sollen. Ich habe, wie oben (Abschn. 1) gesagt, bis jetzt vergeblich sicherzustellen gesucht, ob diese Elemente auch beim Ei Fadenschleifen sind. Die Verhältnisse sind dafür selbst an sonst günstigen Objecten (Echinodermen) zu klein, und zu sehr verdeckt durch das dotterhaltige Plasma der Eizelle. An Pflanzenzellen, wo die Dimensionen der chromatischen Elemente relativ bedeutender sind (Fig. 22-26), sieht man dagegen ja deutlich, dass es Fäden sind und nicht Körner, und an einzelnen besonders günstigen Objecten, wie die der beiden genannten Figuren, lässt sich denn auch nahezu noch sehen, dass Fadenschleifen vorhanden sind, die an der Polseite umbiegen (Fig. 23), gerade wie in den Aequatorialplatten bei Salamandra (Fig. 10-14). Ebenso bei den Hodenzellen (Fig. 44, 45). Also in Fällen, wo die dentlichsten, feinfadigen ach romatischen "Kernspindeln" vorliegen, wie hier, walten daneben in der chromatischen Figur dieselben Verhältnisse ob wie bei den Theilungen der Zellen, in welchen von den feinen achromatischen Fäden nichts zu erkennen ist. Da liegt doch wohl die Annahme am Nächsten, dass es sich ebenso auch bei den Eizellen u. A., und überhaupt allerwege ähnlich verhalten wird, dass die Dinge, die hier wegen ihrer Kleinheit und Undeutlichkeit wie Körner aussehen, ebenfalls Fadenschleifen sind; dass also die Reihe der chromatischen Figuren iberall in den Hauptsachen übereinstimmen wird mit der Reihe, die ich bei den Amphibien finde und bei so vielen anderen $\mathrm{Ob}$ jecten bestätigen konnte. Dies ist natürlich bis auf Weiteres nur eine Annabme; aber es muss zugegeben werden, dass sie die einfachste und nächstliegende ist, weil sie eine allgemeine Uebereinstimmung unter Formen herstellen kann, die sonst als äusserst heterolog. erscheinen miissten.

Eben deshalb, um die Aussicht auf eine solche allgemeine 
Homologie möglichst weit offen zu halten, habe ich auch hier und weiter oben (Abschn. I) besonders hervorgehoben, dass die Möglichkeit eines allgemeinen Vorkommeus der achromatischen Fadenfigur neben der chromatischen nicht ausgeschlossen erscheint, obschon die erstere bei vielen Zellenarten nicht zn sehen ist; und habe mich deshalb Strasburger's Unterscheidung von Kerntonnen (denen die achromatischen Fäden fehlen würden) und Kernspindeln (mit solchen) nicht anschliessen wollen. Ich proponire zunächst folgende Betrachtung der Sache:

Man gehe von der Annahme aus, - die übrigens durch die Tinctionsresultate hinlänglich motivirt ist - dass die Kerne verschiedener Zellenarten Chromatin und Achromatin in verschiedenem Mengenverhältniss enthalten; und dass eben diese Differenz, wenn schon in geringerem Grade, auch bei verschiedenen Zellenindividuen einer and derselben Gewebsart vorkommen kann. Wenn ein Kern, der recht reich an Achromatin und relativ arm an Chromatin ist, in Theilung gerïth, so werden die achromatischen Fiiden entsprechend grösser, deutlicher ausfallen und weniger durch die chromatischen Fäden verdeckt werden; dann wird im Trennungsstadium das Bild einer „Kernspindel" hervortreten. Im umgekehrten Fall werden die achromatischen Fäden zart und blass sein, vielfach deshalb ganz unsichtbar bleiben; man sieht dann in den betreffenden Phasen oft nichts anderes als die grobfadige chromatische Kernfigur, wie bei den meisten Zellen von Salamandra, im Integument von Nothoscorodon nach Strasburger, u. A. m. - Unter dieser Betrachtungsweise lassen die scheinbar differenten Formen sich einfach unter einem einheitlichen Gesichtspunkt zusammenfassen, und es wird damit sogar leicht verständlich, dass von zwei Zellen der gleichen Art, im selben Gewebe, die eine nur die grobe chromatische Figur zeigt, die andere daneben die feine achromatische, was ich, wie früher erwähnt, bei Thierzellen wie Pflanzenzellen oft gefunden habe: die Ursache kann lediglich darin liegen, dass der eine Kern chromatinreicher oder -ärmer war wie der andere.

Darum scheint mir diese Anschauung, als die einfachere und einheitlichere, der Annahme zweier ganz verschiedenen Kerntheilungstypen vorzuziehen. Doch gebe ich gern zu, dass erst weitere Untersuchung darïber zu entscheiden haben wird, ob die Letztere wirklich auszuschliessen ist. 
Um die Ergebnisse aus diesem Abschnitt recht ibersichtlich zu machen, bringe ich sie in das tabellarische Schema des Zelltheilungsvorgangs, das im Th. I (p. 409) aufgestellt wurde. Die Hanptglieder der Reihe konnten dabei wie früher bestehen bleiben; in einigen Punkten sind, entsprechend den neuen Ermittlungen, Aenderungen angebracht.

Ich bitte für die Tabelle auch die Holzschnitte I. II. IV oben im Text za vergleichen.

\section{Mutterkern} (progressiv).

1 . Gerüst (Ruhe)

$\downarrow$ Ansammlung des Chromatins zum

2. der sich allmählig lockert, unter Verdickung seiner Fäden.

$\downarrow$

$$
\text { Segmentirung }
$$

d. i. deutliche Trennung ${ }^{1}$ ) in Fadenstücke.

Bevor die Segmentirung ganz vollendet ist, tritt gewöhnlich eine

\section{Kranzform}

des Fadengewindes auf, offenbar schon Einleitung zu dem folgenden radiären Typus.

Die Segmente biegen sich $z u$ Schleifen, beginnen sich nach dem Typus: Winkel derSchleife nach dem Centrum, freie Enden ihrer Schenkel nach der Peripherie, zu ordnen, und so entsteht die

3.

$$
\text { Sternform. }
$$

(In dieser und der vorhergehen$\downarrow$ den Phase werden die achromatischen Fäden deutlich.)

Systolen und Diastolen des Sterns (Erklärung vergl. Text, d. Abschn. C.); Längsspaltung der Strahlen, die aber auch schon in den vorigen Phasen geschehen kann.

Nachdem durch die Systolen des Sterns schon Versuche dazu gemacht sind, folgt die

definitive Umordnung der Schleifen in den Typus: Winkel $\mathrm{nach}$ den Polen, freie Enden nach dem A equator (gilt für je eine Hälfte der vorhandenen Schleifenzahl).

Damit ist entstanden die

\section{Tochterkerne \\ (regressiv).}

(1.) Ger üst (Ruhe).

Wiedervermischung des Chromatins und Achromatins.

der sich allmählig verdichtet, Unterbrechungen des Fadengewindes sind nicht mehr deutlich.

Unterbrechungen des Gewindes werden immer weniger und undeutlicher sichtbar (Verschmelzung von Fädenenden?)

Oft: Kranzform.

Die Fäden nehmen geschlängeltere Lagen an.

$$
\text { (3.) Sternform. }
$$

Längsverschmelzung von je zwei Fäden?

$\uparrow$

Allmählige Wiederordnung der Schleifen in je einer Tochterfigur nach dem Typus (in Beziehung auf die künftige $\mathrm{Halbzelle):}$ Winkel nach dem Centrum, freie Enden nach der Peripherie.

$\searrow$ 4. Aequatorialplatte.

1) Es soll hiermit die Möglichkeit offen bleiben, dass die Segmentirung, 
Wenn in diesem Schema in der That der allgemeine, typische Lagewechsel gegeben ist, den die Kernfäden bei der Theilung durchmachen, so ist damit natuirlich eine wirkliche Theorie der Kerntheilungsmechanik noch bei Weitem nicht gewonnen. Das Unbekannte, das hier wie iuberall in den Kauf genommen werden muss, ist die Ursache des Uebergangs von der Monocentrie in die Dicentrie: die Zerlegung e iner hypothetischen, attrahirenden oder richtenden centralen Kraft, in $\mathrm{zwei}$ derartige Richtungscentren, die nach den Polen auseinanderriicken.

Auch in den Anschaungen, welche Strasburger tiber das mechanische Wesen der Zelltheilung geäussert hat ${ }^{1}$ ), ist die Ursache, aus welcher sich ein polarer Gegensatz in der Zelle, beziehungsweise in der Kernspindel oder Kerntonne ausbildet, um deren Theilung zu veranlassen - als unbekannt und gegeben hingenommen. Gedanken über die speciellere Mechanik des Theilungsvorganges hat Strasburger bis jetzt nur an ein Stadium geknüpft, das der Aequatorialplatte, Kernspindel oder Kerntonne, also das der Theilung unmittelbar vorangehende. Er hält es für annehmbar ${ }^{2}$ ), dass bei den Kernspindeln eine abstossende Action von den Polen ausgehe, und die Elemente der Kernplatte (d. i. also meine chromatischen Fidien) in den Aequator zusammendränge. Ich gebe durchaus zu, dass man sich die Kräfte, welche z. B. aus meiner Fig. 9 Taf. 1 die Fig. 10, oder aus meinem Holzschnitt I oben Fig. 1 die Fig. 2 hervorgehen lassen, ebensowohl als von den Polen abstossende, wie als vom Centrum aus richtende vorstellen könnte. Beide Annahmen sind einstweilen rein hypothetisch, ich will keine von beiden verfechten, und habe die obige Darstellung, wonach man sich ein anfangs centrales, später in axialer Richtung getheiltes Kraftcentrum zu denken hätte, ausdrücklich nur zur Erleichterung des Verständnisses benutzt.

Müsste man aber schon zwischen jenen beiden wählen, so wärde ich der letzteren vor der ersteren (Strasburger's) den Vorzug geben miissen. Denn seine Anschauung, dass die Aequa-

oder die Disposition bestimmter Stellen zur Trennung, schon im vorigen Stadium bestanden haben kann, wenn auch nicht erkennbar.

1) Zellbildung und Zelltheilung, 2. Aufl., p. 246, 272, und : 8, p. $285 \mathrm{ff}$.

2) 8 , p. 285. Seine frühere (am oben a. 0.) viel positiver lautende Behauptung in dieser Richtung (vergl. meinen Th. I, p. $416 \mathrm{ff}$.) hat Strasbarger an dieser Stelle schon erheblich gemildert. 
torialplatte durch eine von den Polen ausgehende, abstossende Action gebildet werde, würde eben nur für diese einzelne Figur einen Erklärungsweg zeigen; während die Zuhülfenahme centrirender Attractionen, wie ich sie im Obigen angewandt babe, auch die Sternformen und selbst zum Theil noch die Knäuelformen mechanisch verständlich machen hilft (s. oben). - Ferner kann ich nicht zugeben, dass, wie S tras b u rger jetzt vermuthet (8, p. 286), bei der Bildung der "Kerntonnen“" das Kräftespiel ein ganz anderes sein sollte wie bei den „Kernspindeln". In dem Object z. B. meiner Fig. 13 u. 14 (Epithel, Salamandra), die nach Strasburger doch Kerntonnen wären, sind zwar die achromatischen Fäden nicht erkennbar, diese Figuren sind aber gewiss darum nicht specifisch verschieden von Fig. 12 (dasselbe Epithel, Salamandra), welche die achromatischen Fäden eben wahrnehmen lässt. Damit hat sie aber alle Requisite einer „Kernspindel"; es sind in ihr gewiss die gleichen wirkenden Kräfte anzunehmen, wie in Figur 23 - und, wie ich eben denken muss, in allen Kernfiguren dieser und anderer Phasen, ungeachtet äusserlicher Formunterschiede.

Ueber diese wirkenden Kräfte selbst wissen wir also noch nichts. Der Weg zu ihrer Erforschung aber wird, wie mir scheint, erleichtert durch die hier gegebene, genauere Darstellung der Morphologie des Vorganges. Es wird dadurch möglich, zunächst die Frage nach Sitz und Wesen dieser Kräfte exacter zu stellen, wie es bisher geschehen konnte. Es fragt sich:

1) Haben wir ein materielles Substrat dieser Kräfte in derjenigen Substanz zu suchen, welche zwischen den Kernfäden liegt?

oder 2): gehen die richtenden Kräfte in der Zelle vielmehr eigentlich von den Kernfäden selbst aus?

oder 3) : gehen dieselben vielleicht gar nicht von den Kernsubstanzen selbst, sondern vom Protoplasma der Zelle aus, und üben ihre richtende Wirkung auf die ersteren nur von Aussen? oder endlich 4): Wirken mehrere dieser Factoren, oder Alle, zugleich?

Wenn man die Annahme 1) zu Grunde legen will, so wurden die Kraftcentren in die achromatische Substanz zu liegen kommen, die zwischen den chromatischen Kernfäden bleibt, und welche, in Gestalt der achromatischen Fäden, ja auch einen morphologischen Bau besitzt. 
Unter der Annahme 2) ist es klar, dass die chromatischen Kernfäden sich nicht in allen ihren Abschnitten physikalisch gleichartig verhalten können. Dasselbe wird jedoch gleichfalls schon postulirt durch die Annahme 1). Mögen die Fäden in der Weise des Holzschnitts II typisch gerichtet werden, oder mögen sie selbst sich durch Anziehung und Abstossung richten, in beiden Fällen müssen sie dann je zur Zeit an den Winkeln anders beschaffen sein wie an den Schenkelenden. Man wollte einmal die Voraussetzung machen, die oben bei der Beschreibung der Einfachheit wegen zu Grunde gelegt wurde: es handle sich in Fig. 1. 2 jenes Holzschnitts um ein Centrum, das attrahirend auf die Winkel der Schleifen wirkt, abstossend auf ihre Schenkelenden, und das sich in Fig. 3. 4 ebenda in zwei getheilt babe, die nach den Polen rücken. Die Umlagerung der Fäden würde sich dann sehr einfach z. B. unter der Annahme darstellen: jeder Schleifenschenkel sei ein Magnet, der etwa seinen positiven Pol am Winkel, seinen negativen am freien Ende habe; und das hypothetisch gedachte Centrum sei ein negativer Magnetpol, der in 1. 2 im Centrum läge, in 3. 4 in zwei getheilt nach den Polen rückte. Unter der Voraussetzung, dass der Magnetismus des Centrums stärker wäre, als der der Fäden, wird ein Blick auf die Figur und die zngehörige Erläuterung im Text das hinreichend klar stellen. - Ich brauche wohl kaum zu bemerken, dass ich hiemit nicht eine magnetische Theorie der Zelltheilung aufgestellt baben will; aber man wird zugeben, dass es den Erscheinungen gegenüber in der That sehr nahe liegt, hier an Vorgiiuge electropolarer Natur zu denken, und dass sich damit eine Aussicht ergeben würde, dem Wesen der Zelltheilung auch von physiologischer Seite näher zu kommen.

Ich habe diesem Gedanken schon im Anfang 1879 in einem, im Kieler physiologischen Verein gehaltenen Vortrag kurz Ausdruck gegeben; in dem schon vorher entstandenen, und alsbald nachher erschienenen Werke von Herman Fol (6) ist derselbe, ganz unabhängig von meinen Arbeiten, ebenfalls für das Verständniss des Theilungsvorgangs herangezogen worden (v. a. a. 0.: La théorie électrolytique des mouvements protoplasmiques, p. $264 \mathrm{ff}$.). Da Fol sich in diesen Erörterungen wesentlich nur auf die Vorgänge im Protoplasma der Eizellen bezieht, die näheren Formveränderungen am Kern aber ihm bei der Abfassung noch nicht bekannt waren, so will ich ein Eingehen auf seine Ideen so lange ver- 
schieben, bis die Zahl der Ankntipfungspunkte sich vermehrt haben wird.

Wenn man eine Construction in obigem Sinne, also nach electrischen oder magnetischen Polaritäten, zu Grunde legen wollte, so würde offenbar die obige Annahme 1) vor 2) den Vorzug verdienen. Denn es wäre, Annahme 2) vorausgesetzt, sehr schwierig ein Verständniss dafiir zu finden, dass die Schleifenwinkel in je einer Tochterfigur, welche alle die gleiche Polarität haben, einander genähert bleiben, und ebenso dass die Enden der Schleifenschenkel, ebenfalls gleich-polar, sich einander in der Aequatorialplatte nähern. Unter der Annahme 1) dagegen, welche zuliisst, dass die Polarität der hypothetischen Richtungscentren die der Kernfäden an Kraft überwiegen mag, wären jene Umstände einfacher erklärbar.

Für die unter 3) und 4) aufgeführten Annahmen giebt es, so viel ich sehe, bis jetzt keinen bestimmten Anhalt; da aber nichts ihrer Möglichkeit im Wege steht, durften sie nicht unerwähnt bleiben. -

Es ist hier der Ort, auch den Versuch zur Erklärung der strahligen Plasmastructuren zu erwähnen, den Klein in seiner letzten Arbeit (12, p. 416-417) gemacht hat. Klein nimmt am ruhenden Kern einen Zusammenhang der Fäden des Kernnetzes mit Fädengerüsten im Zellplasma an ${ }^{1}$ ), und denkt, dass die Radiensysteme im Plasma bei der Zelltheilung entstehen, indem das Netzwerk des Kernes sich contrahire und damit die Netzfaiden des Zellplasma concentrisch zu sich heranziehe. Ich bin ebenfalls gewiss der Ansicht, dass die Strahlungen im Plasma und die Kernfigurenformen mechanisch mit einander in Beziehung stehen; ich habe dies früher (Th. I p. 421 ff.) schon hervorgehoben und dargelegt, dass offenbar die Muttersternfigur des Kerns im Ganzen dem Monaster im Plasma, die Sternformen der Tochterkerne dem Dyaster im Plasma entsprechen. Es ist aber auch ersichtlich, dass unter Bericksichtigung der Metamorphose des Kerns, und aller der hier beschriebenen Lageveränderungen der Kernfäden,

1) Wie auch Frommann. Ich möchte hier vorläufig wiederholen, dass ich einen solchen Zusammenhang keineswegs in Abrede stellen kann und will, aber bis jetzt nichts gesehen habe, was ihn positiv beweist. Näheres darüber in der Fortsetzung dieser Beiträge. 
die Erklärung der Strahlung im Plasma nicht in so einfacher Weise gefunden werden kann, wie Klein sie an jener Stelle sucht.

Wenn sonach das ganze physiologische Resultat dieses Abschnitts nur darin besteht, dass sich jetzt mehr Ordnung in unsere Kenntnisse bringen, und eine etwas genauere Fragestellung gewinnen lässt, wie früher, so mag das als ein sehr geringer Fortselritt erscheinen. Ich halte es aber für besser, mich zunächst hiermit zu begnügen, als irgend eine Hypothese aufuustellen, die vielleicht im Anfang Aufmerksamkeit finden wiirde, um nach einiger Zeit das dunkle Schicksal anderer zu theilen.

Das Ergebniss, auf das es mir für jetzt besonders ankommt, ist die Wahrung der Möglichkeit, den Zelltheilungsvorgang ibberall auf principiell und fundamental gleiche Ersehei nungen zurückzu führen, und damit der Annahme überall gleicher spielender Kräfte Raum zu lassen. Wenn es so grosse morphologische Verschiedenheiten gäbe, wie Strasburger und Andere dies noch annehmen, und mit der Voraussetzung gleicher wirkender Kräfte vereinbaren zu können glauben; so wïrde $\mathrm{m}$ ir die letztere Annahme unmöglich werden. Ich gebe sie aber nicht auf. Ich habe hier versucht zu beschreiben, was an meinen $\mathrm{Ob}$ jecten deutlich zu ersehen ist, und damit zu vereinbaren, was Andere gesehen haben, wenn letzteres auch zum Theil recht schwer and nur durch Vermuthungen möglich war. Ich überlasse es nun dem Leser zu urtheilen, ob er lieber fundamentale Verschiedenheiten annehmen, oder mit mir denken will, dass ein genauerer Einblick auch bei anderen schwierigeren Objecten noch Uebereinstimmungen mit dem Typus herausstellen wird, der hier dargelegt wurde.

Uebrigens bin ich ganz darauf vorbereitet, dass meine Angaben uber diesen Typus an vielen Stellen zunächst wenig Glauben finden werden. Namentlich betrifft dies die Schilderung der Scheidung der Kernfigur in ihre Tochterhälften, welche in diesem $\mathbf{A b}$ schnitt unter den Titeln : „Die Segmentirung der Kernfäden“ und: „Die Umordnung der Sternform zur Aequatorialplatte" gegeben ist. Ich sehe ja aus den neuesten oben besprochenen Arbeiten, dass die besten Beobachter unter meinen Mitarbeitern sich noch 
Beiträge zur Kenntniss der Zelle und ihrer Lebenserschcinungen. 233

nicht von der Annahme trennen können, dass erst in der Phase der Aequatorialplatte oder Kerntonne eine Trennung, eine Zcrreissung von vorher zusammenhängenden Elementen erfolgen mïsse, weil es an den relativ kleinen, oder sonst ungünstigen Elementen ihrer Objecte so aussieht. Da ich einen ziemlichen Theil dieser Objecte nachuntersucht habe, so darf ich mir das Urtheil erlauben, dass es dort zwar so aussieht, aber nicht so zu sein braucht, vielmehr ganz gut ebenso sein kann wie bei Salamandra. Deshalb sehe ich.ruhig den Zweifeln entgegen, die sich wahrscheinlich gegen die hier gegebene Darstellung erbeben werden. Es wird ja wobl einmal ein Untersucher mit der erforderlichen Sorgfalt die Kerntheilung bei Salamandra nachprüfen; dann wird er finden, was ich beschrieben habe - und ausserdem hoffentlich noch mehr nnd wird bestätigen miissen, dass meine Construction des Vorganges ibre hinreichende Begrïndung hat, so seltsam sie auf den ersten Blick Demjenigen erscheinen mag, der die Vorzüge dieses Objectes noch nicht aus eigener Anschauung und aus dem Vergleich mit anderen kennt.

Absehnitt 3 .

Ueber die Entwicklung der Samenfaden bei Salamandra.

Ich habe diesen Gegenstand im Sommer 1879 zur Untersuchung genommen, hauptsïchlich, um damit vielleicht etwas Neues iiber die Lebenerscheinungen des Zellkerns zu erfabren. Denn dass die Spermatozoenköpfe sich aus der Substanz von Zellkernen hervorbilden, kann man nach den vielen neueren Arbeiten über dies Thema wohl ausgemacht nennen. Wenn auch einige Untersucher ( . Ebner, Ne umann) der Ansicht sind, dass die Gebilde, welche die Köpfe liefern, durch eine freie Neubildung im Zellprotoplasma entstehen, so wird doch auch von ihnen den entsprechenden Gebilden die Natur von Kernen nicht direct abgesprochen.

Es fragte sich also für mich, was sich an den günstigen, grosskernigen Elementen von Salamandia iiber das Wesen des 
Vorgangs ergeben witrde, und $o b$ irgend eine Stütze für eine fre i e Kernbildung, im eben gedachten Sinn, sich finden liesse.

War Letzteres nicht der Fall - und das habe ich freilich a priori vermuthet - so ergab sich eine andere Frage. Wenn das Material, das die männliche Keimdrüse danernd oder periodisch neu zu liefern hat, nicht auf Grund freier Zellbildung, sondern nach dem bisher allein bekannten Modus, durch Zellth eilung entsteht, so mlissen sich hier massenhafte Zelltheilungen finden; und das wird auch gewiss von allen den Forschern, die eine freie Kernbildung hier nicht annehmen, vorausgesetzt. Aber unter allen den vielen und genauen Specialuntersuchungen, die über die Spermatogenese angestellt wurden, ist keine, in welcher sich indirecte Kernvermehrung bei Wirbelthieren in den Samendrïsengängen beschrieben findet '). v. la Valette $S$ t. George, bei dem man die Vermehrungsart der Hodenepithelien besonders nahe bericksichtigt findet, schildert sie durchans unter dem Bilde einer directen Kern- und Zellabschnürung. Kommt solche hier wirklich vor? Oder wenn nicht, was ist der Grund, dass bei den vielen Studien tiber den Gegenstand hier die indirecte Kerntheilung nicht schon massenhaft gesehen worden ist?

Dass sie hier im Hoden tiberhaupt sich findet, war mir von vornherein sicher durch eine Angabe von J. Spengel (26). Auf S. 31 dieses Werks beschreibt derselbe aus dem Hoden einer Coecilia rostrata eine Zelle mit einer sternförmigen, durch Hämatoxylin stark gefärbten Figur an Statt der Körner, und ferner von verschiedenen Gattungen (besonders Epicrium glutinosum, Taf. II l. c. Fig. 23 u. 32): „dass an einzelnen. Zellballen des Hodens fast sämmtliche Kerne in höchst eigenthümlicher Weise umgebildet waren: es fand sich an ihrer Stelle eine oft wunderbar gestaltete, in Hämatoxylin beinahe schwarz gefärbte Figur, die ich am Liebsten mit chinesischen Schriftzeichen vergleichen möchte." Es sind dies nach den Zeichnungen jedenfalls Kerntheilungsfiguren, durch die Aufbewahrung in Alkohol etwas verstlimmelt. Spengel selbst sagt weiter: „Da so umgewandelte Zellen sehr oft wiederkehren, in verschieden behandelten Präparaten, und stets massenhaft beisammen, so bin ich geneigt auch diese Bilder auf Zelltheilungen

1) Abgesehen von der gelegentlichen Angabe von Spengel (1. c.), die im Text alsbald zur Sprache kommt. 
Beiträge zur Kenntniss der Zelle und ihrer Lebenserscheinungen. 235

zu beziehen." Diese vorsichtige Ausdrucksweise ist dadurch erklärlich, dass zur Zeit der Abfassung (vor 1876) die ersten Angaben über Gewebszellentheilung (Strasburger, Mayzel 1875), dem Verfasser noch kaum bekannt sein konnten.

Ausserdem wissen wir ja schon durch Bütschli und Auerbach (Lit. siehe im I. Theil), dass bei Wirbellosen (Arthropoden), die Theilung der Spermatozoen-Keimzellen mit Fadenfiguren einhergeht ').

In der That habe ich denn auch gefunden, dass die Vermehrung der Hodenepithelkerne resp. Zellen von Salamandra, behufs der Samenfädenbildung, mit indirecter Kerntheilung verläuft. - Diese findet sich zur Zeit vor der Samenreifung in solchen Massen, dass es nicht motivirt ist, daneben noch an irgend einen anderen Theilungsmodus, etwa directe Kernzerschnïrung, zu denken; und ausserdem ergiebt sich kein positiver Befund, der für einen solchen andern Modus sprechen könnte.

Der Grund aber dafür, dass von diesen massenhaften indirecten Theilungen im Hodenepithel bei Wirbelthieren noch nichts bekannt geworden war, liegt grossentheils darin, dass dieselben sch ub w ei se, und auf kurze Zeiträume zusammengedrängt, verlaufen, in den (viel grösseren) Intervallen aber sistiren. Wer mit seiner Untersuchung in die Intervalle geräth, hat keine Aussicht, auch nur eine einzige Theilung zu finden $\left.{ }^{2}\right)$. Die Aufklärung hiertiber folgt am Schluss.

1) Während meiner Untersuchungen schrieb mir Mayzel, dass er sehr schöne Kernfiguren in den Hodenzellen von Raupen gefunden hat; ebenso dass er sich auch mit der Vermehrung der Hodenzellen bei Triton und Salamandra beschäftigt habe, doch sei es ihm hier noch nicht gelungen, alle typischen Theilungsfiguren aufzufinden.

2) Indem ich vermuthe, dass hierauf die negativen Befunde der Autoren grossentheils beruhen, mache ich allerdings den noch unbewiesenen, aber wahrscheinlichen Schluss, dass es sich hierin bei Raninen und Säugethieren ebenso verhält, wie bei Urodelen.

Ein weiterer Grund für jene negativen Befunde liegt aber auch in den bisher gebrauchten Reagentien. Kali bichromicum z. B. zerstört die Kernfiguren (Siehe Lit. 13). 
Während des April, Mai und Juni habe ich vergebens eine ziemliche Anzahl von Salamandramännchen getödtet; keine Theilung war im Hoden zu finden. In der letzten Hälfte des Juli traten dieselben in Menge auf, und waren dann bis gegen Ende September, doch in abnehmender Masse, anzutreffen. Gleichzeitig mit den ersten Theilungsschüben im Juli trat auch die erste Spermatozoenbildung auf, anfangs spärlich und bis gegen Ende September an Frequenz zunehmend 1). Aber beides findet sich auch dann keineswegs durch die ganze Geschlechtsdrüse gleichmässig verbreitet.

Die Hoden von Salamandra, Triton $u$. A, bestehen, wie durch die Untersuchungen von Leydig (21), Duvernoy (20) und S pengel (l. c.) bekannt ist, aus einer Reihe grösserer und kleinerer, an Aesten des Samenganges aufgereiliten Abschnitten oder Lappen, von verschiedener Farbe, die, entsprechend Leydig's Beschreibung l.c., etwa zwischen grau, weiss und blass-schwefelgelb wechselt. Es fällt auf, dass beiderseits nicht nur die Zahl der Lappen gleich, sondern auch die Grösse, Form und auch Farbe der symmetrisch gegeniiberliegenden nahezu eine und dieselbe ist. Ich muss mich Spengel in der Annahme anschliessen, dass diese segmentirte Form ,nur das Resultat complicirter Wachsthums-, Degenerations- und Regenerationsvorgïnge sei" (1. c. p. 65). Die verschiedene Farbe der Abschnitte aber ist jedenfalls bedingt durch den Entwicklungszustand der Driisenepithelien, wie dies schon Leydig erkannt hat (1. c. p. 74).

Leydig sagt an dieser Stelle von den jüngeren Entwicklungsstufen: „In den grauen Lappen haben die kurzen Driisenschlïuche keine Spermatozoiden, sondern sind von grossen, $0,0120 \mathrm{~mm}$ messenden Zellen angefïllt. Der Inhalt der Zellen ist blass, feinkörnig, der grosse Kern hat mehrere Nucleoli." - Es muss hiernach zufällig Leydig ebensowenig, wie einem anderen Beobachter bei Salamandra und Triton geglückt sein gerade einen Theilungsschub za treffen; denn sonst würden die massenhaften und

1) $\mathrm{Ob}$ diese Zeitverhältnisse an allen Orten und bei in Freiheit lebenden Thieren die gleichen sind, kann ich nicht sagen. Die von mir benutzten Salamander waren aus Prag, Tübingen und Heidelberg bezogen (einige schon überwintert, die meisten diesjährig), wurden in grossen Behältern mit Moos und Erde halb im Freien gehalten und mit Regenwürmern gefüttert. 
auffallenden Kerntheilungsfiguren hier gewiss von ihnen nicht unbemerkt geblieben sein.

Mein Präparationsverfaluren war: 1. Untersuchung des frischen Objects, Anschneiden des Hodenlappens, etwas Zupfen, Abstreichen der hervorquellenden Fliissigkeit auf das Objectglas, Eindeckung ohne Zusatz. 2. Ebenso, und Färbung anf dem Objectglas mit Bismarckbraun in Essigsäure gelöst "), oder ebenso, nach vorheriger Pikrin- oder Chrombehandlung, mit Hämatoxylin. 3. Schnitte vom in Alkohol abs. gehärteten Hoden, Färbung mit Carminalaun.

Was zunächst die ruhenden Epithelzellenkerne angeht, so ist Leydig's Aeusserung "sie hätten mehrere Nucleoli", wohl nicht wörtlich zu nehmen, sondern auf ihre sehr dichten und dickbalkigen Reticula zu beziehen (Fig. 37, 48 Taf. 3). Offenbar liegt das gleiche in der Abbildung Spengel's vor (l. c. Fig. 27, 28 Taf. II), obschon auch er nur Körner gezeichnet und ihrc Verbindung zu Netzen nicht beachtet hat ${ }^{2}$ ). Uebrigens sind die Balken nicht gleichmässig dick, sondern enthalten zahlreiche Knoten. -

Diese dichten, grobbalkigen Kernnetze scheinen eine allgemeine Eigenthümlichkeit der Hodenepithelien $\mathrm{z} u$ sein, auch bei Wirbellosen: ich verweise u. a. auf die Abbildungen von Grobben (Decapoden), Lit. Th. I.

Das Protoplasma der Hodenzellen kamn ich nicht eben feinkörnig nennen: frisch sieht es homogen aus und enthält einzelne, aus Fett oder Lecithinkörpern bestehende Körnchen, an Essigpräiparaten sieht man darin oft Streifungen, ähnlich wie sie im Plasma frischer Knorpelzellen vorkommen (Th. I, Taf. 15 Fig. 2 c).

In einem Hodencanalabschnitt ${ }^{3}$ ), der keine Theilungen hat, sind die Epithelzellen alle von etwa gleicher, und zwar bedeu-

1) Diese bequeme Kerntinction verdanke ich einer brieflichen Mittheilung von Mayzel. Die Präparate blassen leider in Glycerin nachträglich oft ab; im Anfang sind die Tinctionen schön und scharf. Die Bismarckbraunfärbung ist, wie bekannt, von Weigert angegeben.

2) Offenbar entsprechen wohl diesem Zustand der Kerne auch die $\mathrm{Ab}$ bildungen, welche v. la Valette in Fig. 5, 6 Taf, 34, Fig. 34, 35, 36 Taf. 35 giebt und als zweites Bildungsstadium der Spermatocyten bezeichnet.

3) Damit ist nicht ein ganzer Hodenlappen gemeint, sondern nur eine gewisse, variabel grosse Strecke seines Canalsystems. Ehe die Theilungen überhaupt beginnen, könmen aber allerdings selbst durch den ganzen Lappen hindurch die Elemente von gleicher Grösse sein. 
tender Grösse. Wo schon Theilungen geschehen sind, finden sich in verschiedenen Stufen $\mathrm{klei}$ ere Zellen resp. Kerne; und zwar immer solche von gleicher Grösse baufenweise bei einander. Und wo man Theilungen in flagranti findet, da liegen sie gleichfalls in grosser Ausdehnung haufen- oder nesterweise (s. Fig. 48 a), offenbar ganz dasselbe, was Spengel bei Epicrium glutinosum gesehen hat (L. c. Fig. 26).

Wie von la Valette St. George ${ }^{1}$ ) gefunden und ausfubrlich beschrieben hat, geschieht die Spermatogenese bei Anuren (Frosch, Kröte) in der Weise, dass die Hodenepithelzellen durch Kernvermehrung zu grossen Mutterzellen anwachsen, zugleich aber durch interne Zellenabgrenzung den Charakter von blossen vielkernigen Zellen verlieren. v. la Valette hat diese Gebilde passend Spermatocysten genannt, die Inhaltszellen, aus denen je ein Samenfaden entsteht, Spermatocyten. Er nimmt an, dass bei Triton und Salamandra ganz die gleichen Verhältnisse vorliegen.

In der That lässt sich das, was ich beschrieben und weiter zu beschreiben habe, mit diesen Angaben gut vereinigen. An frischen Zupfpräparaten sowohl von solchen Stellen, die noch keine Theilungen haben, als von solchen mit Theilungen, findet man zahlreiche mehr- und vielkernige Zellen wie in Fig. 49, beziebungsweise Zellen mit mehreren oder vielen Theilungsfiguren, wie in Fig. 50-52. Ich habe solche Schollen gesehen, die ïber 12 Kernfiguren der gleichen Phase fübrten; bis zu solchen Zuständen ist das Protoplasma der Zelle noch vielfach ein Ganzes, keine Abgrenzung im Zellenterritorium lässt sich darin sehen - ich bemerke, dass ich besondere Aufmerksamkeit auf diesen Punct verwandt habe, und dass die Abwesenheit von Zellengrenzen hier ganz leicht und sicher festzustellen ist, da die mehrfachen Kerne vielfach einander berùhren (Fig. 49). Bei stärkerer Kernvermehrung (und vielleicht auch manchmal schon bei geringerer tritt dann aber die Abmarkung von Zellenleibern ein. In jedem Zupfpräparat findet man als grösste Masse der vorhandenen Elemente zwar nicht Spermatocysten, sondern einzelne Zellen mit ruhenden Kernen oder Kernfiguren, wie sie die Figg. 36-47 zeigen; aber es steht natürlich der Annahme nichts im Wege, dass diese sämmtlich aus zerstörten, geplatzten Spermatocysten

1) Vierte Mittheilung etc., in diesem Archiv. 
frei geworden sind. Und der Befund an Schnitten von gehärteten Hoden bekräftigt es hinreichend, dass die gesammte Samenzellenvermehrung auch hier auf jenem von v. la Valette entdeckten Wege der endogenen Zellbildung vor sich geht. Die Schnitte zeigen, dass in der That jene Haufen oder Bezirke im Epithel der Canäle, die wie oben gesagt, Theilungen von gleichen Phasen, oder Kerne von gleicher Grösse führen (Fig. 48 T. 3), dem Inhalt je einer Spermatocyste entsprechen; man kann vielfach deutlich am Schnitt die kernhaltige Cystenmembran erkennen (Fig. 48) ${ }^{1}$ ).

Auffallend ist bei Salamandra nur die Grösse der Spermatocysten, die Massenhaftigkeit der Zellenvermehrung in ihnen: denn es kann hier als das Gewöhnliche gelten, dass eine Cyste es auf viele $\mathrm{Hu}$ derte von Tochterzellen bringt, während bei Anuren, wenigstens nach v. la Valette's Zeichnungen zu urtheilen, diese Zahl geringer bleibt.

Nur in einem wesentlichen Punct also differiren meine bisher besprochenen Befunde von denen v. la Valette's, und können zu ihrer Ergänzung dienen: er hat keine Bilder indirecter Zelltheilung gefunden, der Art wie die hier beschriebenen, sondern er lässt die Kerne sich durch Abschnürung („Furchung“, dies. Arch. Bd. 12 p. 820) theilen ${ }^{2}$ ) (viele seiner Figuren 1. c.). Dies beruht aber wohl nur darauf, dass v. la Valette gerade keine Theilungsschübe getroffen hat, vielleicht auch darauf, dass die Kernfiguren bei den kleineren Elementen seiner Objecte schwieriger zu erkennen sind. Als Vermuthung möchte ich es immerhin äussern, dass die eigenthümlichen Bilder der Kerne in einigen Cysten seiner Fig. 34 (Bómbinator) Kernfiguren entsprechen könnten.

Von den Eigenthümlichkeiten, welche die Formen der Kernfiguren in den Hodenzellen gegenüber anderen:Zellenarten zeigen, ist schon oben im Abschnitt 2 die Rede gewesen, auf den ich

1) Dagegen habe ich nicht feststellen können, dass an meinen Objecten ausserdem noch bindegewebige, radiär durch die Canäle ziehende Septa vorkämen, wie sie von la Valette bei Anuren gefunden und unter dem Namen Follikelhaut beschrieben hat.

2) Doch halte ich es für möglich, dass der Fig. 4 und Fig. 119 in von 1a Valette's neuester Abhandlung (Fünfte Mitth., dieses Archiv 1878, p. 261) indirecte Kerntheilungen zu Grunde gelegen haben; er deutet dieselben aber nicht in dieser Weise. 
hier verweise. Es mag nur noch besonders betont sein, dass der synchronische Verlauf der Theilungen aller Kerne oder Tochterzellen in je einer Mutterzelle oder. Spermatocyste zwar durchaus als die Regel anzusehen ist, daher eben die haufenweise Vertheilung gleicher Theilungsphasen; dass aber von dieser Regel doch auch zallreiche Ausnahmen vorkommen.

An den Hoden von Rana temporaria habe ich zum Vergleich einige Priifungen im Lauf des October vorgenommen, und auch hier bei einigen Thieren Stellen (resp. Cysten) mit indirecten Kerntheilungen gefunden, wenn auch bis jetzt nicht zahlreich. Es ist nicht zll zweifeln, dass es sich bei den Anuren mit den Theilungen ganz ähnlich oder grleich verhalten wird wie bei den Urodelen, da die ganzen Verhältnisse der Spermatocystenbildung in beiden Fällen doch wohl homolog sind. Ich habe es daher für iberflïsig gehalten, noch weiter bei Fröschen nach Theilungen zu suchen.

Ieh wende mich nun zu der Entwickelung der Samenfäden a us den Zellen der Cysten.

Zur Orientirung vorher einige Worte über die fertigen Samenfäden der Urodelen. Ihr Bau ist lange bekannt (Leydig, Lehrb. der Hist. u. a. a. O.), besonders genau von Schweigger-Seidel (23, 1865) bei Triton beschrieben: sie bestehen danach (Fig. 54 hier) ans dem lang spiessförmigen Kopf k, dem kurz cylindrischen Mittelstïck m und dem, mit undulirendem Kamm versehenen Schwanz (f). Schweigger-Seidel hat bereits gefunden, dass auf Essigsäurezusatz das Mittelstiick aufquillt und eine feine Membran sich vom Kopfe abhebt (l. c. Fig. B. 4, hier 54). Auch die Tinctionsfähigkeit bei Carminbehandlung hat Schweigger-Seidel geprüft, und festgestellt, dass das Carmin bei vorsichtiger Anwendung nur das Köpfchen des Samenkörpers, nicht Mittelstück und Schwanz färbt (p. 326) ${ }^{\mathfrak{l}}$ ).

1) Die Stelle auf Schweigger-Seidel's p. 315 a. a. O., nach welcher sich bei Triton das Mittelstück (b) gefärbt hätte, scheint mir ein Druckfehler zu sein, da er diese Sache sonst wohl auf p. 326 hätte crwähnen müssen. 
Er hat bei diesen Färbungen nach eigner Angabe viel Schwierigkeiten gehabt, und sie sind nur blass gerathen. Unsere heutige Tinctionstechnik macht die Sache leichter. Ich habe seit lange die gewöhnliche Färbung mit Methylviolett, oder anderen Anilinen in Cursen benutzt, um an Hodenschnitten zu zeigen, dass die Samenfädenköpfe Kernen entsprechen: sie färben sich damit brillant. Sehr branchbar ist dazu auch das Alauncarmin (Fig. 56 hier), mit Untersuchung in Wasser oder Glycerin: der Kopf allein ist scharf rosenroth gefärbt, das Mittelstück ganz nngefärbt, glänzend, Faden und Kamm blass und farblos.

Auf die weiteren Feinheiten im Bau der Samenfäden, welche an anderen Objecten von mehreren Forschern, besonders genau von Th. Eimer (24) studirt worden sind, habe ich hier noch nicht einzugehen, und wende mich nunmelr zu der Spermatogenese.

Es existirt, so viel mir bekannt ist, nur eine kurze Beschreibung und wenige Abbildungen v. la Valette's, welche den Vorgang der Samenfadenbildung bei Salamandra betreffen ${ }^{1}$ ). Es heisst dort: „Der Kern streckt sich.und wird zum Kopfe des Samenkörpers. Mehrfach sieht man ihn eingerollt in der Zelle. Seine äusserste Spitze bildet in der Länge von $0,008 \mathrm{~mm}$ einen vom übrigen Kopfe deutlich abgesetzten Anhang. Die zwei, von v. la Valette gezeichneten späteren Entwicklungsstadien der Fiden (l. c. Fig. VII, 5, 6) entsprechen im Ganzen der Fig. 55 a b c hier.

Uebrigens lässt er es möglich, dass das Mittelstück bei Urodelen nicht ganz dem bei Raninen entsprechen möge.

Während des Schreibens dieser Arbeit erhalte ich Nr. 76, October, des Quart. journ. micr. science, mit dem Aufsatz von Heneage Gibbes: Structure of the Vertebrate Spermatozoon. Der Verfasser beschreibt die bekannten, hier oben erwähnten Formeigenschaften der Urodelen-Samenfäden, wobei man eine Erwähnung der früheren Literatur, namentlich SchweiggerSeidel's, vermisst. Als neu hat Gibbes gefunden, was ich bestätigen kann, dass der Rand des undulirenden F'lossenkammes sich als ein verdickter, spiraliger Strang darstellt (filament, Gibbes). Bezüglich der Tinction findet der Verfasser, wie Schweigger-Seidel und ich (s. hier oben), dass das Mittelstück sich gegen Färbung nicht wie der Kopf, sondern wie der Schwanz verhält.

Die wichtigste, und höchst interessante Angabe von Gibbes ist jedenfalls die, dass die Samenfäden der Säugethiere ebenfalls ein ,filament“, also ein Homologon des Flossenkammes besitzen.

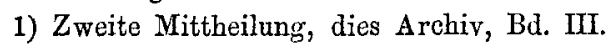


Die drei bei ihm dargestellten jungen Stadien dagegen (Fig. VII 2, 3, 4), die als „Zellen mit verändertem Kerne“ erläutert sind und nur einen nach und nach sich verlängernden Kern im Innern einer kleinen Zelle zeigen, enthalten nicht ganz das, was ich gefunden habe.

Man braucht im August und September nicht lange zu suchen, um auf Thiere zu treffen, in deren Hoden alle Bildungsstadien der Samenfäden neben einander vorliegen. Fig. 53 und 55 zeigt ibre Bilder vom frischen Präparat, ohne Zusatz; Fig. 57 nach Essigsäure-Bismarckbraun-Behandlung; Fig. 56 nach Fixirung mit Alkohol und Alauncarminfärbung.

Allerdings ist es mit der Samenzellenbildung in sofern gerade so wie mit den Theilungen, dass sich die Elemente einer Cyste fast alle im gleichen Stadium befinden; und der Leser könnte sich deshalb wundern, dass in den betreffenden Abbildungen die verschiedenen Entwicklungsstadien bunt durcheinanderliegen. Dafür ist zu berïcksichtigen, dass diese Bilder nach Präparaten gezeichnet sind, die von der frisch abgestrichenen Flüssigkeit aus dem angeschnittenen und zerzuptten Hoden, mit Fixirung und Färbung, auf dem Objectglas gemacht wurden: dabei gerathen natürlich vielfach die Elemente aus verschieden weit entwickelten Cysten durcheinander, und es sind gerade solche Stellen, die zum Zeichnen ausgesucht wurden.

Es fällt vor Allem auf, dass die Figur, die sich offenbar als die Bildungsgrundlage des Samenfadenkopfes ausweist (Fig. 53, 56 , 57), nicht ein Kern ist und nicht als solcher in der Zelle liegt, wie es v. la Valette's Figuren entsprechen würde; sondern der künftige Kopf ist eine Substanzportion des Kerns nnd liegt in diesem, umschlossen von der Kernmembran $\mathrm{km}$. Und weiter fällt es sofort auf, wenn man einen vergleichenden Blick auf die gefärbten Präparate wirft, dass dieser Körper, der zum Kopf wird, nichts anderes ist als die tingirbare Substanz des Kerns. Wie sich dieselbe sondert, zeigt am Klarsten die Fig. 57. Durch die Essigsäure und Farbe sieht man an den noch nicht in Umwandlung getretenen Kernen hier die sebr dichten, grobbalkigen Reticula scharfmarkirt; die jungen Köpfe sind an Masse und Quantität der Farbe, die sie anfnehmen, klärlich gleich mit der Substanz des Netzwerks; addirt mit der färbbaren Substanz, die noch in der Zwischenmasse des Kerns vertheilt, ge- 
steckt hat; sie selber sind in diesen ihren jüngsten Stadien netzförmig gebaut $(\mathrm{a} \mathrm{b} c)^{1}$ ) in den folgenden (d) verdichten sie sich immer mehr und verschmelzen endlich $(e, f)$ zu einer homogenen Masse. Bei solchen Reagentienwirkungen, wo die Reticula überhanpt nicht deutlich hervortreten ${ }^{2}$ ), s. Fig. 56, hat man ganz entsprechende Bilder: es sind hier die jungen Köpfe gerade ebenso, wie die noch unveränderten Kerne, scheinbar ohne Reticulirung; aber die Gesammintensität der Farbe zeigt sich auch hier grösser am jungen Kopf als am noch unveränderten Kern, und wiederum am gereiften Kopf grösser als am jungen.

Man braucht diese Bilder nur kurz anzusehen, um sofort den Schluss zu ziehen: es ist nicht der ganze Kern, sondern die tingirbare Substanz des Kerns, das Chromatin, was zum Samenfadenk opf wird.

Die Formen nun, welche der junge Kopf successiv annimmt, sind in Fig. 56 und 57 successiv gezeigt; es ist zuerst ein längliger und dabei umgeknickter, nicht rein cylindrischer Strang, der immer mehr in die Länge wächst, dabei dünner wird, und zugleich an Lichtbrechungsvermögen (und ebenso an Tinctionsfahigkeit) zunimmt. Je länger er wird, desto mehr windet er sich, und es entstehen dabei in den Stadien der Fig. 53 u. 57 c knäuelförmige Anordnungen, die den Knäuelformen bei der Zelltheilung (z. B. Fig. 36) sehr ähnlich sein können; man könnte sie fast mit solchen verwechseln, wenn nicht in Hodenabschnitten, bei denen die Samenfadenbildung schon im Gang ist, die Theilungen überbaupt ganz fehlten oder doch nur selten noch vorkämen.

Weiter liegt der immer schlanker gewordene Kopf in schön geschwungener Spiralanordnung innerbalb des Kerns: das dickere Ende ist das hintere (Fig. d, e, f u. a.).

Der Contour des Kerns, also die Kernmembran ( $\mathrm{k} \mathrm{m}$ ) ist in Stadien, wie Fig. $56 \mathrm{f}$, meist deutlich wahrnehmbar; von da ab getraue ich mir nicht mehr zu sagen, wo er geblieben ist. In Formen, wie $56 \mathrm{~g}$ und $57 \mathrm{~d}$, f sieht man zu beiden Seiten des Kopfes meist einen blassen, aber deutlichen Substanzstreifen entlanglaufen, so wie ihn die Zeichnungen angeben; es scheint mir dies aber sicherlich schon die Anlage des Schwanzes zu sein und

1) Bei a in Fig. 57 (rechts) ist der Buchstabe a vergessen.

2) Ich verweise zur Erläuterung dieser Wirkungen auf Th. I, p. $329 \mathrm{ff}$. 
ich muss mit den früheren Forschern annehmen, dass dieser aus dem Plasma der Zelle, nicht aus dem achromatischen Rest des Kerns entsteht. Den Verbleib dieses Restes möchte ich vielmehr anderswo suchen: wenn man zu dem reifen Samenfaden Essig: säure setzt, so hebt sich, wie Schweigger-Seidel fand, vom Kopf eine zarte, vorher unsichtbare Membran ab, die nicht tingirbar zu sein scheint. Ich möchte vermuthen, dass dies das Residuum der achromatischen Kernsubstanz ist.

Das Mittelstück des Samenfadens wird seit SchweiggerSeidel allgemein als ein Product der Zellsubstanz, nicht des Kerns angesehen; dafür besteht der gewichtige Grund, dass es sich bei Kerntinctionen nicht fürbt. Wer seine Entwicktung; einen jedenfalls wichtigen Punkt, habe ich noch nichts sicher ausmachen können. Der Vorgang kann kaum anders gedacht werden als in der Art, dass das dickere (dem ktinftigen Schwanze zusehende Ende des Kopfes (Fig. 57 bei c) mit dem Zellplasma jetzt in Verbindung tritt, und zwar in der Art, dass diese Verbindungsstelle (als „Mittelstück“) differenzirt bleibt. - Die Kernmembran ist an solchen Formen (wie eben an der Stelle Fig. $57 \mathrm{c}$ ) oft noch gut erkennbar, aber es ist nicht sicher zu entscheiden, ob sie an der betreffenden Stelle wirklich klafft, oder nur eine Falte macht.

Die fast reifen Samenfädenköpfe in meiner Fig. 55 - Formen, wie sie auch schon v. la Valette (a. a. 0.) bekannt waren - haben an variablen Stellen, oft an mehreren zugleich, seitlich blasse, plattenförmige Substanzreste ansitzen (s. v. la Valette's und meine Figuren), und ebensolche Substanz findet sich eingeschlossen von den spiraligen Windungen der Köpfe (ebenda). Es sieht am meisten danach ans, dass diese Substanz nicht dem Zellprotoplasma entstammt, sondern den Rest des Achromatins im Kern darstellt, welches nach und nach ganz zu der oben erwähnten, hyalinen Hialle des Kopfes verdichtet wird.

An diesen Stadien fällt noch ein, bisher unbeschriebenes Merkmal auf: auf das Mittelstick folgt gegen den Schwanz zu zunächst eine Verdïnnung, dann ein kleines, meist raub contourirtes Knötchen, das direct in den Schwanzfaden übergeht (Fig. 55 ab bei k). Die Verdūnnung ist nicht mit dem „Hals" der Samenfäden gleichzusetzen, welcher von Eimer (l. c.) bei anderen Objecten entdeckt wurde; denn dieser folgt direct nach hinten auf den Kopf, jene Verdiznnung aber auf das Mittelstiuck. - Uebrigens ist 
am reifen Samenfaden von Salamandra weder die Verdünnung noch das Knötchen mehr erkennbar.

Ueber die Bildung des Schwanzes und seines Flossenkammes habe ich bisher nichts mit Sicherheit ermitteln können; dass diese Theile aus dem Protoplasma des Spermatocyts gebildet werden ohne Mitbetheilignng der Kernsubstanz, lässt schon ihr negatives Verhalten gegen Kernfärbungsmittel schliessen. Denn das Achromatin des Kerns würde seiner Masse nach bei weitem nicht ausreichen, um jene Theile zu liefern; und ausserdem konnte ich ja den Verbleib des Achromatins anderswo finden.

Es scheint mir jedoch, dass der Schwanzfaden und Kamm in folgender Art entstehen: das Zellplasma faltet sich zwischen die Windungen, in die sich der Kopf legt, hinein, indem es sich so zu einem gleichfalls gewundenen Strange verdichtet, der nachher mit dem Kopf sich allmählig grade streckt. So liegt er denn zunächst neben dem Kopf entlang gelagert, sein freies Ende nach derselben Seite hin gekehrt, wie das des Kopfes (Fig. $55 \mathrm{~d}$ ) - eine Lage, - in der diese jungen Samenfïden in der That oft gefunden werden, wo sie nicht schon durch die Präparation verzerrt sind (in Fig. 55 a, b, c hat der Sehwanz zwar im Ganzen noch diese Lage, hat sich aber schon etwas daraus gelöst). - Dies entspräche auch dem Situs, den bei Bombinator igneus Kopf und Schwanz bleibend gegeneinander behalten (vergl. die Angaben Eimer's a. a. 0).

Was die späteren Entwicklungsstadien der Samenfüden, bez. Spermatocysten angeht, so habe ich die Ergebnisse v. laVa lette's ${ }^{1}$ ) nur zu bestätigen. Ich gebe in Fig. 58 noch einen Ueberblick von einem Hodenschnitt, welcher Durchschnitte mehrerer Cysten verschiedener Entwicklungsstufen zeigt; in jeder Cyste sind die Fäden alle ganz oder nahezu im gleichen Ausbildungsstadium.

Das wesentlichste allgemeine Ergebniss dieser Befunde lässt sich in Folgendem ausdrücken:

Man kann die Zelltheilung einen ungeschlechtlichen Fortpflanzungsprocess nennen. Bei ihr sondert sich das Chromatin des Kerns rom Achromatin, sammelt sich zu typisch geform-

1) S. dessen Mittheilung in dies. Arch. Bd, 12, Fig. 31, 32 u. a. a. 0. 
ten Figuren und scheidet sich in zwei Theile, die die Grundlagen der Tochterkerne abgeben.

Es giebt nun jedenfalls zu denken, dass, wie ich hier gezeigt habe, bei der geschlechtlichen Fortpflanzung, der Conjugation von Samenzelle und Eizelle, die Vorbereitung der ersteren za diesem Vorgang in der Hauptsache den gleichen Charakter trägt wie dort: auch hier eine morphologische Trennung des Chromatins, das offenbar den wesentlichen Theil, so zu sagen das Befruchtungsorgan des Samenfadens liefert, nämlich den Kopf, von dem Achromatin.

Es stellt sich damit von selbst die Frage, ob auch bei der Vorbereitung des Kerns der Eizelle, also bei der Reifung des Eies im Ovarium, sich eine entsprechende Scheidung beider Substanzen ausspricht ${ }^{1}$ ).

Was im Speciellen in meinen Befunden gegenüber denen $\mathbf{v}$. la Valette's (s. o.) abweicht, stelle ich hier nochmals kurz zusammen: Es ist nicht der ganze Kern, weleher sich streckt und zum Kopf wird, sondern der Kopf bildet sich im Kern, aus dessen Chromatin. Eine abweichende Beschaffenheit der äussersten Spitze des Kopfes konnte ich nicht constatiren. Die Zellenvermehrung im Hoden behufs der Samenbildung geschieht nicht mit directer Kerntheilung, welche iberhaupt noch nirgends nachgewiesen ist, sondern mit indirecter.

Vor langer Zeit hat Kölliker (19) angegeben, dass beim Meerschweinchen die in Bildung begriffenen Samenfäden spiralig aufgerollt im Innern der Bildungszelle lägen. Diese Angabe hat bisher yon Allen, die sich daruber äusserten, den directesten Widerspruch erfahren ${ }^{2}$ ). Ich habe über die Verhältnisse beim Meerschweinchen noch keine Erfahrung; merkwürdig und des Notirens werth ist es aber wohl gewiss, dass hier bei einer ganz anderen Wirbelthierform Bilder vorkommen ${ }^{3}$ ), die auf das Augenfälligste an das von Kölliker Beschriebene erinnern. Freilich ist dabei festzuhalten: das Spiralig-Aufgewundene ist hier bei

1) Hierauf gerichtete Arbeiten habe ich seit dem letzten Frühling, gemeinsam mit Hrn. Stud. Wiebe, unternommen und es wird darüber im nächstfolgenden Theil dieser Beiträge berichtet werden.

2) Vergl. w. A. Schweigger-Seidel, a. a. O.

3) z. B. meine Fig. $53 \mathrm{~d} \mathrm{e}, 56 \mathrm{~g}$. 
Salamandra nicht ein Samenfaden, sondern ein Samenfaden k o p f, und liegt nicht bloss in einer Zelle, sondern in einem Kern. Auch will ich hiermit nicht die Vermuthung aufstellen, dass ähnliche Verhältnisse, wie diese Spirallagerung, überall vorkämen, wogegen die Befunde Anderer wenigstens bis jetzt durchaus zu sprechen scheinen.

Eine Darstellung übrigens, welche für die Plagiosto men auf ein ähnliches Verhalten schliessen lässt, findet sich in dem umfassenden unter Nr. 25 d. Lit.-Verz. citirten Werke Semper's. In Fig. 14 seiner Taf. 17, und dem zugehörigen Text (s. p. 262 u. a.) beschreibt derselbe die jungen Formen der Samenfädenköpfe aufs Deutlichste als geschwungene Stäbcben. Auch sonst lassen sich meine Befunde in sehr Vielem mit denen Semper's in Homologie bringen; seine Ampullen sind offenbar gleichwerthig den Spermatocysten der Amphibien; Semper hat erkannt und in vielen Abbildungen dargestellt, dass der Inhalt einer solchen an Spermatozoen sich zur Zeit stets in gleichem Reifungsstadium befindet. Ueber die Vermehrung des Ampulleninhalts durch Zelltheilung finde ich bei ihm keine Angaben, die mit meinen Befunden in sichere Beziehung zu bringen wären, möchte aber vermuthen, dass die kleinen und eigenthumlichen Kernformen, die er in Taf. 17 Fig. 18 dargestellt hat, vielleicht dahin gehören; bei den ziemlich kleinzelligen Geweben der Fische wird das Detail der Formen schwer festzustellen gewesen sein. Auch das ist hervorzuheben, dass Semper die jungen Spermatozoenköpfe als deutlich in Bläschen eingeschlossen erkannt hat (p.262 unten, Fig. 18b). Er spricht diese Bläschen zwar als Zellmembranen an, vielleicht darf ich aber darin statt dessen die Kernmembranen erkennen und damit auch hierin unsere Befunde in Einklang bringen.

Im Uebrigen kann ich die vielen werthvollen Detailangaben, die in Bezug auf andere Thierformen über die Genese der Samenfadentheile vorliegen (Kölliker, v. la Valette, Ankermann, Schweigger-Seidel, v. Ebner, Merkel, v. Brunn, Neumann; Sertoli u. A.) hier ohne eigene Kenntniss der Objecte noch nicht in Vergleich ziehen; das geht auch obnedem aus ihnen hervor, dass an eine durchgreifende Uebereinstimmung in allen Einzelheiten für die ganze Wirbelthierreihe nicht zu denken ist. Dennoch, so gross auch die morphologischen Abwei- 
Walther Flemming:

chungen sind, glaube ich die Möglichkeit festhalten zu können, dass e in Princip sich überall wiederfinden lassen wird: die Scheidung der Kernsubstanz in die zwei Substanzen, die ich hier Chromatin und Achromatin genannt habe, und die Verwendung der ersteren, um den essentiellen Theil des Samenfadenkopfes zu bilden.

Ich habe mich ganz fern gehalten vom Eingreifen in dic Erörterung über die Spermatogenese, die besonders von v. la Valette, Merkel, v. Ebner, Ne umann und Sertoli während des letzten Jahrzehnts geführt worden ist; denn ich wäre mit der Untersuchung einer einzelnen Thierform dazu nicht berechtigt. Für diese Form: Salamandra, oder ich darf wohl gleich ohne Scrupel sagen: für die Urodelen - muss ich mich den letzten Angaben v. la Valette's in der Hauptsache, um die es sich bei jener Controverse bisher gehandelt hat, durchaus anschliessen: dass sich hier, wie bei seinen Objecten, durch Kerntheilung bez. Zelltheilung Spermatocysten bilden, deren Inhaltszellen dann je einen Samenfaden liefern. Es ist hierbei nicht ansgeschlossen, dass auch eine einzelne Hodenepithelzelle, ohne sich zu theilen, frei werden und sich irgendwo im Innern des Canals zu einem Samenfaden umbilden könnte. Ich finde an meinem Object nichts, was an die langgestreckten Spermatoblastenzellen anderer Autoren und an anderes von ihnen Gesehene erinnerte; aber ihre Beschreibungen sind viel zu präcise, als dass ich zweifeln könnte, dass ihnen richtige Beobachtungen zu Grunde liegen. Die grossen Abweichungen in der Form, auf welche diese Beobachtungen hinweisen, lassen aber meines Erachtens noch immer die Möglichkeit zu, dass das Princip der Spermabildung für alle Thierformen das gleiche bleibt und sich ïberall im Wesentlichen auf das Gesetz zarückführen lässt, das v. la Valette am Schlusse seiner fünften Mittheilung formulirt hat.

Jedenfalls kann ich nach dem vorliegenden Material nicht annehmen, dass ein Spermatozoenkopf sich auf andere Weise zu bilden vermag, als aus einem vorhandenen, durch indirecte Theilung entstandenen Zellkern. 
Beiträge zur Kenntniss der Zclle und ihrer Lebenserscheinungen. 249

Ich bin endlich noch Rechenschaft schuldig für die Angabe (s. oben), dass die Theilungen der Hodenepitheiien bei Salamandra, und wahrscheinlich wohl auch anderswo, schubweise eintreten. - Dieser Schluss gründet sich auf Folgendes:

Wo man bei einem Salamander an irgend einer Stelle eines Hodenlappens Theilungen gefunden hat, da finden sie sich auch in ziemlich ebensogrosser Zahl an anderen Stellen durch den ganzen Lappen vertheilt; und ebenso in anderen Lappen von gleicher Farbe beim selben Thier, auch auf der anderen Seite.

Wo man umgekehrt bei der ersten Probe keine Theilungen findet, da wird man fast immer bei demselben Thier anch weiter vergeblich danach suchen.

Nun finden sich aber Thiere mit Theilungen und Thiere o hne Theilungen stets nebeneinander während der ganzen Zeit von Juli bis Ende September ${ }^{1}$ ). Ich habe immer sofort, wenn ich ein Thier mit Theilungen fand, noch einige andere untersucht, um zu sehen ob nunmehr vielleicht allgemein die Zellvermelrung im Gange sei; aber es fanden sich sowohl im Juli, als August, als auch gegen Ende September auch solche ohne Theilungen, und zwar ziemlich in gleicher Zahl wie die anderen.

Man kann aber nicht annehmen, dass die Thiere, bei denen man keine Theilungen gefunden hat, überhaupt an Samenfäden steril geblieben wären: denn es fand sich um Anfang October bei allen (7) Männchen, die ich um diese Zeit untersuchte, Sper matozoenbildung; und angesichts der Masse der dann gebildeten Spermatozoenköpfe, uiberhaupt der gewachsenen Grösse der Hodenlappen, ist nothwendig anzunehmen, dass überall bei diesen Thieren vorher eine starke Kern- bez. Zellvermehrung vor sich gegangen sein muss.

Nach dem Allen scheint die Annahme unmöglich, dass bei einem Thier, bei dem die Theilungen einmal begonnen haben, dieselben nun ohne. Unterbrechung fortliefen, bis die Spermatozoenbildung beginnt; es müssen vielmehr Pausen in den Theilungen angenommen werden.

Doch sind diese Pausen in der genannten Zeit bei Salamandra nicht so lang, dass man nicht im Ganzen doch bei jedem

1) Nur während der Zeit vom 22. August bis 15. September habe ich mit der Untersuchung pausirt. 
zweiten oder dritten Thier auf Theilungen träfe. Wenn es bei Anuren ebenso ist, so kann man fragen, warum die Untersucher beim Frosch nicht schon längst die wahren Zelltheilungen gefunden haben. Dafür ist nicht zu vergessen, dass bei der geringeren Grösse der Elemente die Kernfiguren hier nicht so leicht zu erkennen sind. Ich habe, wie oben erwähnt, solche bei Rana temporaria gefunden; ich glaube aber selbst, dass sie mir entgangen wären, wenn ich vorher nicht die Formen der indirecten Kerntheilung an grösseren, giinstigeren Objecten kennen gelernt hätte ${ }^{1}$ ).

Der nächste Theil dieser Beiträge wird iuber weitere Ergebnisse bezüglich der Structur von Zelle und Kern, ferner über die Entwicklungsgeschichte und den Bau des Ovarialeies berichten.

\section{Bemerkungen zur Technik.}

Bei fortgesetzter Vergleichung habe ich immer wieder bestätigt gefunden, dass die von mir bisher gebrauchte Pikrin- und Chromsäure, mit nachfolgender Hämatoxylin- oder Anilinfärbung, für Wirbelthierzellen (auch Säugethiere) vor dem Alkohol u. a. Reagentien Vorzüge hat. Dass man auch mit ersteren Mitteln oft Schrumpfungen und Verzerrungen (mit Pikrinsäure zuweilen auch andererseits Quellungen) der Kernfiguren und ruhenden Kerne bekommt, geht schon aus meiner Darstellung hervor; durch die andern Reagentien geschieht dies aber noch häufiger und stärker, namentlich der Alkohol hat Neigung, die Fäden in allen Phasen mit engerer Lagerung zusammenzuklumpen. - Essigsäure bewirkt oft das.Gleiche und lässt die Kernfäden oft etwas aufquellen, wodurch namentlich die Doppelstrahlen unkenntlich werden können.

Doch habe ich zur Bequemlichkeit vielfach jetzt auch angewendet: 1) directe Färbung des frischen Objects mit Essigsäure-Bismarckbraun nach Mayzel (s. oben, Hodenzellen; jetzt auch von Peremeschko benutzt). Die

1) Ausserdem aber werden die Kernfiguren gerade durch die Reagentien, welche leider für die genannten Arbeiten meistens benutzt wurden Chromkali, Osmium - zerstört oder undeutlich. 
Beiträge zur Kenntniss der Zelle und ihrer Lebenserscheinungen. 251

Präparate blassen bei Aufbewahrung in Glycerin leicht ab, sind aber Anfangs sehr brauchbar. 2) Präparate aus Alkohol, Färbung mit Alauncarmin nach Partsch ${ }^{1}$ ), Darstellung nach Grenacher ${ }^{2}$ ). 3) Färbung von Pikrin- oder Alkoholpräparaten mit Picrocarmin. Letzteres macht oft Quellungen, besonders wenn nicht ganz neutral.

Wo man Zeit ersparen will, und es nicht darauf ankommt, Kerntheilungen möglichst schön zu erhalten, sondern nur ihre Hauptformen festzustellen, können alle diese Methoden dienen. Die Anilin- und Hämatoxylinfärbungen erfordern, wie früher (Th. I) gesagt, ziemliche Sorgfalt, und die letzteren gerathen mir nur dann recht schön, wenn ich sehr langsam mit sehr dünnen Lösungen färbe und öfter probire, um Ueberfärbung zu vermeiden. Doch würde ich immer nur die letzteren Behandlungen wählen, wo es auf feineres Studium der Karyokinesis abgesehen ist.

Am Amphibienhoden habe ich bisher bei Härtung mit Chromund Pikrinsäure nur schlechte Erfolge gehabt; beide härten ihn nicht genug, machen sehr störende Gerinnungen in der Zwischenflüssigkeit, und öfter wie anderswo Schrumpfungen der Kernfiguren. Mit Chrom- oder Pikrinbehandlung des frischen Hodenpräparats auf dem Objectträger nebst Färbung bekommt man jedoch gute Erfolge (s. Fig. 42 bis 47 Taf. 3), man muss sich nur vor Ueberfärbung hüten.

Bei Pflanzenzellen gerathen alle gebräuchlichen Kernfärbungen besonders leicht und intensiv, die mit Hämatoxylin (nach Chrom-, Pikrin- oder Alkoholbehandlung) meistens so dunkel, dass sie für feincre Studien schlecht brauchbar sind. (Weiteres s. oben bei: Pflanzenzellen, Abschn. 1.)

In einer während des Druckes d. Beitr. erschienenen Abhandlung ${ }^{3}$ ) spricht A. Brandt in einer persönlichen Bemerkung sein Bedauern darüber aus, dass ich im I. Theil zwar zwei seiner Arbeiten citirt habe, einer Analyse derselben aber ausgewichen sei.

Ich habe die Arbeiten Brandt's, gleich vielen anderen, welche das $\mathrm{Ei}$ und die Eitheilung betreffen, dort lediglich deshalb ${ }^{4}$ ) nicht analysirt, weil jener Theil meiner Schrift sich zunächst mit Zelltheilungen in Geweben beschäftigen wollte. Es war naturgemäss, die Besprechung jener Literatur auf den folgenden Theil meines Arbeitsplanes zu verschieben, der selbst specieller mit der Eizelle zu thun haben wird. Dies war mit Bezug auf die Arbeiten

1) Dies Archiv, Bd. 14, 1877, p. 180.

2) Ebenda Bd. 16, 1879. Für Curszwecke finde ich die Methode besonders bequem und empfehlenswerth.

3) A. Brandt, Commentare zur Keimbläschentheorie des Eies. II. Dies. Arch. Bd. XVII, Heft 4. 1880, p. 571.

4) Th. I, p. 398 Anmerkung, p. 400. 
Brandt's um so mehr motivirt, als ich dieselben nicht besprechen kann, ohne ihnen in Manchem ausführlicher entgegenzutreten; ich erinnere nur daran, dass Brandt den Kern des Eies als eine amöboide "primäre Zelle“ betrachtet, die Gerüste in Zellkernen als „Verzweigungen des Kernkörperchens" ansieht, die Theilungsmetamorphose des Kerns auf "amöboide" Bewegungen ${ }^{1}$ ) zurïickführt. Wer meine Ergebnisse über den Kern im Th. I p. 356, 357 ff., und hier im Abschnitt 2 berücksichtigen will, wird daraus schon ersehen, dass ich die betreffenden Anschauungen $B$ randt's nicht theilen kaun, und seinen Ausspruch: „dass meine Wahrnehmungen so zu sagen eine Brücke zu seiner Amöboidtheorie bildeten" ablehnen muss. Die nähere Motivirung dafür habe ich aber erst an dem Ort zu geben, wohin sie dem Gegenstand nach gehört.

\section{Citirte Literatur}

auf deren Nummern im Text verwiesen ist.

\section{A. Ueber Zelltheilung.}

(Nach der Reihenfolge der Publication. Frühere Lit. siche unter Nr. 4.)

1. Beneden, E. van, La maturation de l'oeuf cc. des mammifères. Bull. de l'acad. roy. de Belg. 2. Sér. t. 40, 1875.

2. C. J. Eberth, Ueber Kern- und Zelltheilung. Virchow's Archiv, 1876. S. 523.

3. W. Schleicher, Die Knorpel-Zelltheilung. Dies. Archiv. Bd. 16, p. 248, Dec. 1878.

Dec. 1878.

4. W. Flemming, Th. I dieser Beiträge, dies. Arch. Bd. 16, p. 302 .

5. Peremeschko, Ueber die Theilung der thierischen Zellen. Dies. Arch. Bd. 16, 1879.

6. Fol, Herman, Recherches sur la fécondation et le commencement de l'hénogénie chez divers animaux. Genève 1879.

7. E. Klein, Observations on the Structure of Cells and Nuclei, II. Quart. Journ. of micr. Science. Vol. 19. N. S., 1879.

8. E. Strasburger, Neue Beobachtungen über Zellbildung und Zelltheilung. Botan. Zeitung Nr. 17 und 18, 25. April 1879.

9. E. Klein, Ein Beitrag zur Kenntniss der Structur des Zellkerns und der Lebenserscheinungen der Drüsenzellen. Centralbl. f. d. med. Wiss. Nr. 17, 26. April 1879.

1) Vergl. hier p. 155 unten ff. 
Beiträge zur Kenntniss der Zelle und ihrer Lebenserscheinungen. 253

10. W. Flemming, Zur Kenntniss der Gerüste im Zellkern und ihrer Veränderung durch chromsaure Salze. Centralbl. f. d. med. Wiss., Nr. 23, 18. Mai 1879.

11. W. S chleicher, Nouvelles communications sur la cellule cartilagineuse vivante. Bull. de l'acad. roy. de Belg. 2. Sér. T. 47. Nr. 6, Juin 1879.

12. E. Klein, On the glandular epithelium and division of nuclei in the skin of the newt. Quart. Journ. of micr. science, July 1879.

13. W. Flemming, Ueber das Verhalten des Kerns bei der Zelltheilung, und über die Bedeutung mehrkerniger Zellen. Virchow's Arch., Bd. 77, März 1879.

14. E. Strasburger, Ueber ein zu Demonstrationen geeignetes Zelltheilungsobject. Sitz.-Ber. der Jenaischen Ges. f. Med. u. Nat., 18. Juli 1879.

15. Schmitz, Sep.-Abdr. a. d. Sitz.-Ber. der niederrheinischen Ges. $f$. Natur- und Heilk. in Bonn, 4. Aug. 1879: Mehrkernige Zellen und Zelltheilung bei Thallophyten. Eine frühere Mittheil. desselben Autors schon vom 5. Mai 1879 , ebenda.

16. Peremeschko, Ueber die Theilung der rothen Blutkörporchen bei Amphibien. Centralbl. f. d. med. Wiss., Nr. 38, August 1879.

17. M. Treub, Sur la pluralité des noyaux dans certaines cellules végétales. Comptes rendus, 1. Sept. 1879.

18. Peremeschko, Fortsetzung von Nr. 5, dies. Arch., Bd. 17, 1879.

Nachtrag: J. Arnold, Beobachtungen über Kerntheilungen in den Zellen der Geschwülste. Virchow's Archiv, Bd. 78. (Erschien nach Abschluss dieser Arbeit, wird, als in vielen Puncten wichtig, im nächsten Theil näher besprochen werden.)

\section{B. Ueber Entwicklung der Samenfäden.}

19. Kölliker, Beiträge zur Kenntniss der Geschlechtsverhältnisse und der Samenflüssigkeit wirbelloser Thiere, nebst einem Versuch über das Wesen und die Bedeutung der sogenannten Samenthiere. Berlin 1841.

20. Duvernoy, Fragments sur les organes génito-urinaires etc., 3. fragment. Mém. prés. par divers savants à l'Académie des sciences. 1851.

21. Leydig, Untersuchungen über Fische und Reptilien.

22. v. la Valette St. George, Ueber die Genese der Samenkörper. Fortlaufende Arbeiten in diesem Archiv: 1. Mittheilung Bd. 1, p. $403 \mathrm{ff}$; 2. Mittheilung Bd. 3, p. 263; 4. Mittheilung Bd. 12, p. 797; 5. Mittheilung Bd. 15, p. 261.

23. Schweigger-Seidel, Ueber die Samenkörperchen und ihre Entwicklung. Dies. Arch. Bd. 1, p. 309.

24. Th. Eimer, Untersuchungen über den Bau und die Bewegung der Samenfäden. Phys.-med. Gesellsch. in Würzburg, N. F., Bd. 6. 
25. C. Semper, das Urogenitalsystem der Plagiostomen und seine Bedentung für das der übrigen Wirbelthiere. Arb. a. d. zool.-zoot. Institut in Würzburg, 1875.

26. Spengel, Das Urogenitalsystem der Amphibien. Arbeiten a. d. zoolog.-zootom. Inst. in Würzburg. III.

27. E. Neumann, Untersuchungen über die Entwicklung der Spermatozoiden. Dies. Archiv, Bd. 11, p. 292.

28. Grobben, Beiträge zur Kenntniss der männlichen Geschlechtsorgane der Decapoden. Wien, Hölder, 1878.

Nachtrag: Heneage Gibbes, Structure of the vertebrate spermatozoon, Quart. journ. micr. science Nr. 76, 1879.

Veigmann, Beiträge zur Natur-Geschichte der Daphnoiden. Zeitschr. f. wiss. Zool. 1879. (Enthält Manches hier in Betracht kommende; konnte, wie andere Literatur über Wirbellose, hier noch nicht analysirt werden.)

\section{Erklärung der Abbildungen auf Tafel VII, VIII, IX (1, 2, 3).}

Für alle Zeichnungen gilt Folgendes:

1. Sie sind mit Hartnack Syst. 7, 8, 9 à imm., Zeiss 1 und 2 à imm., gezeichnet und zur Verdeutlichung meistens etwas vergrössert dargestellt.

2. Ueberall soll durch die hellere oder dunklere Schattirung an den $F \ddot{a ̈ d e n ~ d e r ~ K e r n f i g u r e n ~ a u s g e d r u ̈ c k t ~ s e i n, ~ d a s s ~ d i e ~ v e r s c h i e d e n ~}$ schattirten Strecken in verschiedenen Ebenen liegen (meistens: die bei tieferer Einstellung gesehenen Theile hell er gehalten).

3. Wo im Verlauf oder an den Enden von Fäden gleich grosse dunkle oder helle Punkte oder $\mathrm{Kr}$ eise dargestellt sind (beispielsweise: Taf. I Fig. 1 b, Fig. 2, 11, 12), da bezeichnen dieselben nicht Körner oder Kernkörperchen, sondern optische Quer- oder Schrägschnitte von Fäden.

4. Die dunkle Schattirung der Kernfadenfiguren entspricht überall der Tinction; in Fig. 35 Taf. 3 (nach dem lebenden Präparat) sind, um Fehler bei der Lithographie auszuschliessen, die Fäden ebenfalls dunkler gegeben als sie in den blassen lebenden Kernfiguren aussehen.

5. Wo in den Figuren der eine Schenkel oder Theil einer Fadenschleife kürzer und dunkler gezeichnet, ist die Kürze nicht reell zu nehmen, es soll dadurch nur ausgedrückt sein, dass der betreffende Theil in optischer Verkürzung gesehen ist.

6. Das Zellplasma ist überall nur schematisch gehalten. 
Tafel VII (1).

(Bitte die Holzschnitte im Abschnitt 2 za vergleichen.)

(Alle Abbildungen von Salamandra).

Fig. 1. a: Ruhender Epithelzellenkern, aus einer Gegend, wo zahlreiche Theilungen vorlagen. Von den Bälkchen des Gerüstes sind nur diejenigen gezeichnet, die bei nahezu der gleichen Eiustellung zu sehen waren.

b: Ein Anfangsstadium der Theilung, mit drei noch erhaltenen Nucleolenresten. Zwischensubstanz des Kerns schon nicht mehr tingirbar. Auch hier nur etwa die Hälfte der sichtbaren Fadenwindungen gezeichnet. - Alle anscheinenden Körner sind optische Querschnitte ausser den drei Nucleolen.

Fig. 2. Ein Kern, der durch den Schnitt zerbrochen ist; man sieht unten in der Figur nur die untere Wand der Kernfigur, oben, an der Spitze, ist sie ganz geblieben. Man kann so im unteren Theil der Figur jeden einzelnen Faden sehr klar verfolgen. Vergrössert dargestellt.

Das Stadium ist um Weniges weiter, wie das der vorigen Figur in b. Zeigt deutlich (auch mit Seibert XI à imm. controlirt), dass kein einziges Korn, sondern nur gewundene Fäden da sind. Da diese vielfach abgebrochen, glaubt man freie Enden zu sehen, solche sind aber sicher nicht vorhanden gewesen, denn im oberen, noch ganz erhaltenen Theil der Figur ist keine einzige Unterbrechung; die Stellen, an welchen hier Fäden als aufhörend gezeichnet wurden, sind solche, an denen dieselben senkrecht in die Tiefe biegen, wo sich jeder weiter verfolgen lässt. Dies konnte der Deutlichkeit $z$ L Liebe nicht mitgezeichnet werden.

Fig. 3 und 4. Kernfiguren in ähnlichen Knäuelstadien, Fig. 4 etwas weiter, schon mit deutlichen Unterbrechungen, mit noch sichtbarer Kernmembran.

Fig. 5. Ein Knäuel schon durchweg in Schleifen segmentirt, in Auflösung.

Fig. 6 und 7. Ebenso, dabei (als nicht regelmässige Erscheinung) Sonderung der Fäden in zwei etwa gleiche Gruppen, die aber nicht direct zur Theilung führt; es würde vielmehr Stern und Aequatorialplatte folgen (s. Folgende Figuren).

Fig. 8. Sternform, in der einige (3) Schleifen zeitweilig abgerückt sind.

Fig. 9. Locker angeordnete Sternform, zugleich Längsspaltung der Fäden. Die bei höherer Einstellung sichtbaren Fädentheile sind dunkler dargestellt. (Ist in der Lithographie nicht gehörig ausgedrückt.)

Fig. 10, 11. Auf die Sternform folgend, Aequatorialplatten.

Fig. 12. Ebenso, etwas stärker vergrössert dargestellt: an den Polen sieht man achromatische Fäden, doch sehr blass, hervorragen - am 
unteren Pol nur eben erkennbar. - Die dunklen Kreise entsprechen überall optischen Quer- und Schiefschnitten von Fäden; Körner sind nicht vorhanden, wie überhaupt in keiner der Figuren der Tafel.

Fig. 13 und 14. Aequatorialplatten mit einzelnen etwas abgerückten Schleifen.

Fig. 15. Schematische Figur, den Bau der auf die vorige folgenden Form (Kerntonne) erläuternd.

Fig. 16. Eine dreikernige Epithelzelle mit eben erfolgter Kerntheilung (drei Paar Tochtersterne).

\section{Tafel VIII (2).}

Fig. 17-26: Theilungen von Pflanzenkernen, 17-19 von Nothoscorodon fragrans, die übrigen von Allium odorum.

(Alle nach Tinctionspräparaten, die Kernfiguren sind überall in der Intensität gefärbt zu denken, wie in Fig. 25-26. Alkohol-Alauncarmin.)

Fig. 17. Ruhender Kern aus dem Endosperm.

Fig. 18. Mutterknäuel ebendaher, Nucleolen hier noch vorhanden.

Fig. 19. Früheres Anfangsstadium; erscheint körnig, bei gutem Licht sind jedoch Fäden zu sehen und lassen sich die sämmtlichen scheinbaren Körner als optische Schnitte von Fäden annehmen (vergl. Fig. 1 b und 2 Taf. 1, Fig. 2 c Taf. 17 Th. I).

Fig. 20. Ein etwas weiter vorwärts liegendes Stadium; hier ist die Deutung der anscheinenden Körner als optische Schnitte ganz einleuchtend.

Fig. 21. Sternform von Allium (wie die folgenden aus der Peripherie des Fruchtknotens). Ein Theil der Fäden mit deutlicher Spaltung; diese ist nur bei denjenigen gezeichnet, wo sie ganz unzweifelhaft zu sehen war.

Fig. 22. Flache Sternform ebendaher, an den Enden tritt die achromatische Fadenspindel hervor. (Die dunkel gehaltenen Fadenenden sind die in optischer Verkürzung, also von oben gesehenen; die Fäden liegen etwas gebogen.)

Fig. 23. Aequatorialplatte von Allium (vergl. vor. Tafel und den Text unter: Pflanzenzellen, Abschn. 1). Das Element links oben ist wahrscheinlich eine abgerückte Fadenschleife (vergl. Fig. 43-45, Fig. 13); es ist klar erkennbar, dass nur Fäden und nicht Körner vorliegen, im Uebrigen sind die Verhältnisse so dargestellt, wie sie zu sein scheinen, denn die Kernfigur ist um ein Drittel kleiner wie diejenigen in Fig. 10-14 Taf. 1, wo gerade noch das Gezeichnete klar erkennbar ist.

Fig. 24. Tochtersterne von Allium. Liegen schief übereinander, bei verschiedener Einstellung sichtbar.

Fig. 25. Allium, kurz nach der Trennung der Kernfigur. Achromatische Fadenspindel sowohl in der Mitte, als an den Polen sichtbar. 
Beiträge zur Kenntniss der Zelle und ihrer Lebenserscheinungen. 257

Fig. 26. Ebenso, etwas späteres Stadium: die Tochtersterne von Hacher und gehöhlter Form, man sieht in die Höhlung der unteren hinein. Bestehen ganz aus distincten, unverschmolzenen Fäden.

Fig. 27, 28, 29 vom Mundepithel der Krötenlarve, Chrom-Saffranin. 27 Mutterknäuel, Seibert imm. XI; 28 Tochterknäuel, Hartnack 9 imm. 3; 29 Tochterknäuel, in denen die Fäden durch Reagentienwirkung conglutinirt sind, so dass sie wie homogene Ballen erscheinen.

Fig. $30 \mathrm{a} \mathrm{bc}$. Theilungen von Bindesubstanzzellen im Omentum des saugenden Kätzchens, worin massenhafte Theilungen; a aus einer Fettanlage; Essigsäure-Alkohol-Hämatoxylin; d. Bindesubstanzzelle in Theilung (Tochtersterne) aus dem Amnion des Kaninchens; dies enthielt hier und im Epithel zahlreiche Theilungen in den verschiedensten Phasen.

Fig. 31-34. Skizzen von Eizellen theilungen zum Vergleich (nach Präparaten von H. Fol, von Toxopneustes lividus, Osmium Carmin). 34 wïrde der Aequatorialplatte entsprechen (Fig. 10-14 vor. Taf.), 31 der Trennung bezw. weiter: Sternform der Tochterkerne, 32 und 33 der Knäuelform der Tochterkerne (vergl. Fig. 15b, 28).

Folgende Figuren: Nachträge zu Taf. I, von Salamandra, Epithel.

Fig. 15 a: Aequatorialplatte mit theilweise geschlängelten und unregelmässig gelagerten Fäden.

Fig. 15 b: Zelltheilung, wie immer während der Knäuelphase der Tochterkerne (vgl. Fig. 28, 32); man sieht hier am Einschnürungshals cine sehr zarte helle Marke, darin äusserst feine Elemente gleichmässig vertheilt (entsprechend den Zellplattenelementen Strasburger's?).

Fig. $15 \mathrm{c}$ : Tochtersterne kurz nach der Trennung, das Paar etwas schief gcsehen: deutliche polar-centrale Umbiegungen.

Fig. $15 \mathrm{~d}$ : Ebenso, etwas später; ebenfalls schrägliegend. Vom Pol gesehen, würde der obere Kern als Ring mit freier Mitte erscheinen, doch an der einen Seite (oben) nur schwach geschlossen durch eine einzelne Fadenschleife; der Ring des unteren Kerns nicht geschlossen, würde bei Polansicht Hufeisenform haben. Vies wird oft gefunden.

Beide Figuren zeigen, dass die Existenz von isolirten $\mathrm{F}$ adenschleifen aus der Aequatorialplatte bis in diese Sternform fortdauert (Vrgl. die Holzschnite im Abschn. 2).

\section{Tafel IX (3).}

Aus den männlichen Keimdrüsen von Salamandra, Juli, August, September.

Fig. $35 \mathrm{ag}$ : Lebend verfolgte Theilung einer Hodenepithelzelle (aus Spermatocyste) frisches Präparat ohne Zusatz. Die Fäden der Deutlichkeit 
halber dunkler dargestellt, als sie lebend erscheinen. Von a bis $\mathbf{g}$ verlief nahezu eine Stunde.

Die isolirt abgerückten Fadenschleifen in a am oberen Pol sah man sehr langsam abgerückt und wieder herangezogen werden; dann die in b am unteren $\mathrm{Pol}$ ebenso abrücken, waren in $\mathrm{c}$ wieder vollständig einrangirt. d verlängerte sich etwas und führte dann rasch zur Trennung über (e). Nach $g$ starb die Zelle ab, nachdem eben die Einschnürungsmarke (links) erschienen war.

Fig. 36, wie alle folgenden: Zellen aus Spermatocysten. 36: Mutterknäuel.

Fig. 37. Zelle nicht in Theilung, das charakteristische dichte, grobbalkige Kerng erüst der Hodenzellen. 38, 39 Mutterknäuel. 40 Mutterstern (die Winkel der Schleifen sind schematisch dunkel dargestellt. Vergl. Fig. 9 Taf. I). 41 und 42 Aequatorialplatten (hier mit der Kerntonne zusammenfallend), 41 schräg von oben, und mit leicht geschlängelten Fäden, 42 von der Seite. Wie meistens, die tieferliegenden Fäden hlasser dargestellt. 44-45 solche Kerntonnen in beginnender Trennung, einzelne Fäden bezw. Schleifenschenkel sind unregelmässig abgerückt (nach den Polen) oder ausgeklappt. Man sieht die a chromatischen Fäden. 46, 47 Tochtersternform und -Knäuelform, die achromatischen Fäden erscheinen körnig (vielleicht nur Reagentienwirkung).

(Fig. 37-41. Essigsäure-Bismarckbraun nach Mayzel, Fig. 36 und 42-47 Chromsäure-Hämatoxylin).

Fig. 48. Aus einem Schnitt durch einen Juli-Hoden, schwache Vergrösserung, Alkohol-Alauncarmin. 4 Spermatocystendurchschnitte, Inhaltszellen je in gleichen, gegeneinander in verschiedenen Theilungsstadien: die Formen der Kerne sind an den nebengezeichneten Zellen vergrössert dargestellt (a: vergl. Fig. 42, b: etwa Fig. 36, c schon fertige Theilungen, d: Fig. 37). Das gleiche Verhalten überall im Hoden vertheilt.

Fig. 49-52: Vielkernige Zellen und deren Theilung. EssigsäureBismarckbraun.

Fig. 49. Vierkernige Zelle ebendaher, Kerne ruhend.

Fig. 49 a. Zelle mit einem ruhenden Kern und zwei Tonnen.

Fig. 50 mit 6 Kerntonnen, 51: mit 6 Paar Tochterknäueln, 52: nebeneinander in der Zelle zwei Kerntonnen (eine schräg liegend) und 1 Paar Tochtersterne, der letztere Kern war also früher in Theilung getreten als die beiden anderen.

Fig. 53. Schmalere Kerntonne, in der an einzelnen Fäden die äquatorialen Anschwellungen oder Aufquellungen aufgetreten sind(vergl.Abschn.3); 
Beiträge zur Kenntniss der Zelle und ihrer Lebenserscheinungen. 259

links eine solche im Profil, in der Mitte von vorn, bei a: die letztere Anschwellung stärker vergrössert dargestellt. (Vielleicht nur Reagentienwirkung.) Essigsäure-Bismarckbraun.

Zugleich Unregelmässigkeit der Kernfigur. Oben ein Schleifenschenkel herausgeklappt, unten eine Schleife abgerückt, beide sehr in Verkürzung gesehen (vergl. z. B. Fig. $35 \mathrm{~d}$, rechts unten).

(Aus Versehen ist diese Figur und die folgende mit 53 bezeichnet).

Fig. 53-58: Spermatogenese. (Salamandra, September-0ctober.)

Fig. 53. Bildung von Samenfädenköpfen in Kernen, nicht Zellen; das Protoplasma der Zellen ist nicht mitgezeichnet, jede Figur gleich einem Kern. Frisch ohne Zusatz.

Fig. 54. Fertiger Samenfaden, Vordertheil: k. Kopf, m. Mittelstück, f. Schwanz mit Flossensaum. Sofort nach Zusatz sehr verdünnter Essigsäure beobachtet, das Mittelstïck ist dadurch etwas gequollen.

Vergl. Fig. $56 \mathrm{~h}$ : fertiger Samenfaden mit Alauncarminfärbung. Mittelstück $(m)$ und Schwanz ungefärbt.

Fig. 55 a b c d aufeinanderfolgende spätere Bildungsstadien von Samenfäden, frisch s. Text. k: fragliches Knötchen hinter dem Mittelstïck; letzteres ist frisch nicht $z u$ erkennen. $d$ : anfängliche Lage von Schwanz und Kopf zu einander.

Fig. 56 (Alkohol-Alauncarmin) und 57 (Essigsäure-Bismarckbraun) zeigen die Uebergangsstadien der Bildung der Köpfe in den Kernen, aus dem Chromatin derselben. Vergl. Fig. 53 (frisch, schwächer vergr.), s. Text Abschn. $3 . \mathrm{km}$. in Fig. 56 und 57 : Kernmembran.

Die Mittelstücke der jungen Fäden in d, e, f Fig. 57 durch die Essigsäure aufgequollen.

Fig. 58. Skizze aus dem Schnitt von einem Octoberhoden, Alcohol-Alauncarmin; schwache Vergr. - 7 Spermatocysten in einem Canaldurchschnitt, mit Inhalt in verschiedenen Bildungsstadien.

Kiel, December 1879. 